\title{
Estudo Sobre Redes Definidas por Software Aplicado em Jogos Digitais
}

\author{
Lucas Dário \\ DISSERTAÇÃO APRESENTADA \\ $\mathrm{AO}$ \\ Instituto De Matemática e EstatísticA \\ DA \\ Universidade DE SÃo PaUlo \\ PARA \\ OBTENÇÃO DO TÍTULO \\ $\mathrm{DE}$ \\ Mestre em CiÊnCIAS \\ Programa: Ciência da Computação \\ Orientador: Prof. Dr. Daniel Macêdo Batista
}

Durante o desenvolvimento deste trabalho o autor recebeu auxílio financeiro da CAPES

São Paulo, Fevereiro de 2020 


\section{Estudo Sobre Redes Definidas por Software Aplicado a Jogos Digitais}

\footnotetext{
Esta versão da dissertação/tese contém as correções e alterações sugeridas pela Comissão Julgadora durante a defesa da versão original do trabalho, realizada em 09/12/2019. Uma cópia da versão original está disponível no

Instituto de Matemática e Estatística da Universidade de São Paulo.
}

Comissão Julgadora:

- Prof. Dr. Daniel Macêdo Batista (orientador) - IME-USP

- Prof. Dr. Christian Esteve Rothenberg - UNICAMP

- Prof ${ }^{a}$. Dra . Cintia Borges Margi - POLI-USP 


\section{Resumo}

DÁRIO, L. Estudo Sobre Redes Definidas por Software Aplicado em Jogos Digitais. 2020. 71 f. Tese (Mestrado) - Instituto de Matemática e Estatística, Universidade de São Paulo, São Paulo, 2020.

Redes Definidas por Software (RDS) são uma abordagem de arquitetura para Redes de Computadores que busca fornecer ao administrador da rede a capacidade de configurá-la de uma forma dinâmica, programada e centralizada. Nesse paradigma, o plano de controle é separado do plano de dados por conta da criação de um novo elemento na rede, denominado Controlador. O controlador é responsável por monitorar e administrar os diversos dispositivos de comutação presentes na rede. Com isso, sempre que alguma alteração deve ser feita nas regras de roteamento da rede, o administrador pode efetuá-las apenas no controlador, sem a necessidade de interferir direta e manualmente em cada um dos dispositivos existentes no restante da rede. A capacidade de monitoramento e dinamicidade das RDS é um importante diferencial para cenários nos quais as aplicações em execução são sensíveis a problemas ou instabilidades na rede. Um exemplo de aplicações com esse perfil são Jogos Eletrônicos Multi-jogador. Nesse tipo de aplicação, diversos usuários compartilham de um mesmo cenário simulado e interagem com ele através da rede. Diversos jogos são extremamente sensíveis a cenários com latência alta, pois essa situação faz com que vários elementos dos jogos funcionem de forma errada, comprometendo a experiência do usuário final. Este projeto apresenta um estudo sobre Redes Definidas por Software, as tecnologias existentes atualmente e como essa nova arquitetura pode ser aplicada para melhorar a experiência de usuários de um jogo eletrônico, quando submetidos a cenários que simulam conexões ruins entre os jogadores. Para esse fim, foi projetado e desenvolvido um mecanismo que automatiza a seleção dos caminhos quando são detectados problemas nas conexões dos jogadores. Para atestar a eficácia do mecanismo foram realizados experimentos utilizando o jogo 0 A.D., um jogo de código aberto do gênero de Estratégia em Tempo Real, sendo executado sobre uma RDS composta por Switches programados utilizando a linguagem P4. Através dos experimentos, foi possível observar alguns benefícios da utilização das RDS para monitorar e modificar os fluxos da rede em tempo real com o objetivo de melhorar a comunicação entre os hosts do jogo.

Palavras-chave: Jogos digitais, redes definidas por software, redes de computadores, latência, OpenFlow, P4. 


\section{Abstract}

DÁRIO, L. Study About Software Defined Networks Applied to Digital Games. 2020. 71 f. Dissertação (Mestrado) - Instituto de Matemática e Estatística, Universidade de São Paulo, São Paulo, 2020.

Software Defined Networks (SDN) is an architectural approach to Computer Networks aiming to provide the network administrator with the ability to configure networks dynamically, programmatically and centralized. In this paradigm, the control plane is separate from the data plane with the creation of a new element in the network called Controller. The controller is responsible for monitoring and managing the various switching devices on the network. With that, if changes should be made to the network routing rules, the administrator can make them by rules defined only in the controller, without the need to directly and manually interfere with each device existing in the rest of the network. The monitoring capacity and dynamism of the SDN is an important differential for scenarios where running applications are sensitive to problems or instabilities on the network. An example of applications with this profile are Multiplayer Video Games. In this applications several users share the same simulated scenario and interact with it through the network. Many games are extremely sensitive to high latency scenarios because this situation causes various elements of the games to work in a wrong way, compromising the end user experience. This project presents a study on Software Defined Networks, reporting existing technologies and how this new architecture can be applied to improve the experience of users of an electronic game when submitted to scenarios that simulate bad connections between players. To this end, a mechanism has been designed and developed to automate path selection when player connection problems are detected. To attest the effectiveness of the mechanism, experiments were performed using the game 0 A.D., an open source game in the Real Time Strategy genre, running on a SDN composed of Switches programmed using the P4 language. Through the experiments, it was possible to see some benefits of using SDN to monitor and modify network flows in real time in order to improve communication between the game hosts.

Keywords: digital games, software defined networks, computer networks, latency, OpenFlow, P4. 


\section{Sumário}

Lista de Abreviaturas vii

$\begin{array}{ll}\text { Lista de Figuras } & \text { ix }\end{array}$

Lista de Tabelas $\quad$ xi

1 Introdução $\quad 1$

1.1 Motivação . . . . . . . . . . . . . . . . . . . . . . . . . 3

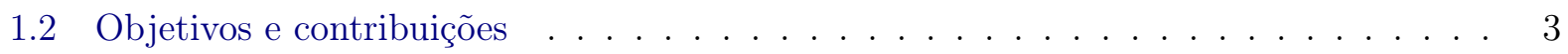

1.3 Organização do trabalho . . . . . . . . . . . . . . . . . . . 3

2 Conceitos $\quad 5$

2.1 Redes de computadores tradicionais . . . . . . . . . . . . . . . . . 5

2.2 Redes Definidas por Software . . . . . . . . . . . . . . 7

2.2 .1 OpenFlow . . . . . . . . . . . . . . . . . . . . . 10

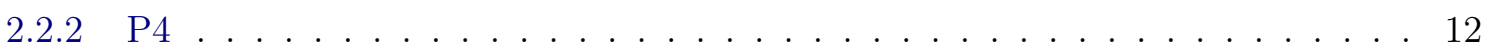

2.2.3 Contextualização sobre RDS e o cenário atual . . . . . . . . . . . . . . . . . 14

2.2 .4 Limitações . . . . . . . . . . . . . . . . . . . . . . . . . . 16

2.3 Jogos digitais . . . . . . . . . . . . . . . . . . . . . . 16

2.3 .1 Jogos digitais em rede . . . . . . . . . . . . . . . . . 17

$\begin{array}{lll}3 & \text { Trabalhos relacionados } & 19\end{array}$

4 Mecanismo proposto $\quad 23$

4.1 Funcionalidades e Objetivos . . . . . . . . . . . . . . . . . . . . 23

4.2 Arquitetura . . . . . . . . . . . . . . . . . . . . . 24

4.3 Possibilidades de Implementação $\ldots \ldots \ldots \ldots$. . . . . . . . . . . . . . . 25

4.4 Considerações finais . . . . . . . . . . . . . . . . . . . 25

5 Experimentos $\quad 27$

5.1 Implementação de referência . . . . . . . . . . . . . . . . . . . 27

5.2 Ambiente elaborado para os experimentos . . . . . . . . . . . . . . . . 29

5.2 .1 Jogo escolhido . . . . . . . . . . . . . . . . . . . . . . . . 30

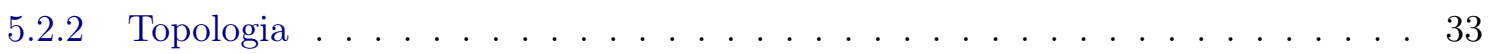

5.2 .3 Fluxo de dados . . . . . . . . . . . . . . . . . . . . . . . 34

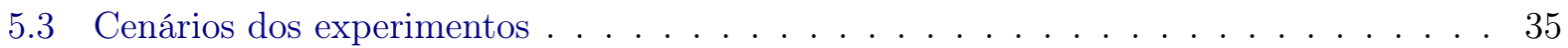


$5.3 .1 \quad$ Experimento A . . . . . . . . . . . . . . . . 35

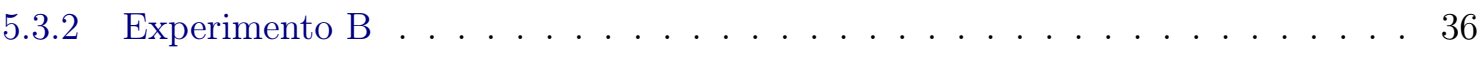

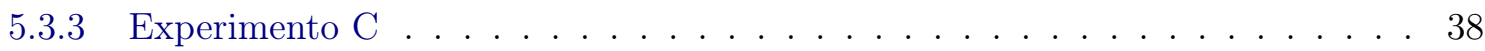

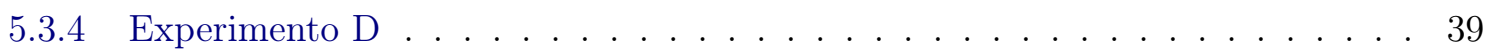

5.4 Resultados obtidos com os experimentos . . . . . . . . . . . . . . . 40

6 Conclusão $\quad 49$

6.1 Discussão sobre os resultados . . . . . . . . . . . . . . . . . . . . . 49

6.2 Obstáculos . . . . . . . . . . . . . . . . . . . . . . . . . 49

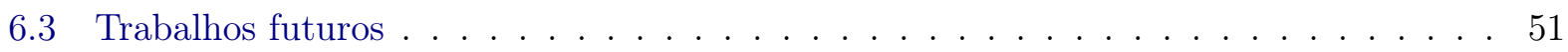

Referências Bibliográficas $\quad 53$ 


\title{
Lista de Abreviaturas
}

\author{
API Application Programming Interface \\ GRAMI Granular RTT Measurement Infrastructure \\ HTTP Hyper Text Transfer Protocol \\ HTTPS Hyper Text Transfer Protocol Secure \\ ICMP Internet Control Message Protocol \\ INT In-band Network Telemetry \\ IP Internet Protocol \\ IPV4 Internet Protocol Version 4 \\ JC Jogo de Computador \\ MMOG Massive Multiplayer Online Games \\ ONF Open Networking Foundation \\ ONOS Open Network Operating System \\ RDS Redes Definidas por Software \\ RFC Request For Comments \\ RPG Role-Playing Game \\ SDN Software Defined Networks \\ SMTP Simple Mail Transfer Protocol \\ TC Traffic Control \\ TCP Transmission Control Protocol \\ UDP User Datagram Protocol
}




\section{Lista de Figuras}

2.1 Diagrama de uma rede tradicional . . . . . . . . . . . . . . . . . 6

2.2 Diagrama de uma rede definida por software . . . . . . . . . . . . . . 8

2.3 Diagrama dos elementos que compõem uma arquitetura de rede definida por software 9

2.4 Diagrama mostrando os passos envolvidos na programação de um target. Imagem retirada da especificação da linguagem $\mathrm{P} 4[\mathrm{Con} 19 \mathrm{~b}] \ldots$. . . . . . . . . . . . . . . 13

4.1 Arquitetura proposta do mecanismo . . . . . . . . . . . . . . . . . . 25

5.1 Fluxograma do funcionamento do Mecanismo . . . . . . . . . . . . . . . . 28

5.2 Captura de tela do 0 A.D. em uma partida com um único jogador, e um oponente controlado pelo computador . . . . . . . . . . . . . . . . . . . . 31

5.3 Captura de tela do 0 A.D. com dois jogadores . . . . . . . . . . . . . . . . . 32

5.4 Diagrama da topologia da rede utilizada durante os experimentos . . . . . . . . . . 33

5.5 Topologia utilizada para a realização do Experimento A, com valores de latência incluídos . . . . . . . . . . . . . . . . . . . 36

5.6 Topologia utilizada para a realização do Experimento A, com valores de latência atualizados após influência do "tc" . . . . . . . . . . . . . . . . . . 37

5.7 Topologia utilizada para a realização do Experimento B, com valores de latência incluídos . . . . . . . . . . . . . . . . . . . . . . 37

5.8 Topologia utilizada para a realização do Experimento B, com valores de latência atualizados após influência do "tc" . . . . . . . . . . . . . . . . . . 38

5.9 Diagrama com capturas de tela do jogo . . . . . . . . . . . . . . . . . . . . . . 42

5.10 Diagrama contendo um experimento com alteração automática de rotas . . . . . . . 43

5.11 Diagrama comparando as medições da Rota A e B feitas pelo mecanismo e as medições feitas pelo "ping" . . . . . . . . . . . . . . . . . . . . . 45

5.12 Diagrama comparando as medições reformuladas da Rota A e B feitas pelo mecanismo e as medições feitas pelo "ping" . . . . . . . . . . . . . . . . . . . 46 


\section{Lista de Tabelas}

3.1 Tabela de comparação entre os trabalhos relacionados e o projeto apresentado . . . . 22

5.1 Tabela contendo medições dos experimentos realizados . . . . . . . . . . . . . . . . 44

5.2 Tabela contendo a comparação entre as medições do mecanismo e do comando "ping" 45

5.3 Tabela contendo a comparação entre as medições reformuladas do mecanismo e do comando "ping" . . . . . . . . . . . . . . . . . . . . . . . . . 46 


\section{Capítulo 1}

\section{Introdução}

Desde seu surgimento, é inegável que a Internet vem sendo uma das maiores invenções dos últimos tempos. Podemos descrevê-la como uma rede de redes de computadores que são responsáveis por conectar usuários espalhados por diversas regiões do planeta.

Conforme a internet foi evoluindo, a extensão que sua rede abrangia e a estrutura por trás dessa rede também foi aumentando, porém a arquitetura geral que compunha a rede permaneceu sem muitas alterações. Conforme mais e mais tecnologias que faziam uso dessa rede foram surgindo e os padrões de utilização dos recursos foram se alterando, a estrutura e arquitetura das redes parecia não atender mais às exigências de seus usuários.

Entre as novas utilizações da rede que exigiam condições diferentes, podemos citar o surgimento e grande avanço na utilização de tecnologias de computação em nuvem, a grande diversificação de dispositivos sendo utilizados nas diversas redes existentes com diversos perfis de utilização de dados, o grande crescimento nas tecnologias que manipulam gigantescas quantidades de dado (o considerado "Big Data") e fazem exigências de maiores taxas de transferência.

Esse ecossistema de redes em constante evolução fez aparecer a necessidade de novas formas de controlar e administrar os diversos fluxos de dados que permeavam esse ambiente. Era preciso encontrar uma solução capaz de garantir a escalabilidade das redes, facilitando a administração de redes compostas por cada vez mais dispositivos, e que também fosse capaz de apresentar uma boa manutenibilidade a esses ambientes. Além disso, essa nova solução deveria ser capaz de atender de forma responsiva a aplicações que tivessem suas exigências de rede modificadas, reconfigurando rapidamente suas regras de funcionamento e de entrega de qualidade.

Com essas exigências em mente, foi surgindo o conceito do que seriam as Redes Definidas por Software (RDS). Sua proposta principal consiste na separação entre o plano de dados e o plano de controle, permitindo que a tarefa de decidir as regras que definem os caminhos pelos quais os dados são transmitidos seja separada da ação de ativamente transmitir esses dados. Tendo esse plano em mente, as primeiras materializações do que seria essa nova arquitetura chegaram a esse objetivo com a inserção de um novo elemento à rede, que até então era inexistente: o controlador.

O controlador seria um agente dentro da rede capaz de centralizar a responsabilidade em descrever o seu funcionamento. Além disso, por ser desacoplado do plano de dados, esse controlador seria programável, permitindo que a rede fosse alterada e administrada através dele, que poderia utilizar programas automatizados garantindo uma maior dinamicidade e adaptabilidade a essas redes. Com esse controlador fazendo parte da estrutura, teríamos como solução final o seguinte esquema: as aplicações em produção se comunicariam com esses controladores através de alguma interface, requisitando os recursos que fossem necessários, e esse controlador, por sua vez, conseguiria atuar sobre os elementos do plano de dados, gerenciando-os e fazendo com que as exigências das aplicações fossem atendidas.

A solução que deu início à adoção mais forte do conceito de RDS foi o protocolo OpenFlow, proposto em um artigo publicado em 2008 [MAB $\left.{ }^{+} 08\right]$. Sua versão 1.1 foi disponibilizada em 2011 e, a partir desse ano, sua evolução e desenvolvimento passaram a ser realizados sob responsabilidade da Open Network Foundation (ONF). Sua proposta é de ser um protocolo capaz de oferecer a comuni- 
cação entre uma aplicação considerada um Controlador e os dispositivos que irão compor o plano de dados da rede. O projeto, com o passar dos anos, passou a ser aceito e fez com que diversas empresas fabricantes de dispositivos comutadores, como a Marvell [Ltd19b] e a Larch Networks [ltd19a], construíssem produtos que fossem compatíveis com esse novo protocolo. Além disso, esse projeto também chamou atenção de outras empresas, como a Big Switch Networks [BSN19], que implementou o primeiro projeto de um controlador que fizesse uso do protocolo OpenFlow, chamado Floodlight[Flo19]. Com o passar do tempo, grandes empresas fabricantes de dispositivos de rede passaram a suportar o OpenFlow[Fou16] como a Cisco[Cis18b] e a Juniper[Net18].

Durante muito tempo, Redes Definidas por Software e OpenFlow foram considerados sinônimos, pois este último era, até então, a solução mais discutida e adotada pelos pesquisadores e desenvolvedores que atuavam nessa área. Porém, com o passar do tempo, diversas soluções alternativas passaram a surgir: empresas implementando suas próprias soluções de RDS, como a VMWare NSX [VMw19] ou Cisco ACI [CS19], e a Pluribus Adaptive Cloud Fabric [Net19a] [PN18], que propõe uma solução sem a utilização de controladores, ou mesmo a linguagem P4 [Con19h], uma linguagem que, ao invés de focar na programação do plano de controle, tem seus esforços direcionados à programação do plano de dados, adicionando lógica aos próprios dispositivos de comutação da rede. Essa linguagem, em especial, possui a propriedade de ser independente de quais tipos ou formatos de pacotes o dispositivo programado irá transmitir, garantindo a ela o poder de ser capaz de trabalhar com qualquer especificação de pacote que exista e também com qualquer um que venha a existir. Essa propriedade é benéfica, pois permite ao administrador de rede contornar alguns problemas ainda existentes do protocolo OpenFlow, que não é compatível com todos os pacotes existentes na Internet e apresenta muita demora em incluir novos pacotes em sua especificação.

Diversas empresas atualmente fazem uso de soluções baseadas em Redes Definidas por Software, como por exemplo a Symantec [Cis18a] e a Pulsant [Cis15], que escolheram a Cisco ACI como solução para seus negócios. Outro exemplo que faz uso de RDS é o AmLight-INT[AML19], um projeto dentro da RDS AmLight[AML], cujo objetivo foi expandir essa rede para se tornar uma rede capaz de realizar a telemetria de seus dados em tempo real, inspirada na aplicação In-band Network Telemetry (INT) [Con15] proposta pelos desenvolvedores da linguagem P4. Para isso, a solução faz uso de duas tecnologias até então apresentadas nesse projeto: eles utilizam dispositivos de comutação que são compatíveis tanto com a linguagem P4 e aplicações como o INT quanto com o protocolo OpenFlow. Assim, eles são capazes de utilizar as funcionalidades oferecidas pelo P4 para implementar uma versão própria do INT, e depois utilizam o protocolo OpenFlow para administrar os fluxos de rede em seus dispositivos de comutação. Uma das motivações para realização desse projeto está em estudar formas de garantir a transferência de grandes quantidades de dados através de grandes distâncias geográficas de uma forma confiável e previsível, utilizando como caso de estudo para isso os dados compartilhados pelo Large Synoptic Survey Telescope (LSST), que precisam ser entregues em um período curto de tempo e que não pode ser afetado por falhas presentes na rede.

Utilizações das RDS como a apresentada no projeto AmLight-INT sugerem que esse novo paradigma pode ser uma solução boa e eficiente para servir como infraestrutura para aplicações que sejam dependentes de boas condições de rede, ou que sejam altamente impactadas por alterações bruscas e repentinas na qualidade da conexão. Uma categoria de aplicações que seguem esse perfil pode ser considerada a dos Jogos Eletrônicos Multijogador em Rede. Esse tipo de jogo costuma conectar vários usuários, de diversas localidades, ao mesmo tempo e em um mesmo ambiente online. Esses usuários, então, trocam dados constantemente, e instabilidades na conexão e comunicação entre esses jogadores causam efeitos extremamente negativos na experiência desses usuários.

Dessa forma, a proposta desse projeto consiste primeiramente em explorar o estado atual das pesquisas e tecnologias existentes de RDS e, em seguida, avaliar a utilização de RDS em um cenário de Jogos Digitais em Rede como uma solução para alguns problemas recorrentes existentes nesse cenário. Para tanto, é proposto um mecanismo que possa se valer dos benefícios dessa nova arquitetura de redes para melhorar a experiência de usuários desse tipo de aplicação quando submetidos a condições negativas de rede. Como contribuição adicional dessa dissertação são apresentados experimentos avaliando uma implementação de referência do mecanismo apresentado e os ganhos obtidos 
com sua utilização. Por fim, são discutidas algumas conclusões sobre os resultados do projeto, obstáculos durante sua produção, e trabalhos futuros.

\subsection{Motivação}

Com a origem ainda recente da arquitetura de Redes Definidas por Software, o assunto continua sendo considerado emergente e, por conta disso, essa área de pesquisa ainda apresenta pouco material disponível. Com as tecnologias base dessa nova arquitetura ainda em desenvolvimento e com padrões em constante mudança e evolução, se torna difícil acompanhar as melhores soluções e ferramentas a serem utilizadas. Além disso, ainda há um extenso espaço de experimentação possível, no qual mais áreas podem avaliar os benefícios produzidos pela utilização de um ambiente de RDS. Em particular, ainda há espaço para se avaliar o impacto de utilizar RDS em conjunto com Jogos Digitais em Rede.

\subsection{Objetivos e contribuições}

Tendo em vista as motivações acima, este projeto de pesquisa tem como objetivo principal projetar e implementar um mecanismo baseado em RDS para melhorar a experiência de usuários de um jogo eletrônico em rede, quando submetidos a cenários que simulam conexões ruins entre os jogadores. Além disso, um objetivo secundário é avaliar os ganhos obtidos com a utilização deste mecanismo em um cenário realista.

Como contribuições, nesta dissertação é apresentado um estudo sobre as tecnologias em uso na área de RDS, discutindo diversos exemplos de soluções sendo utilizadas tanto no cenário acadêmico quanto no comercial. Além disso, são também indicados alguns obstáculos encontrados durante o projeto, resultantes do fato da área em estudo ainda ser recente. Por fim, como contribuição principal, são apresentados os detalhes acerca do projeto e definição do mecanismo baseado em RDS para melhorar a experiência de usuários de um jogo eletrônico em rede. Vale destacar que o código-fonte de uma implementação de referência do mecanismo e dos cenários de experimentação criados são disponibilizados como software livre ${ }^{1}$.

\subsection{Organização do trabalho}

O restante desta dissertação está organizado da seguinte forma. No Capítulo 2 são apresentados os conceitos essenciais que ajudarão no entendimento do projeto. Primeiramente é oferecida uma noção básica do que são redes de computadores e, em seguida, essa explicação é aprofundada ao introduzir o que são Redes Definidas por Software e duas tecnologias utilizadas por essas redes, que são o protocolo OpenFlow e a linguagem P4. Também é apresentada uma contextualização sobre RDS atualmente. São discutidos alguns exemplos de projetos que já vem utilizando as tecnologias em suas atividades. São também expostas algumas limitações existentes para qualquer um que queria iniciar o desenvolvimento de algum projeto que utilize essas tecnologias. Por fim, o capítulo contextualiza jogos digitais e jogos digitais em rede.

No Capítulo 3, são apresentados trabalhos em tópicos relacionados de alguma forma ao projeto. Os trabalhos apresentados possuem relação com Redes Definidas por Software e alguns exemplos de utilização desse paradigma com Jogos Eletrônicos.

O Capítulo 4 apresenta o mecanismo baseado em RDS proposto para garantir uma boa experiência de jogadores em situações em que a rede se encontra com baixa qualidade. Neste capítulo são apresentadas os objetivos e funcionalidades do mecanismo, bem como a proposta de sua arquitetura. Encerra-se o capítulo com um conjunto de considerações finais sobre sua elaboração.

O Capítulo 5 traz todas as informações relevantes para o processo de experimentação do mecanismo proposto no capítulo anterior. Neste capítulo é apresentada uma implementação de referência

\footnotetext{
${ }^{1}$ https://github.com/Tuiuiu/ArquivosMestrado
} 
do mecanismo proposto no projeto e o conjunto de ferramentas de software necessárias para criação de um ambiente capaz de comportar os experimentos. Por fim, são apresentados os resultados dos experimentos realizados.

O Capítulo 6 finaliza a dissertação expondo as conclusões obtidas no projeto, incluindo comentários sobre os resultados obtidos pelos experimentos, os obstáculos encontrados durante sua elaboração, além de algumas sugestões de trabalhos futuros. 


\section{Capítulo 2}

\section{Conceitos}

Neste capítulo são mostrados diversos conceitos que devem ser apresentados para completo entendimento do projeto. Primeiramente, é abordado o assunto de redes de computadores, que compõe a grande área de conhecimento dentro da computação na qual o projeto está inserido. Em seguida, é apresentada uma breve introdução sobre Redes Definidas por Software, que é o assunto em foco do trabalho. Em seguida, são introduzidos os dois principais projetos de código aberto utilizados no contexto de Redes Definidas por Software: o protocolo OpenFlow e a linguagem P4. O cenário atual de RDS incluindo algumas limitações também são apresentados. Por fim, são apresentadas definições relacionadas com jogos digitais e jogos digitais em rede.

\section{$2.1 \quad$ Redes de computadores tradicionais}

Redes de computadores são, de maneira simplificada, redes que interligam diversos nós e permitem o compartilhamento de dados entre esses nós, que, no caso da Internet, podem se encontrar em qualquer lugar do mundo. Nessa rede, todo dispositivo capaz de originar, transmitir e consumir esses dados pode ser considerado um nó.

Seguindo com a descrição oferecida por Kurose e Ross no livro Computer Networking: A TopDown Approach [KR01], intitulada de "Nuts-and-Bolts Description", cada um desses nós pode ser ou um host ou um packet switch. Todos esses nós se comunicam através de communication links, que são as vias pelas quais os dados são transmitidos. Na Internet, dispositivos que podem ser considerados hosts são, por exemplo, TVs, computadores, consoles, smartphones, tablets, laptops, automóveis e basicamente qualquer tipo de dispositivo que forneça algum tipo de informação ou serviço.

Já os packet switches são dispositivos que não geram dados, mas recebem e encaminham dados entre os hosts. Dispositivos que se encaixam nessa categoria são, por exemplo, os roteadores, cuja função é receber dados através de um link de comunicação e então retransmitir esses dados através de outro link de comunicação - ou seja, enviar esses dados de um host para outro.

Todas essas informações são enviadas através dos links de comunicação em um formato cujo nome é um jargão da área, que são os pacotes. Antes de serem enviados, os dados passam, dentro do host que os originou, por um processo de empacotamento, no qual esses dados, que costumam ser compostos por longas mensagens, são quebrados em mensagens menores que são combinadas com informações que indicam dados sobre seu local de origem e o destino para o qual esses dados estão sendo enviados, formando o que conhecemos, como citado acima, por pacote. Outro termo importante é o nome dado ao caminho percorrido pelo pacote dentro da rede. Esse caminho é conhecido como "rota", e consiste em todos os links e switches pelos quais o pacote percorre desde sua origem até o seu destino. A Figura 2.1 apresenta um diagrama simplificado de uma rede de computadores com 5 hosts e 3 roteadores. Um desses roteadores (O Roteador 3) tem a função de conectar a rede à Internet.

Dada essa maneira descrita acima de como são compostas as Redes de Computadores, podemos concluir que, mesmo que essas redes sejam locais, sua configuração é considerada descentralizada, 
uma vez que, para que possa haver comunicação entre todos os elementos pertencentes a ela, todos esses dispositivos, sejam eles hosts ou switches, precisam ser configurados individualmente pelo administrador da rede.

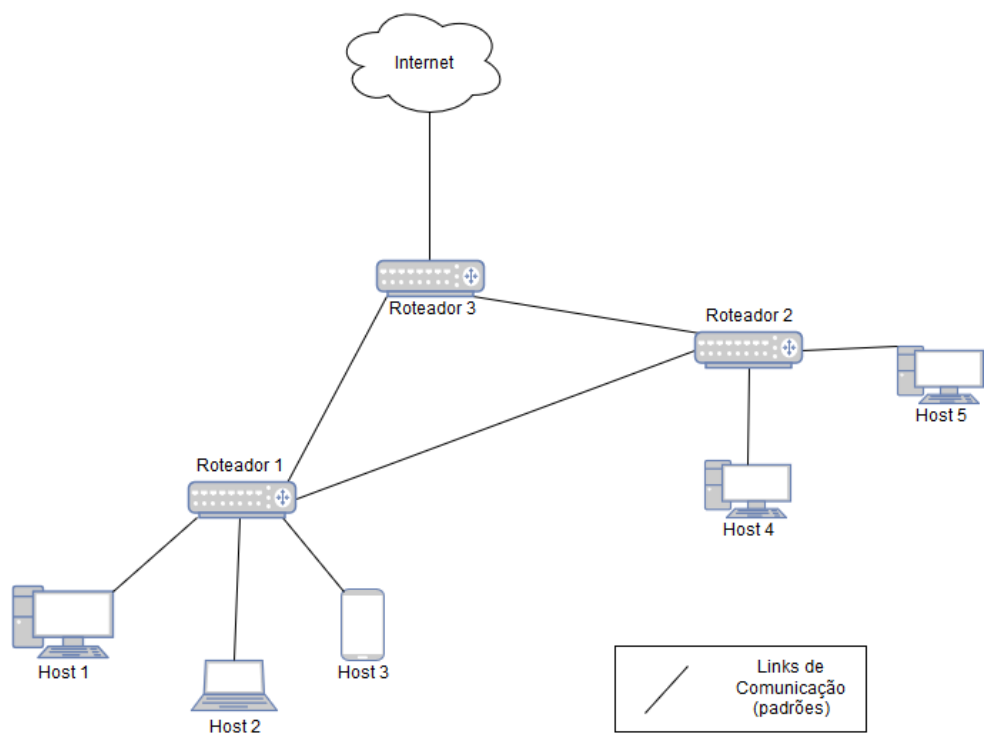

Figura 2.1: Diagrama de uma rede tradicional

Com todos os dispositivos conectados a alguma rede e pacotes prontos pra serem enviados através dos links, em condições ideais espera-se que todos esses dados cheguem imediatamente ao seu destino, porém isso é fisicamente impossível. Os pacotes, conforme percorrem uma rota até chegar a seu destino, sofrem diversos tipos de atraso a cada nó que visitam. Esse atraso é chamado de atraso de processamento nodal e é composto por 4 elementos:

- Atraso de Processamento - corresponde ao tempo necessário até que o nó examine as informações contidas no cabeçalho do pacote, que é o local onde ficam as informações extras adicionadas aos dados que estão sendo transmitidos. Esse atraso também pode incluir o tempo necessário até que o nó faça uma verificação em busca de erros no pacote;

- Atraso de Fila - diz respeito ao tempo em que um pacote fica esperando, dentro desse nó em uma fila de pacotes, até o momento em que ele será transmitido. Isso ocorre porque apenas um pacote pode ser transmitido de cada vez. Dessa maneira, essa fila existe para que os pacotes sejam organizados antes de serem transmitidos;

- Atraso de Transmissão - representa a quantidade de tempo necessária até que um pacote seja transmitido, ou seja, até que o nó consiga enviar todos os bits do pacote para dentro do link de transmissão. Esse valor é diretamente proporcional ao tamanho do pacote e inversamente proporcional à taxa de transmissão do link;

- Atraso de Propagação - que consiste no tempo necessário até que o pacote percorra toda a extensão do link do nó em que ele está até o nó seguinte na sua rota. Esse valor é diretamente influenciado pelo material que compõe o link (fio de cobre, fibra-óptica, entre outros) e a distância entre suas pontas.

Quando temos a soma de todos os atrasos nodais do nó de origem até o nó de destino, adquirimos um tempo referente ao tempo necessário para que um pacote saia da sua origem e chegue até seu destinatário. Esse tempo é conhecido como Latência, que é um dos valores importantes quando queremos avaliar a qualidade de uma rede. Vale ressaltar que alguns desses atrasos não são constantes, como por exemplo o atraso de fila - quando o nó fica congestionado, a fila de pacotes a serem enviados aumenta, e o tempo para que um pacote que esteja no fim da fila seja enviado é 
bem maior que o mesmo tempo para o pacote que é o próximo na fila de envio. Sendo assim, temos que a latência não é um valor estático, mas sim variável, e a essa variação de latência damos o nome de Jitter.

Além dos valores de atraso, uma outra situação a qual os pacotes encontram-se em risco é a de um efeito conhecido como perda de pacotes. Uma vez que, em cada dispositivo de rede, essa fila de pacotes a serem enviados pelas interfaces de comunicação possui um número limitado de entradas, quando essa fila está cheia e um novo pacote tenta ser inserido nela, por não ter mais espaço, esse pacote é perdido, ou seja, não é enviado e é ignorado.

Mais um valor que é de extrema importância quando olhamos para a qualidade de uma rede é o dado conhecido como Vazão, também chamado de Taxa de Transferência. Ela pode ser descrita como a velocidade, em bits por segundo, com que um host que é um destino consegue receber dados de outro host, que é a origem desses dados. Cada uma dessas três medidas diferentes é importante na verificação da qualidade de uma rede e, dependendo das exigências de cada aplicação, alguns desses valores podem se tornar mais relevantes que os outros na hora de se planejar a rede.

Vale comentar que, antes de haver qualquer medição de desempenho, é preciso garantir que todos os dispositivos, inclusive de qualquer lugar do mundo, possam se comunicar. Para isso, é necessário que haja uma certa linguagem, ou algum padrão, que dite como essa comunicação é efetuada. A maneira, então, pela qual ocorre essa comunicação é através dos protocolos, que são especificações que definem estruturas para organizar os dados em um pacote, de maneira que esse pacote possa ser identificado e lido da maneira correta. Dos protocolos mais importantes da Internet, vale citar o Transmission Control Protocol (TCP) e o Internet Protocol (IP).

Esses protocolos possuem diversas utilidades. Desde sua concepção, a Internet foi construída através de uma arquitetura de camadas. Sendo assim, cada protocolo atende a apenas uma camada da Internet, e cada camada atua provendo serviços para a camada imediatamente superior. Ainda segundo Kurose e Ross, da camada mais superior à mais inferior, temos a Camada de Aplicação, Camada de Transporte, Camada de Rede, Camada de Enlace e Camada Física. O TCP é um protocolo da Camada de Transporte enquanto o IP é um protocolo da Camada de Rede.

Como os protocolos são muito importantes para garantir o funcionamento da Internet, é importante que todos concordem com o que cada um dos protocolos faz, de modo que as pessoas possam criar sistemas capazes de se comunicar. Para isso, existe uma organização que é responsável pela manutenção e desenvolvimento desses padrões, que é a Internet Engineering Task Force (IETF), cujos documentos que contém os padrões são chamados de Requests for comments (RFCs). Essas RFCs são as responsáveis por definir boa parte dos protocolos que utilizamos hoje em dia, como TCP (Transmission Control Protocol), IP (Internet Protocol), HTTPS (Hyper Text Transfer Protocol Secure), SMTP (Simple Mail Transfer Protocol) e ICMP (Internet Control Message Protocol).

\subsection{Redes Definidas por Software}

Com o passar dos anos e o grande crescimento da Internet, toda essa evolução fez com que alguns problemas começassem a ser notados. Uma vez que as arquiteturas de rede comumente utilizadas começaram a esbarrar em problemas como escalabilidade e manutenibilidade, principalmente devido à natureza altamente dinâmica com que as aplicações evoluem e fazem uso dos dados, além da utilização intensiva de tecnologias baseadas em computação na nuvem, notou-se a necessidade de adotar um novo paradigma de comunicação, que tratasse de outra forma esses problemas. Um novo paradigma era necessário principalmente por conta do perfil descentralizado do modelo atual de redes, onde qualquer tentativa de implementação de alguma política na rede ou alteração de dispositivos que a compõem exige uma grande carga de trabalho, consumindo muito tempo e sendo muito complexa.

A solução para isso veio através da concepção das Redes Definidas por Software, uma arquitetura cuja principal característica é a separação entre o plano de controle e o plano de dados. Essa nova arquitetura, a razão do seu surgimento e seus principais elementos e componentes são explicados de forma clara e detalhada no trabalho Software-Defined Networking: A Comprehensive 
Survey $\left[\mathrm{KRV}^{+} 15\right]$.

$\mathrm{Na}$ arquitetura convencional de redes, esses dois planos coexistem dentro do firmware dos roteadores. O plano de controle (ou Control Plane) é composto pelos processos responsáveis por definir os caminhos pelos quais os pacotes devem ser encaminhados, produzindo para isso um conjunto de regras que irão ditar as rotas pelas quais os dados serão transmitidos pela rede. Já o plano de dados, também conhecido como plano de encaminhamento (ou Forwarding Plane), é composto pelos processos e funcionalidades responsáveis pelo encaminhamento dos pacotes entre as interfaces presentes na rede. O plano de dados, portanto, utilizará as regras produzidas pelo plano de controle para guiar suas funções de encaminhamento.

Já na arquitetura das Redes Definidas por Software, as responsabilidades de ambos os planos são mantidas, porém o plano de controle é desacoplado fisicamente do plano de dados. Ao realizar essa separação, duas principais consequências são produzidas: O plano de controle pode ser implementado de uma forma diretamente programável, enquanto que o plano de dados pode ter sua infraestrutura abstraída para ser utilizada por aplicações e serviços de rede. Além disso, uma vez que o plano de controle não está mais presente em todos os dispositivos comutadores da rede, é possível concentrar a lógica em um único ponto, simplificando a maneira como alterações na rede podem ser feitas. Para alcançar esse fim, uma das alternativas encontradas, e que inicialmente foi adotada, foi a inserção de um novo elemento na rede, chamado de Controlador.

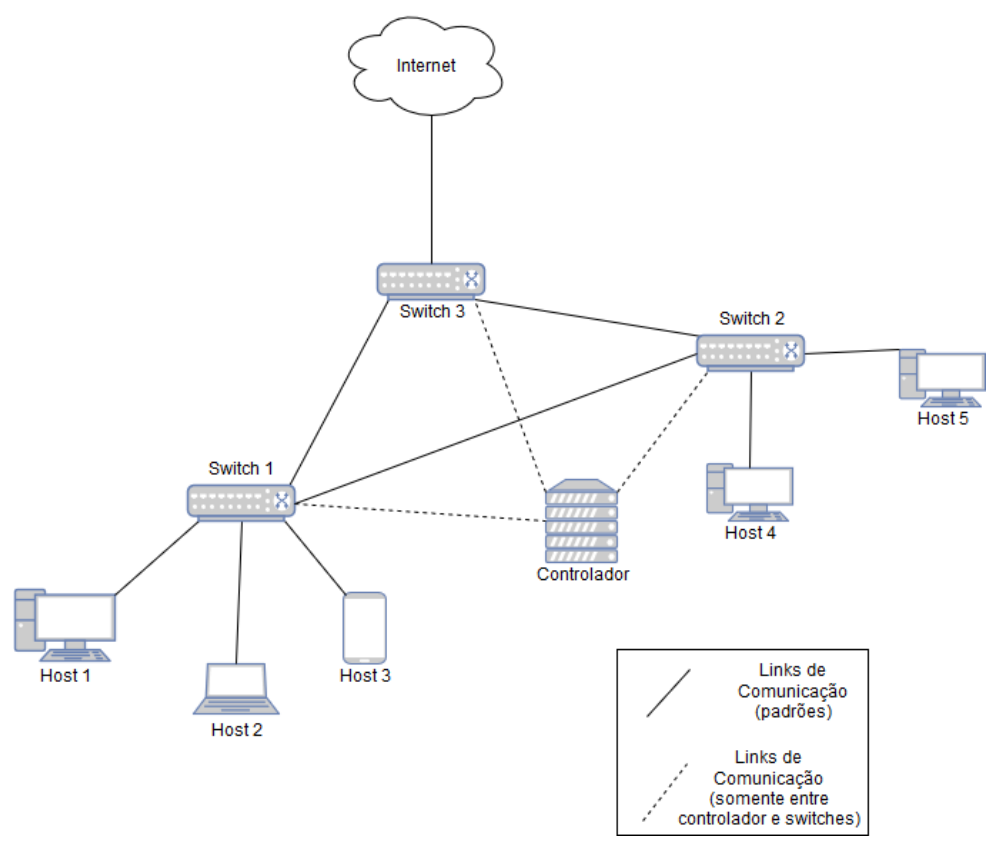

Figura 2.2: Diagrama de uma rede definida por software

A Figura 2.2 exemplifica o diagrama de uma RDS com 3 switches, 5 hosts e 1 controlador. É importante observar que as linhas tracejadas apresentadas na figura não necessariamente precisam ser implementadas como conexões físicas dedicadas a conectar os switches ao controlador. Elas podem usar a própria rede de transmissão dos dados já existentes para permitir a existência dessas conexões de forma lógica.

Durante este trabalho, faremos uso do termo "fluxo". Utilizando a figura anterior como referência, podemos definir "fluxo" como um conjunto de pacotes, que se move de uma origem A (como o Host 1), para um destino B (como o Host 5), percorrendo um certo caminho (por exemplo: Switch 1 -> Switch $3->$ Switch 2). O caminho que esses pacotes irão percorrer é definido dentro do que chamaremos de "regras de fluxo", que são instruções, presentes em cada um dos elementos comutadores da nossa rede, e que indicarão a esses dispositivos, de acordo com as informações contidas nesses pacotes, em que direção (ou para qual porta) estes pacotes devem ser encaminhados. Em algumas tecnologias, essas regras de fluxo são armazenadas em uma estrutura conhecida como tabela de fluxos (ou Flow Table). 
O controlador, então, tem como sua principal função centralizar a lógica que administra a rede. Para isso, ele deve possuir uma visão completa da rede e, a partir dessas informações, ser capaz de intervir na camada inferior, a do plano de dados, através da alteração das regras de fluxo. O meio pelo qual se dá a comunicação entre o Controlador, que compõe o plano de controle, e os comutadores, que constituem o plano de dados, recebe o nome de Interface Sul (ou Southbound $A P I)$. Através dessa interface, o Controlador é capaz de não apenas obter as informações que precisa sobre a rede e sua topologia, mas também de aplicar as alterações nas regras e rotas de encaminhamento de pacotes, que estarão armazenadas nos dispositivos dessa camada inferior.

Além disso, existe uma terceira camada que pode compor uma RDS, que é chamada de Camada de Aplicação. Nela estão localizadas as Aplicações de Rede. Essas aplicações são peças de software que irão trabalhar em conjunto com os controladores para definir as políticas que guiarão os fluxos da rede administrada. Alguns exemplos de aplicações de rede podem ser considerados programas como firewall, serviços de monitoramento da rede, controle de acesso, balanceadores de carga entre outros. Para que as aplicações possam ajudar nessa administração, os controladores devem ser capazes de oferecer uma abstração dos recursos presentes na rede, eliminando dessas aplicações a necessidade de compreender os procedimentos mais internos envolvidos na comunicação entre as camadas mais inferiores (pela Interface Sul). A essa abstração, ou meio, pelo qual as aplicações dialogam com os Controladores, é dado o nome de Interface Norte (ou Northbound API).

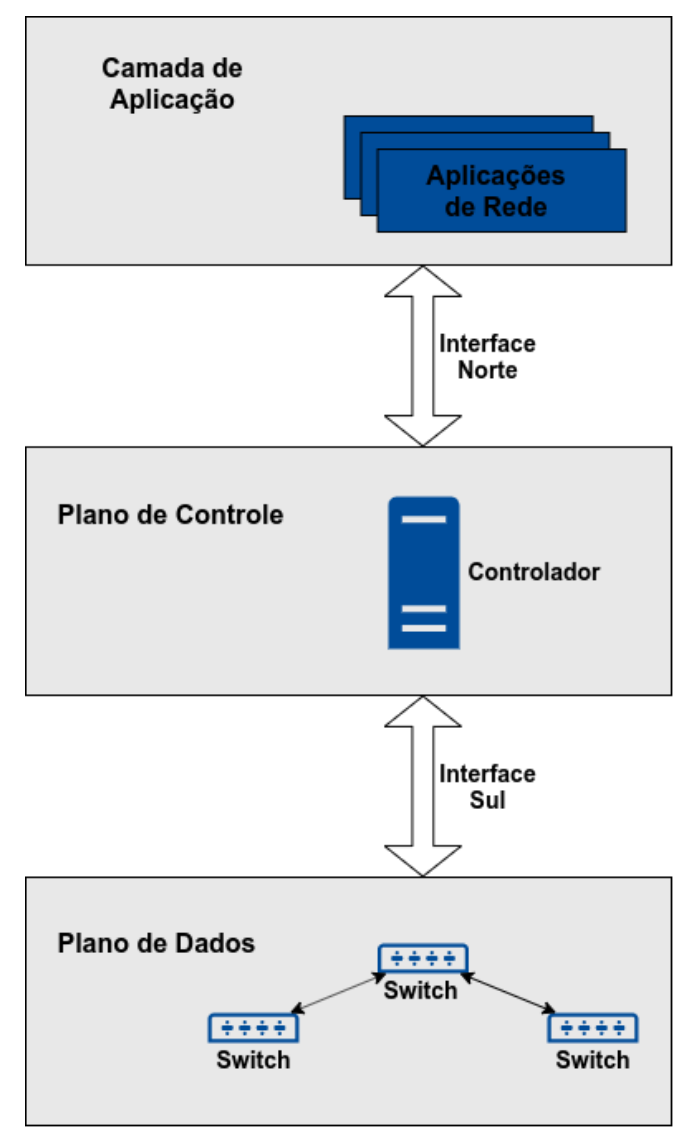

Figura 2.3: Diagrama dos elementos que compõem uma arquitetura de rede definida por software

Essa abordagem permite que os administradores da rede possam planejar e efetuar toda a configuração da rede de forma dinâmica e programada, através de aplicações rodando em conjunto com o controlador (ou os controladores). A flexibilidade introduzida por esses controladores permite que a rede sofra alterações em tempo real, de maneira a suprir as necessidades exigidas, mesmo que elas mudem a todo instante. Além disso, como esse esquema propõe que programas lógicos controlem o trabalho exercido por dispositivos físicos, isso permite que mais de uma rede lógica atue paralelamente nesses mesmos dispositivos, criando diversas possibilidades, como por exemplo a existência de cenários de experimentação em execução junto do cenário considerado "de produção". 
A Figura 2.3 acima sintetiza em uma imagem todos os elementos descritos anteriormente no texto. Nela, são representadas as 3 camadas existentes numa arquitetura de Redes Definidas por Software, a Camada de Aplicação, o Plano de Controle e o Plano de Dados, e as camadas que conectam esses elementos, que são a Interface Norte e a Interface Sul.

Além das propriedades indicadas acima, existe mais uma característica a ser citada, referente a essa nova arquitetura, e que contrasta com a forma tradicional na qual as redes são configuradas. As primeiras concepções do conceito de RDS previam que toda interação entre os elementos que compõem a rede fosse definida e implementada através de padrões abertos. Ou seja, as interfaces pelas quais os controladores se comunicariam com os outros elementos da rede (Interface Norte e Interface Sul) deveriam ser independentes de qualquer marca ou fabricante. Assim, as implementações de RDS ficariam mais simples, dependendo apenas das instruções oferecidas pelos controladores, por exemplo, e não por dispositivos e protocolos específicos, que tivessem comportamentos e regras diferentes para cada marca presente nos aparelhos compondo a rede. As duas soluções que serão apresentadas neste trabalho, o protocolo OpenFlow e a linguagem $\mathrm{P} 4$, a princípio respeitam essa propriedade.

Com o passar do tempo, novas abordagens vêm sendo testadas, como a utilização de plano de controle distribuído, com a existência de diversos Controladores, trabalhando de forma simultânea [BTK $\left.{ }^{+} 15\right]$ [AAKM18]. Outras soluções de plano de controle distribuído incluem a não utilização de um elemento centralizado de lógica, como o Controlador, espalhando esse controle através de alguns switches especiais presentes na rede, porém permitindo que todos possam ser administrados como se fossem um só. Um exemplo dessa abordagem é o serviço de Adaptive Cloud Fabrics [PN18] da empresa Pluribus [Net19b]. Porém, no decorrer desse projeto, consideraremos apenas o modelo tradicional de Redes Definidas por Software, no qual a existência de um Controlador se faz necessária.

\subsubsection{OpenFlow}

Tendo as limitações do modelo tradicional de redes em mente, foi criada em 2011 a Open Networking Foundation (ONF), que é uma organização liderada por usuários da comunidade da área de Redes de Computadores e que tinha como intuito promover o estudo sobre Redes Definidas por Software. Para isso, essa organização passou a administrar, em 2011, a especificação e desenvolvimento do protocolo OpenFlow, que foi descrito como o primeiro padrão a definir a interface de comunicação entre as camadas de controle e de encaminhamento de uma estrutura de Redes Definidas por Software. Apresentado inicialmente em 2008, o protocolo não havia tido uma adoção relevante até então, mas devido a promoção feita pela ONF sobre esse protocolo, além do árduo trabalho realizado nele, o OpenFlow passou a ser adotado pela maior parte das soluções envolvendo RDS realizadas até o momento.

Sua utilização atualmente é possível pois, com o incentivo gerado pela ONF, diversas empresas adaptaram seus aparelhos que atuam como Switches para serem compatíveis com o protocolo. A principal função do OpenFlow é servir como a Interface Sul em uma RDS, atuando como a forma pela qual os planos de Controle e de Dados irão se comunicar, permitindo assim que eles sejam desacoplados. O Controlador pode utilizar o protocolo para aplicar alterações nas regras de fluxo dos dispositivos do plano de dados, enquanto que esses elementos da topologia podem reportar seus estados para o Controlador para que este possa acompanhar a situação geral da rede e, assim, direcionar suas alterações.

Dentro da especificação sobre o protocolo OpenFlow, temos três elementos relevantes: o Controlador OpenFlow, o Switch OpenFlow e o Protocolo OpenFlow. O Controlador OpenFlow é qualquer entidade na rede que seja capaz de interagir com os Switches OpenFlow utilizando o Protocolo OpenFlow para isso. Assim, na maior parte dos casos, o Controlador será um software que fará o controle de diversos Switches OpenFlow ao mesmo tempo.

O Switch OpenFlow, por sua vez, pode ser tanto um dispositivo físico compatível com as especificações do protocolo OpenFlow, quanto uma implementação em Software, como por exemplo o OpenVSwitch [Fou19a], que pode ser executado sobre algum hardware programável ou virtualizado. 
Para que esse dispositivo seja considerado um Switch OpenFlow, terá de respeitar algumas condições: deve possuir uma ou mais tabelas de fluxo e uma tabela de grupos, que serão consultadas para decidir a direção de encaminhamento dos pacotes; deve apresentar um ou mais canais OpenFlow, que serão utilizados para realizar a comunicação do Switch com os Controladores; deve ser capaz de receber, reconhecer e interpretar todas as instruções enviadas pelo Controlador através do Protocolo OpenFlow e, a partir dessas instruções, realizar as alterações necessárias em suas tabelas de fluxo, bem como produzir e enviar pacotes do Protocolo OpenFlow em direção aos Controladores para se comunicar com eles.

Quando um Switch OpenFlow recebe pacotes da rede, ele irá consultar as suas tabelas de fluxo para decidir qual ação de encaminhamento deve ser tomada. A consulta começa na primeira tabela desse dispositivo, e pode continuar para outras tabelas dentro dessa pipeline. Cada entrada nessa tabela é chamada de Regra de Fluxo, e estão ordenadas em ordem decrescente de prioridade, que é um valor atribuído a cada uma dessas regras no ato de sua criação, e que pode ser modificado caso a regra seja atualizada. Cada uma dessas regras contém um conjunto de informações:

- campos de match, que são compostos por informações como cabeçalhos de pacotes ou portas de ingresso. Essas informações são comparadas às informações contidas no pacote recebido e, se o pacote apresentar as mesmas informações que as contidas nesses campos, ele é processado por essa regra;

- contadores, que marcarão quantos pacotes foram processados por essa regra;

- um conjunto de instruções, que podem ser ações ou modificações na sequência de processamento desse pacote. Essas ações podem ser por exemplo a alteração de algum campo do pacote, encaminhamento desse pacote para outra tabela de fluxos ou de grupo, encaminhamento do pacote através de uma porta específica ou mesmo descarte desse pacote. Essas ações serão executadas sobre o pacote caso ele seja processado por essa regra;

- um tempo de vida, indicando por quanto tempo a regra continuará disponível nessa tabela.

As tabelas de fluxo do Switch OpenFlow devem apresentar, ainda, uma regra especial, chamada de table-miss rule, que é invocada quando o pacote não é processado por nenhuma das regras existentes na tabela. O comportamento dessa regra é escolhido em sua definição, e pode ser encaminhar esse pacote para a próxima tabela, descartar esse pacote, ou então enviá-lo ao Controlador, através dos canais OpenFlow, para que o Controlador possa decidir qual a maneira mais correta de lidar com esse pacote.

A instalação de regras de fluxo pode ser feita de forma tanto proativa quanto reativa. A instalação de forma proativa é feita durante a configuração inicial dos Switches pelo Controlador, antes mesmo do início do tráfego de pacotes, enquanto que a instalação de forma reativa ocorre, durante o tráfego de pacotes, em situações onde algum pacote desconhecido recebido pelo Switch é enviado ao Controlador, por exemplo, ao ser processado pela table-miss rule. O controlador, então, poderá utilizar os metadados do pacote encaminhado para decidir se alguma alteração deverá ser feita nas regras de fluxo do Switch responsável por lidar com esse pacote.

Por fim, o último elemento definido pela especificação oferecida pela ONF é o Protocolo OpenFlow, que é implementado através de mensagens OpenFlow que serão transmitidas através do canal OpenFlow. Todas as mensagens OpenFlow possuem um cabeçalho padrão, contendo informações sobre a versão do protocolo, tipo da mensagem, comprimento dela e uma identificação. Após o cabeçalho, o protocolo pode ser seguido de diversas estruturas diferentes. São elas:

- Estruturas Comuns, que são informações que podem estar presentes em diversas mensagens diferentes, como estruturas para descrição de portas, fluxos, instruções e ações;

- Mensagens do Controlador para o Switch, com a função principal de permitir ao Controlador adicionar, atualizar e remover regras de fluxo nas tabelas dos Switches, além de permitir a ele fazer requisições de informações e estatísticas, e a configurar o Switch; 
- Mensagens Assíncronas, como por exemplo as mensagens enviadas dos Switches para os Controladores, informando a chegada de pacotes desconhecidos, ou mensagens indicando alterações realizadas no Switch, como regras de fluxo removidas ou novas portas adicionadas;

- Mensagens Simétricas, contendo mensagens enviadas tanto pelo Controlador quanto pelos Switches, por exemplo mensagens de manutenção de conexão, como Echo, utilizada para checar a latência da comunicação, ou mesmo para verificar se a conexão entre os 2 elementos ainda está ativa.

A especificação do OpenFlow, porém, não apresenta nenhuma definição da Interface Norte, que seria o meio pelo qual as aplicações de rede deveriam se comunicar com os Controladores que estão gerindo a rede. Dessa forma, cada implementação de Controlador é livre para definir sua própria interface pela qual as aplicações de rede solicitarão as alterações na rede. Dessa mesma forma, cada aplicação deverá ser implementada diferentemente, de acordo com o controlador que for escolhido para utilização.

\subsubsection{P4}

A linguagem P4, cujo nome significa Programming Protocol-Independent Packet Processors, é uma linguagem de programação criada para expressar a forma como pacotes devem ser processados pelo plano de dados de um dispositivo comutador programável. A linguagem foi descrita inicialmente através de uma publicação realizada em 2014 [BDG ${ }^{+}$14], e hoje em dia tem a organização P4 Language Consortium [Con19h] como responsável por administrar sua especificação [Con19b].

A criação da linguagem teve duas principais motivações. A primeira motivação vinha do fato de que o Protocolo OpenFlow, até então a contribuição mais importante e mais utilizada nas pesquisas de RDS, operava com um número limitado de cabeçalhos de protocolo, o que até hoje é considerado uma das limitações da especificação atual do OpenFlow. Isso fazia com que o OpenFlow não fosse flexível o suficiente, pois não suportava a quantidade cada vez maior de protocolos requisitados pela comunidade de usuários. A segunda motivação surgiu por conta do desacoplamento dos planos de controle e de dados e a consequente criação do OpenFlow, o que resultou no surgimento de diversas implementações de Controladores, que permitiam aos administradores a programação do plano de controle. O que faltava, porém, era a possibilidade de programar o plano de dados, que até então tinha seu comportamento limitado pelas funcionalidades que cada um dos fabricantes decidia instalar em seus dispositivos.

A linguagem P4 foi projetada, então, seguindo três objetivos principais:

- Reconfigurabilidade: os programadores devem ser capazes de modificar o funcionamento dos Switches mesmo depois que eles tiverem sido implantados;

- Independência de protocolo: os Switches não devem ser obrigados a trabalhar apenas com alguns protocolos específicos. Ao invés disso, o administrador deve ser capaz de especificar um analisador sintático (parser) para poder extrair cabeçalhos de nomes e tipos específicos, além de uma coleção de tabelas "match+action" capazes de processar esses cabeçalhos;

- Independência de target: o programador deve ser capaz de descrever as funcionalidades do processamento de pacotes do plano de dados sem precisar saber detalhes sobre a estrutura de hardware do dispositivo comutador em que o código será utilizado. Esse mapeamento será de responsabilidade do compilador. 


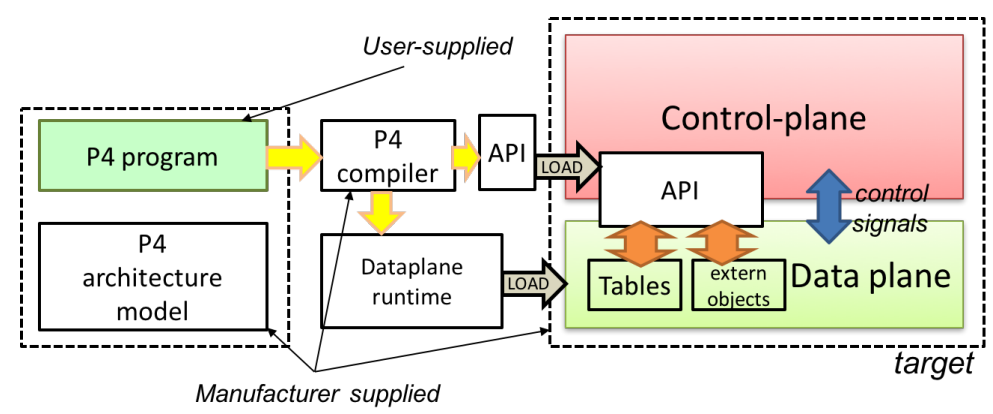

Figura 2.4: Diagrama mostrando os passos envolvidos na programação de um target. Imagem retirada da especificação da linguagem P4[Con19b]

Segundo a especificação da linguagem P4, um target é qualquer sistema de processamento de pacotes capaz de executar um programa escrito em P4. A Figura 2.4 mostra o processo típico necessário para se programar um target usando a linguagem P4. O fabricante irá disponibilizar o hardware ou uma implementação em software de target, uma definição de arquitetura, e um compilador P4 para esse target. Tendo isso em mãos, o programador poderá escrever um programa em P4 para essa arquitetura específica. Esse código, então, é compilado usando o compilador fornecido, produzindo assim dois artefatos: um arquivo de configuração de plano de dados, que irá implementar a lógica de encaminhamentos escrita no programa; e uma API que será utilizada pelo plano de controle para gerenciar os objetos do plano de dados.

Para que um programador possa escrever um código na linguagem P4, além de conhecer sua sintaxe, ele deve conhecer a arquitetura para a qual está programando. Uma arquitetura, para o P4, é uma definição contendo um conjunto de componentes programáveis através da linguagem P4 e as interfaces de plano de dados entre esses componentes. Essa definição irá expor para o programador quais são os recursos que os targets que seguem essa arquitetura deverão possuir. Essa característica permite que um mesmo programa, escrito para uma arquitetura, seja compatível com diversos hardwares diferentes, desde que todos implementem essa mesma arquitetura.

Seguindo os objetivos esperados para linguagem, P4 busca ser "independente de protocolos". Isso não significa que a linguagem não irá lidar com protocolos, muito pelo contrário. A linguagem provê um conjunto de abstrações que irão permitir ao programador que ele expresse uma grande variedade de protocolos e comportamentos do plano de dados. Entre as abstrações, temos: tipos de cabeçalho, que serão utilizados para descrever os possíveis cabeçalhos de pacotes que serão transportados; analisadores sintáticos, que serão utilizados para identificar sequências de cabeçalhos e quais campos deverão ser extraídos dos pacotes; tabelas, que associarão chaves definidas pelo usuário com ações. Essas tabelas podem ser usadas para definir tabelas de fluxo, tabelas de roteamento, listas de controle de acesso entre outras utilidades; ações, que são trechos de código que descrevem como os campos de cabeçalho e metadados são manipulados.

Essa característica é muito positiva, pois além de permitir que os dispositivos comutadores sejam compatíveis com tipos novos de protocolo, possibilita que os programadores adicionem outras funcionalidades interessantes a esses dispositivos, como por exemplo fazer com que os Switches adicionem, em alguns pacotes específicos, informações sobre seu estado, com o intuito de permitir ao administrador monitorar a situação atual da rede. Essa proposta vem de um projeto, chamado de In-band Network Telemetry (INT) [Con15], mantido por um grupo de trabalho do P4 Language Consortium, conhecido como P4 Applications Working Group [Con19f], que trabalha em aplicações que fazem uso da linguagem P4. O INT propõe o monitoramento do estado da rede fazendo uso apenas do plano de dados, sem a necessidade de interferência do plano de controle. Nele, pacotes com um cabeçalho INT são disparados pela rede e, quando esses pacotes percorrem a rede através de Switches compatíveis com esse cabeçalho, as informações desse pacote indicam para esse dispositivo quais informações podem ser coletadas, e o dispositivo, por sua vez, insere essas informações referentes a seu estado dentro desse pacote e, em seguida, o encaminha para a rede. Esses pacotes, então, após circularem pela rede são coletados por elementos responsáveis por isso na rede e, 
com as informações coletadas, decisões de administração da rede podem ser tomadas. Informações que podem ser coletadas são, por exemplo, um identificador do dispositivo, a latência para que o pacote seja transportado através desse dispositivo, tamanho da fila dos comutadores, entre outras informações.

O último objetivo, sobre reconfigurabilidade, é atingido uma vez que é possível alterar o comportamento de um Switch que está em produção. Isto é realizado de forma simples: basta alimentar o target com um novo arquivo de configuração de plano de dados, produzido a partir da compilação de um programa escrito em P4, descrevendo o novo comportamento esperado para esse Switch.

Além da especificação da linguagem, a P4 Language Consortium mantém alguns outros repositórios contendo recursos interessantes. O primeiro deles é o bmv2 [Con19e], que é um arcabouço responsável por implementar alguns exemplos de targets. Um deles se chama simple_switch, que segue a arquitetura conhecida como V1Model, também criada por essa organização, e que juntos compõem os principais elementos utilizados na realização de testes e experimentos envolvendo a linguagem P4. Também é disponibilizado um compilador chamado $p 4 c$ [Con19c], que é capaz de compilar programas escritos em P4 para o target simple_switch. Outro repositório muito relevante é o de tutoriais [P419b], que contém diversos exemplos de exercícios que são utilizados pela $P 4$ Language Consortium quando algum curso sobre a linguagem P4 é oferecido.

A utilização do P4 ainda é pouco expressiva em empresas de pequeno e médio porte, uma vez que as tecnologias existentes, principalmente da arquitetura tradicional de Redes de Computadores, já supre suas necessidades. A versatilidade e grande espectro de possibilidades abertas tanto pela abordagem de RDS quanto pela utilização do ecossistema do P4 é, hoje em dia, necessária e benéfica apenas para empresas grandes e já consolidadas, que apresentam um fluxo gigantesco de dados, uso massivo de tecnologias de cloud, e grandes datacenters, geralmente em mais de uma região do globo. As vantagens e o potencial dessa nova tecnologia, porém, não são nada dispensáveis ou desprezíveis, o que pode ser percebido pelo grande número de empresas e universidades que apoiam a linguagem P4 e seu ecossistema. O número de contribuidores, segundo o próprio website da P4 Language Consortium, já passa de 100, sendo que mais de 90 desses são de empresas [Con19g].

\subsubsection{Contextualização sobre RDS e o cenário atual}

Para fins acadêmicos e de experimentação, atualmente existem diversas aplicações e projetos capazes de compor uma estrutura inicial completa de RDS para a implementação de um ambiente de testes funcional. Para a criação de uma topologia virtual para os experimentos, é possível utilizar o Mininet [Min17], uma ferramenta de código aberto muito utilizada pelo meio acadêmico para essa finalidade. Utilizando o Mininet, é possível utilizar em sua topologia os Switches criados pelo projeto OpenVSwitch [Fou19a], ferramenta integrada ao Mininet, também de código aberto e que cria switches compatíveis com as especificações do protocolo OpenFlow.

Para a programação do comportamento do plano de controle, existem diversas opções de controladores OpenFlow capazes de oferecer uma interface para programação das aplicações de rede. Esses controladores são compatíveis com diversas linguagens de programação. Alguns dos exemplos de controladores mais populares hoje em dia são o POX [Rep19b] e Ryu [Com19], compatíveis com a linguagem Python, o controlador NOX [Rep19a], compatível com a linguagem $\mathrm{C}++$, e o controlador Floodlight [Flo19], com módulos escritos utilizando a linguagem Java e oferecendo uma API baseada em REST para a utilização pelas aplicações. É possível utilizar o Mininet e o OpenVSwitch[Fou19a] para produzir o plano de dados de uma RDS e escolher um desses controladores para compor o plano de controle e oferecer uma interface para implementação das aplicações de rede. Com isso, o protocolo OpenFlow poderá ser utilizado como Interface Sul, enquanto as APIs que esses controladores oferecem para as aplicações serão a Interface Norte.

No caso de um ambiente que utilize as funcionalidades oferecidas pela linguagem $\mathrm{P} 4$, o ecossistema de aplicações é gerido pelo próprio P4 Language Consortium [Con19h], que oferece boa parte do que é necessário. Entre as aplicações oferecidas pela comunidade do P4 podemos citar: o p4c [Con19c], compilador da linguagem P4, capaz de gerar um arquivo .JSON para ser utilizado em um target; o bmv2 [Con19e], arcabouço que disponibiliza uma implementação de um target, que é 
basicamente um Switch de software programável por programas em P4, além de uma definição compatível com o Mininet, que permite a utilização dos targets do bmv2 em sua topologia; P4Runtime, que é uma API que permite a comunicação de elementos do plano de controle com elementos do plano de dados programados em $\mathrm{P} 4$, e que é implementada em algumas ferramentas auxiliares nos repositórios do P4, como por exemplo o runtime_CLI [Con19d] e o PI [Con19a]. Com esses recursos é possível definir uma topologia, programar os elementos do plano de dados, criar uma aplicação que faça o papel do plano de controle, utilizando a interface do P4Runtime para alterar o plano de dados, e assim definir o comportamento da rede.

Além dos exemplos anteriores, existe também o ONOS (Open Network Operating System), um sistema operacional criado para fazer o papel do Plano de Controle em uma Rede Definida por Software. O projeto já é compatível tanto com o protocolo OpenFlow quanto com Switches programados usando a linguagem P4. O ONOS é desenvolvido com o apoio da ONF e já é bastante difundido entre as empresas do mercado que apresentam interesse nessa nova área. Vale citar que todas as tecnologias citadas até o momento nesse capítulo são projetos de código aberto, e que receberam contribuições de desenvolvimento da comunidade.

Fora do meio acadêmico, existem diversas empresas de grande expressão utilizando soluções baseadas em RDS. Um exemplo é o B4 [JKM $\left.{ }^{+} 13\right]$, um projeto criado pelo Google, e que consiste em uma rede privada de longa distância definida por software, com a função de conectar os datacenters da empresa ao redor do planeta. O projeto desacopla o plano de controle do plano de dados dessa rede, e faz uso do protocolo OpenFlow para realizar a comunicação entre esses dois planos. Outro projeto interessante em desenvolvimento é o Trellis [Tre19], que é uma implementação em código aberto de uma malha de redes no formato "leaf-spine". O projeto apresenta uma solução completa de infraestrutura, sendo implementada utilizando modelos específicos de componentes de rede, e que tem a empresa Comcast [SDx19] como um caso de uso de sua tecnologia. O Trellis faz uso dentro de sua arquitetura do sistema operacional ONOS e trabalha fazendo uso do protocolo Openflow em seus processos, além de estar desenvolvendo uma integração com P4.

As soluções inspiradas em Redes Definidas por Software já chamam bastante a atenção das grandes empresas de tecnologia ao redor do globo. Segundo um estudo [Res19] publicado pela Adroit Market Research, por volta de 2017, o mercado de Redes Definidas por Software no mundo estava avaliado em torno de 5,74 bilhões de dólares, mas seu crescimento é tão grande que as estimativas apontam para que esse valor ultrapasse a marca de 100 bilhões de dólares até o ano 2025. Segundo o mesmo estudo, as empresas Cisco Systems, Hewlett-Packard Enterprise, Big Switch Networks, Juniper Networks, NEC Corporation, Brocade Communications Systems, IBM Corporation, VMware, Extreme Networks, entre outras, são consideradas as principais empresas presentes no mercado global de Redes Definidas por Software, responsáveis por sempre contribuir através de parcerias, colaborações e acordos.

Por último, um projeto bastante interessante que merece ser citado é o Stratum, também gerenciado pela ONF. O Stratum [Fou19b] é um projeto de código aberto, que consiste em um sistema operacional para Switches de Redes Definidas por Software. Esse projeto é considerado pela ONF como parte fundamental do que eles esperam ser o futuro das RDS. O Stratum é compatível com diversas tecnologias novas e que estão em foco na área, como P4Runtime e OpenConfig, e busca abandonar as limitações existentes pelo controle que fazia uso apenas do protocolo OpenFlow, expandindo as possibilidades de configuração de comportamento da rede por parte dos administradores, e incrementando o conjunto de ferramentas para gestão do ciclo de vida de sua rede. Esse projeto não é visto como uma promessa apenas pela ONF, dado que o Stratum já é apoiado por mais de 20 empresas de diversas áreas do segmento de redes, como provedores de cloud, operadoras de telecomunicação e fornecedoras de equipamentos. Entre os grandes nomes, temos Tencent, China Unicom, Big Switch Networks e Barefoot Networks, além da Google, que fez parte da criação do código inicial que deu origem ao projeto Stratum. 


\subsubsection{Limitações}

A estrutura atual da Internet ainda funciona tendo o modelo tradicional de Redes de Computadores como o padrão. Por consequência disso, existem diversos dispositivos de comutação compondo redes do mundo todo e que não oferecem suporte às tecnologias necessárias para a implantação de RDS. Um exemplo é que diversos modelos de roteadores em uso no momento não possuem suporte ao protocolo OpenFlow. Apesar disso, diversos esforços por parte das equipes por trás das tecnologias desse ecossistema são feitos com o intuito de permitir que essa transição seja o mais sutil e simples possível. Um desses exemplos é o fato do protocolo OpenFlow operar sobre estruturas que já faziam parte da arquitetura tradicional de roteadores, e não partindo de um modelo completamente novo, o que facilitou sua adoção por várias marcas presentes no mercado.

Além da dificuldade estrutural, o fato dessa área ser recente contribui com a dificuldade em trabalhar nela. O termo Software Defined Networks começou a ganhar popularidade apenas em meados dos anos 2010, com os primeiros projetos comerciais envolvendo a tecnologia Open VSwitch realizados pela Nicira (que foi adquirida posteriormente pela VMWare), e mais ainda em 2011, com a criação da Open Networking Foundation, cuja proposta inicial era a de promover tanto o protocolo OpenFlow quanto pesquisas e projetos envolvendo Redes Definidas por Software. Sendo assim, o conteúdo didático disponível na Internet ainda é pouco extenso, e como diversas das pesquisas e projetos são realizados por empresas, boa parte das soluções completas existentes não estão disponíveis em código aberto, reduzindo o número de exemplos de código ao alcance de indivíduos interessados em conhecer e experimentar essas tecnologias.

Vale citar ainda que o fato da área ser recente faz com que os padrões que a definem ainda não estejam completamente solidificados. O OpenFlow, que durante muito tempo foi considerado a base para implementação das Redes Definidas por Software, passou a ser visto pela própria ONF como uma especificação ultrapassada, que apresenta problemas [Fou17], justificando o planejamento de novos projetos, como o Stratum, com o intuito de redefinir as RDS [Pla18].

Outra limitação da arquitetura e que vem sendo um assunto bastante estudado dentro dessa área são os riscos de segurança existentes nas Redes Definidas por Software. Essa nova abordagem tem diversos elementos novos na rede, como os Controladores e as Aplicações de Rede, e soluções para lidar com as brechas de segurança ainda vem sendo estudadas. O fato do controle da rede ser centralizado, por exemplo, já torna uma RDS vulnerável, pois essa centralização cria um ponto de ataque valioso para um intruso na rede. Ataques de negação de serviço em cima desse Controlador podem fazer com que esse elemento fique indisponível e, com isso, os Switches ficam bloqueados, uma vez que, em algumas soluções, esses dispositivos não tem autonomia para tomar decisões sobre pacotes que não são reconhecidos em suas tabelas de fluxo. Embora existam propostas que permitam o uso de diversos controladores redundantes, é reconhecido pela comunidade que mais pesquisa é necessária nessa área com o objetivo de encontrar soluções que levem em conta principalmente particularidades do ambiente onde as RDS serão utilizadas, como no caso da Internet das Coisas (IoT) [FTKS19].

Uma outra parte da rede na qual brechas podem ser encontradas é na comunicação entre as aplicações de rede e o Controlador. Uma vez que diversas aplicações são conectadas ao Controlador, cada uma com diferentes funções, e todas são capazes de instalar novos fluxos na rede sem a necessidade de autenticação de fluxo, isso produz mais um ponto onde possíveis ataques podem ser realizados. Esses e outros exemplos de ataques possíveis, bem como sugestões de soluções para lidar com esses problemas podem ser encontrados no artigo Software-Defined Networking (SDN): the security review $\left[\mathrm{HCA}^{+} 19\right]$, que já faz as suas considerações com base na especificação mais recente do OpenFlow, a versão 1.5.1.

\subsection{Jogos digitais}

Jogos digitais (também conhecidos como Jogos Eletrônicos) são, fundamentalmente, programas de entretenimento. Um jogo pode variar em diversos aspectos, como a posição da câmera do jogador, a temática do jogo, o estilo do gráfico, o gênero do jogo etc. Todos os jogos, porém, seguem a mesma 
ideia de funcionamento: o jogador interage com o jogo através de comandos, enquanto o jogo, por sua vez, responde a esses comandos por meio de estímulos visuais e sonoros. Nessa linha de raciocínio, podemos dizer, então, que jogos também são softwares interativos, pois a proposta é justamente a de oferecer diversão ao jogador por meio dessa interação com a máquina que executa o jogo.

Os jogos estão presentes em diversas plataformas e, por isso, esses meios de interação são diferentes em cada uma delas. No caso de computadores, o jogador geralmente envia seus comandos através do mouse e do teclado e a resposta do jogo é apresentada no monitor (visual) e nos fones de ouvido (sonora). Na plataforma dos consoles, os comandos são efetuados através dos joysticks e a resposta é enviada aos dispositivos nos quais o console está conectado (geralmente uma televisão e seus alto-falantes). O mesmo ocorre em dispositivos móveis: os comandos, hoje em dia, geralmente são capturados por meio da tela do dispositivo (através das telas sensíveis ao toque) e a resposta visual e sonora é reproduzida pela tela do dispositivo e por seu alto-falante interno, respectivamente.

No que diz respeito à implementação, ou ao desenvolvimento de jogos digitais, vale citar a definição de Battaiola [Bat00] sobre jogo por computador (JC), que também vale para um jogo digital: "Um JC pode ser definido como um sistema composto de três partes básicas: enredo, motor e interface interativa".

Dada essa definição, temos o enredo, que consiste no tema e história por trás do jogo; temos o motor, que é considerado o sistema de controle por trás do jogo. É no motor onde encontra-se a implementação do jogo, na qual os valores de entrada oferecidos pelo usuário são traduzidos para alterações no estado atual do jogo; e por fim, temos a interface interativa, que é a responsável por fazer a comunicação entre o motor e o usuário, oferecendo a visualização desse estado atual do jogo de uma forma que seja interessante e informativa para o usuário.

\subsubsection{Jogos digitais em rede}

Com a adição dos modos multijogador online nos jogos, a relação dos jogadores com os jogos digitais começou a mudar. Para o jogador, o jogo deixou de ser uma interação apenas entre o jogador e o computador, e passou a ser uma interação entre jogadores. E não somente jogadores próximos, pois os jogos online passaram a conectar jogadores de todas as regiões do mundo.

Apesar de muito interessante, a ideia de conectar pessoas em lugares distantes do mundo não é perfeita do ponto de vista físico. A partir dessa nova situação, o desempenho do jogo deixa de ser influenciado apenas pela capacidade da máquina local, e passa a ser influenciado também pelas condições da rede. A execução do jogo passa a sofrer alterações por conta do atraso de processamento nodal e, em situações contendo jogadores localizados a distâncias muito grandes, como continentes diferentes, o principal culpado é o atraso de propagação.

Desta forma, busca-se arquiteturas de jogos com o objetivo de reduzir a latência, cujo efeito consequente na execução do jogo é conhecido como Lag (gerando atraso na execução das animações locais do jogo e principalmente dessincronização entre os estados do jogo de cada um dos jogadores). Esses efeitos são notáveis em basicamente qualquer jogo, porém sua presença é mais extrema em jogos de ritmo acelerado, como por exemplo jogos de tiro em primeira-pessoa, pois são gêneros que exigem que o jogador possua reflexos mais rápidos. Nesse estilo de jogo, algumas ações exigem do jogador um tempo de resposta em torno de $200 \mathrm{~ms}$ a $700 \mathrm{~ms}$, o que é um espaço bem curto de tempo. Porém, dependendo da latência encontrada por esse jogador, o atraso gerado por ela pode ser superior a esses valores, o que faria com que a ação toda ocorresse em um espaço de tempo literalmente impossível de se reagir, deixando o jogador prejudicado com relação às mecânicas do jogo.

Para combater essas inconsistências, diversas técnicas foram concebidas ao longo dos anos na área de desenvolvimento de jogos. Métodos como interpolação, compensação de lag, rollback, entre outros, servem para esse propósito e para amenizar os efeitos visuais negativos da presença do lag. Porém, nenhum desses métodos resultam na diminuição da latência, eles apenas tentam remediar os efeitos visuais que são causados por esse atraso no recebimento das informações decorrente das condições da rede.

Outra característica presente no modelo de jogos online, e que não se manifesta em jogos offline, 
é o consumo de dados. Para poder sincronizar o estado do jogo entre todos os jogadores, diversas informações devem ser trocadas entre os clientes e o servidor. É curioso notar como cada gênero de jogo possui suas diferentes quantidades de dados compartilhados. Enquanto um jogo multijogador massivo online de RPG como World of Warcraft chega a consumir entre 10 e $40 \mathrm{MB} / \mathrm{h}$ (Megabytes por hora), jogos de tiro em primeira pessoa, como Counter Strike: Global Offensive consomem uma quantidade bem maior, de $250 \mathrm{MB} / \mathrm{h}$ [nbn16], e chegando a valores bem altos como de Destiny, que diz consumir até $1 \mathrm{~GB} / \mathrm{h}$ (Gigabyte por hora) [Bun14].

Os Jogos Digitais há muito tempo servem como estímulo para pesquisas em diversas áreas da Computação, desde componentes de Hardware até tecnologias avançadas de Software. Não somente na área acadêmica, mas também comercial, uma vez que os jogos, em 2019, produzirão uma receita mundial estimada em mais de 152 bilhões de dólares segundo projeções da Newzoo [New19]. Um exemplo de empresa grande que vem apresentando grande interesse em jogos é a Google, que recentemente apresentou seu novo produto, bastante interessante do ponto de vista de Redes, chamado Google Stadia [Goo19], que é um serviço de Cloud Gaming. Esse projeto se depara com diversos obstáculos interessantes, uma vez que, dado que todo o processamento dos jogos oferecidos pelo serviço são de responsabilidade dos datacenters da empresa, a ponte entre o Stadia e seus consumidores é toda realizada através da rede. Então, além de depender da estrutura interna da empresa, a qualidade do serviço oferecida também será impactada diretamente pela qualidade da conexão entre os jogadores e os servidores da Google, o que faz com que a empresa tenha que buscar otimizar ao máximo os processos que envolvem essa comunicação entre os clientes e seus servidores.

Os Jogos Digitais em Rede, portanto, apresentam diversos desafios a serem contornados através de soluções de Redes de Computadores, com o objetivo final de atender às expectativas dos jogadores do que seria uma experiência positiva de jogo. Pensando nisso, esse assunto foi escolhido como um bom cenário para aplicação do tema de pesquisa deste projeto, uma vez que esses jogos demandam condições boas de conexão e, com o intuito de não prejudicar a experiência de um jogador, exigem respostas rápidas da rede quando problemas forem detectados na comunicação entre os jogadores. 


\section{Capítulo 3}

\section{Trabalhos relacionados}

Neste capítulo, são apresentados trabalhos que possuem relação com o tópico deste projeto. Diversos trabalhos foram encontrados com propostas de se utilizar RDS aplicadas a Jogos Eletrônicos, com a finalidade de melhorar a experiência final do usuário. Entretanto, diferente dos trabalhos apresentados pelos artigos, este projeto agrega ao mesmo tempo três características específicas: atuação global, reativa e independente de ação da aplicação.

No trabalho relatado no artigo SDN-based Game-Aware Network Management for Cloud Gaming [AAOSA15], os autores fazem uso de um método baseado em programação linear para alocar jogadores de um jogo em rede em diversos servidores disponíveis de maneira a garantir as menores latências individuais para todos. Esse processo de alocação é feito com o auxílio de RDS. O trabalho foca em jogos baseados em um serviço de Cloud Gaming, no qual um usuário se conecta remotamente a uma máquina (um de vários servidores) que executa um certo jogo. O jogador, então, em sua máquina, pressiona os comandos como se o jogo rodasse localmente, esses comandos são enviados ao servidor que processa os dados e envia de volta à máquina do jogador, através de streaming de vídeo e áudio, o estado atual do jogo. Segundo o que é relatado no artigo, o método recebe como parâmetros a situação da rede, as exigências do jogo e informações pertinentes ao servidor. Esse método, então, após processar esses dados, encontra uma solução que minimize o atraso para cada jogador tentando conectar-se a essa rede. Após encontrar a solução, ela é enviada aos controladores da rede que, por sua vez, distribuem os usuários através dos servidores e caminhos da rede, com a finalidade de aumentar a qualidade de experiência de cada um ao garantir que o atraso fique dentro de um valor tolerado. Resultados durante a realização de experimentos mostraram que o algoritmo proposto foi capaz de reduzir a média de latência encontrada pelos jogadores de $2 \%$ a $14 \%$, dependendo do jogo escolhido, em comparação aos métodos normalmente utilizados.

O trabalho acima vale ser citado pois adiciona preocupações bastante pertinentes, como por exemplo a busca por um valor tolerável de atraso que cada jogo pode ter, e a partir disso, as ações com relação à distribuição dos jogadores que devem ser tomadas visando manter todos dentro desse limite. Entretanto, comparando o mecanismo proposto nesta dissertação com o proposto no artigo citado, é possível observar que as exigências são diferentes. No cenário desta dissertação não há um datacenter, com a necessidade de distribuição da carga de comunicação entre vários servidores diferentes, portanto não pareceu ser necessária a utilização do algoritmo de programação linear. O foco é em oferecer uma melhora na experiência obtida entre jogadores presentes dentro de uma mesma partida, uma vez que eles sejam submetidos a condições negativas de rede, ou seja, tem um caráter mais reativo do que uma melhor alocação de recursos, como no caso do artigo. Além disso, no artigo trabalha-se com um ambiente de Cloud Gaming, que é um assunto com bastante interesse recente da indústria por conta de projetos como o Google Stadia [Goo19], porém esta dissertação lida com um cenário onde cada jogador executa o jogo em seu dispositivo, eliminando a possibilidade de uma "sobrecarga" de usuários em um mesmo servidor, focando apenas no problema de decidir pelo melhor caminho de comunicação entre os jogadores.

No trabalho relatado no artigo RTF+Shark: Using Software-Defined Networks for Multiplayer Online Games $\left[\mathrm{HDG}^{+} 15\right]$, por sua vez, os autores realizam alterações no motor de jogos Shark 
3D para que esse suporte a interface de redes baseada em entidades do RTF, um arcabouço que oferece recursos para o desenvolvimento de aplicações interativas, que funcionem em tempo real, e online, assim como os MMOG (Massive Multiplayer Online Games), ou Jogos Multijogador Massivos Online. O objetivo é permitir que entidades do jogo tenham informações, como suas relações no mundo 3D, compartilhadas com o RTF. Essa integração permite garantir a certos usuários os requisitos de qualidade de serviço que eles demandam. Com essa interação, é possível que usuários façam pedidos de melhora na qualidade da rede. Esses pedidos são recebidos pelo controlador que, por sua vez, poderá realizar alterações na rede, como redirecionamentos ou mudanças na prioridade do tráfego de certos usuários, com a finalidade de oferecer a melhora requisitada, que no caso é descrita como a diminuição no atraso sofrido pelo jogador. Os resultados experimentais mostraram que, com a integração dessas duas ferramentas, um jogo programado utilizando os recursos novos disponibilizados nesse motor de jogo é capaz de fazer essas requisições de melhora na qualidade de rede, que são disparadas quando eles entram em áreas específicas dentro do jogo. Além disso, o controlador foi capaz de modificar as regras de fluxo da rede, suprindo as necessidades de qualidade de rede exigidas por esses jogadores, que consistiam em manter o tempo de resposta abaixo de 100 milissegundos.

O trabalho citado acima é interessante por ser um exemplo que mostra ser possível a alteração do código de um jogo, principalmente suas componentes de rede, com o objetivo de permitir que um jogador possa fazer requisições ao controlador, demandando melhores condições de rede. O artigo mostrou, inclusive, ser possível que essas requisições sejam feitas automaticamente quando um jogador entrar em uma zona específica, apelidada pelos autores de "QoS Area". A decisão de alterar o código do motor do jogo permitindo que ele faça requisições de rede ao controlador é um possível trabalho futuro da pesquisa relatada nesta dissertação. Entretanto, a diferença principal é que o artigo foca em cenários específicos dentro do jogo, enquanto que este projeto define um limite de atraso considerado aceitável, que é independente da área em que o jogador se encontra dentro do jogo, e tenta manter esse jogador o tempo todo abaixo desse limite.

Outro trabalho relacionado é apresentado no artigo HyperNet Games: Leveraging SDN Networks to Improve Multiplayer Online Games [HG13]. Nele, os autores propõem um serviço capaz de construir uma RDS, gerada em tempo real, e que atende, de maneira otimizada, as necessidades de um grupo específico de jogadores. No caso, o grupo de jogadores presentes em uma mesma partida. Esse trabalho faz uso de servidores compostos por máquinas na nuvem, e que são instanciadas de acordo com a localização dos jogadores. Quando um grupo de jogadores se une em uma mesma partida, a arquitetura proposta no artigo encontra uma máquina que está localizada a uma menor distância de todos os jogadores. Após isso, essa máquina cria uma instância de servidor do jogo, que passa a ser o servidor a hospedar a partida desses jogadores. Os controladores de rede, então, definem as melhores rotas que ligam esse servidor aos clientes presentes nessa partida, que então pode começar. Os resultados apresentados pelos experimentos, que utilizaram como jogo escolhido o OpenArena, mostram que a média de latência obtida entre os jogadores, quando dentro de um servidor criado pela ferramenta, é muito menor do que a média de latência obtida ao se conectar aos servidores públicos disponíveis no momento da realização dos experimentos. Enquanto a média de latência nos servidores públicos ficava em torno de 212 milissegundos, as partidas criadas dentro do HyperNet chegaram a apresentar latência média de 22 milissegundos.

$\mathrm{O}$ artigo citado acima também resolve o problema de reduzir o atraso de propagação, porém a utilização das RDS ocorre apenas no momento da criação da partida, pois esse momento envolve a configuração de um servidor específico para a realização dessa partida, e as regras de fluxo são alteradas pelos controladores da RDS apenas para definir qual a rota a ser utilizada para chegar de um ponto a outro. Em contrapartida, o processo realizado nesta dissertação não trabalha com a criação de um servidor, além de focar na alteração das regras de fluxo durante a execução do jogo, apresentando um perfil mais reativo do que o experimento apresentado no artigo, que tenta minimizar a latência antes da comunicação entre os jogadores ativamente ocorrer.

Abordando também os assuntos RDS e Jogos, temos o artigo SDN-enabled Game-Aware Network Management for Residential Gateways [AOS17]. Nele, os autores tratam de um problema, segundo 
eles, pouco estudado, que seria o de melhorar a qualidade de experiência de usuários que fazem uso do mesmo gateway residencial. O foco, portanto, é em oferecer uma solução para ambientes menores, como a rede local de uma casa, que seja capaz de otimizar a distribuição de recursos disponíveis do roteador de acordo com as exigências de qualidade de rede das aplicações sendo utilizadas pelos usuários. Para isso, é proposta a formulação de um problema de otimização matemática, cuja resolução encontrará valores responsáveis por definir a melhor forma de alocar os recursos do roteador (no caso, o principal recurso considerado é a largura de banda) para as aplicações em execução na rede. Para a alocação desses recursos, a rede contará com um Controlador, que irá alterar as regras de encaminhamento dos pacotes dentro do roteador, implantando as configurações consideradas ótimas pela equação, com a finalidade de melhorar a experiência de uso de todos os usuários. Os experimentos realizados durante esse artigo implementaram um cenário utilizando a equação proposta e o compararam com um cenário sem a utilização de RDS, onde as decisões de encaminhamento eram todas feitas pelo roteador presente na rede e utilizando métodos tradicionais para controle de tráfego. Os resultados mostraram que a função e implementação propostas apresentaram uma melhora na qualidade do serviço oferecida aos usuários em comparação aos métodos convencionais, aproveitando em até $25 \%$ mais a largura de banda disponível, além de apresentar uma distribuição de recursos até 11,5\% mais justa, segundo o índice de justiça proposto por Jain [JCH84]. Os resultados também demonstraram uma redução na média de atraso experimentada pelos usuários, além de uma diminuição na taxa de perda de pacotes.

Esse artigo sobre gateways residenciais apresenta um resultado bastante interessante, porém os escopos abordados são diferentes do projeto desta dissertação. Enquanto que o artigo utiliza as RDS para distribuir os recursos de apenas um roteador, este projeto visa a alteração das regras de diversos dispositivos comutadores com o intuito de alterar a rota, que passa por esses dispositivos, pela qual os dados são trocados entre os usuários. Outra diferença está no fato de que o artigo busca otimizar a distribuição da largura de banda disponível pelo roteador, enquanto que este projeto se atenta menos à largura de banda, e mais à latência da rede. Uma semelhança, porém, é que ambos os trabalhos visam melhorar a qualidade de experiência de um usuário (ou jogador) presente na rede definida por software.

Por fim, no artigo Assisting Delay and Bandwidth Sensitive Applications in a Self-Driving Network [MGS19] os autores propõem uma arquitetura de redes autônomas (Self-Driving Network) capazes de medir, analisar, e dinamicamente controlar o desempenho de aplicações executadas em seu ambiente de forma independente, sem a necessidade de serem configuradas previamente para atingir esse objetivo. Para tal fim, são utilizadas técnicas de aprendizagem de máquina para construir um modelo capaz de classificar os estados de funcionamento dessas aplicações e, ao produzir uma máquina de estados a partir dessas conclusões, utilizar essa máquina para avaliar quando que a qualidade de uso das aplicações da rede encontra-se deteriorada. Essa máquina de estados transita entre os estados de acordo com as informações de fluxo coletadas pela própria rede, que são obtidos utilizando um método proposto pelo próprio artigo. Quando as informações monitoradas fazem com que as máquinas de estado indiquem que alguma aplicação está em um estado que apresenta uma condição ruim de rede, mudanças são instauradas no dispositivo de comutação dentro da rede que é responsável por regular o tráfego de dados dessa rede com o resto da Internet. A estratégia de intervenção nesse dispositivo, adotada pelo artigo, é a de utilização de filas de prioridade para o envio de pacotes, onde os pacotes são movidos de fila de acordo com a prioridade que é dada a eles, mediante avaliação da condição atual da rede e do desempenho das aplicações no ambiente. Os resultados apresentados foram bem positivos, demonstrando uma melhora significativa na qualidade de experiência vivenciada pelas duas aplicações principais presentes na rede: uma de streaming de vídeos; e um jogo digital. Durante períodos de congestionamento da rede simulados dentro do experimento, o funcionamento da arquitetura proposta foi capaz de manter os requisitos de ambas as aplicações dentro de valores considerados bons para sua execução.

Esse último artigo apresenta um resultado bastante positivo, e que mostra funcionalidades e propostas interessantes de serem implementadas em conjunto com o mecanismo proposto neste projeto, uma vez que ambos se preocupam em melhorar a qualidade de experiência de usuários 
ao utilizarem aplicações sensíveis a condições ruins de rede. A diferença, porém, é que a forma de atuação do mecanismo proposto no artigo é pontual e local, ela utiliza um controlador de RDS para atuar diretamente em um dispositivo, que é responsável por regular a prioridade de tráfego de pacotes de uma rede local com o resto da Internet, enquanto que este projeto atua de uma forma mais global, utilizando o Controlador para alterar o funcionamento de diversos elementos intermediários que são responsáveis por conectar dois (ou mais) hosts através de diferentes caminhos em uma rede.

Comparando com os artigos apresentados nessa seção, as principais contribuições deste projeto de mestrado em comparação aos demais trabalhos é o fato de unir duas propriedades interessantes. Este projeto foca em tomar medidas reativas a mudanças da rede, ao invés de medidas passivas como em SDN-based Game-Aware Network Management for Cloud Gaming e HyperNet Games: Leveraging SDN Networks to Improve Multiplayer Online Games, ao mesmo tempo em que busca a realização de alterações globais na rede, buscando a mudança de rotas pelas quais os dados trafegam na rede, e não de forma local, em apenas um ponto específico que regula a comunicação da rede interna com a Internet, como em SDN-enabled Game-Aware Network Management for Residential Gateways e Assisting Delay and Bandwidth Sensitive Applications in a Self-Driving Network. Por fim, o projeto realiza essas alterações utilizando apenas as informações da rede e pré-requisitos das aplicações, sem a necessidade que elas sinalizem o controlador sobre sua condição ou que as aplicações sejam alteradas para comportar essa funcionalidade, como em $R T F+$ Shark: Using Software-Defined Networks for Multiplayer Online Games. A Tabela 3.1 sintetiza como os trabalhos citados anteriormente se relacionam com o mecanismo proposto neste projeto.

\begin{tabular}{|c|c|c|c|}
\hline Solução & $\begin{array}{c}\text { Extensão da } \\
\text { atuação }\end{array}$ & Perfil de atuação & $\begin{array}{c}\text { Autonomia da } \\
\text { Solução }\end{array}$ \\
\hline $\begin{array}{c}\text { SDN-based Game-Aware Network } \\
\text { Management for Cloud Gaming }\end{array}$ & Local & Passiva & Autônoma \\
\hline $\begin{array}{c}\text { RTF+Shark: Using Software-Defined } \\
\text { Networks for Multiplayer Online Games }\end{array}$ & Global & Reativo & $\begin{array}{c}\text { Dependente de Sinalização } \\
\text { das Aplicações }\end{array}$ \\
\hline $\begin{array}{c}\text { HyperNet Games: Leveraging SDN } \\
\text { Networks to Improve Multiplayer Online Games }\end{array}$ & Global & Passiva & Autônoma \\
\hline $\begin{array}{c}\text { SDN-enabled Game-Aware Network } \\
\text { Management for Residential Gateways }\end{array}$ & Local & Reativa \\
\hline $\begin{array}{c}\text { Assisting Delay and Bandwidth } \\
\text { a Self-Driving Network }\end{array}$ & Local & Autônoma \\
\hline $\begin{array}{c}\text { Mecanismo Proposto } \\
\text { neste Projeto }\end{array}$ & Global & Autônoma & Reativa \\
\hline
\end{tabular}

Tabela 3.1: Tabela de comparação entre os trabalhos relacionados e o projeto apresentado 


\section{Capítulo 4}

\section{Mecanismo proposto}

A principal contribuição deste projeto consiste na proposição de um mecanismo capaz de detectar cenários de alta latência nas rotas pela qual os dados de uma aplicação são trafegados e, a partir dessa deteç̧ão, alterar as regras de fluxo de uma Rede Definida por Software para modificar a rota pela qual esses dados são trafegados, melhorando a experiência do usuário da aplicação ao fazer com que os dados passem a ser trafegados por uma rota de latência menor. Neste capítulo serão apresentados os objetivos a serem alcançados por esse mecanismo, a proposição de sua arquitetura e uma explicação do funcionamento esperado desse mecanismo.

\subsection{Funcionalidades e Objetivos}

O mecanismo proposto neste projeto foi planejado para ser executado em um contexto de Redes Definidas por Software. Ele deve ser executado sobre uma topologia existente e, uma vez em execução dentro dela, deverá possuir as seguintes funcionalidades:

Primeiramente, deve ser capaz de detectar cenários dentro dessa topologia que possam ser prejudiciais à experiência de um usuário de alguma aplicação, devido a condições negativas existentes na rede pela qual os diversos usuários dessa aplicação se comunicam. Essa detecção deve ser feita durante a execução dessa aplicação, ou seja, enquanto a rede estiver em funcionamento, para que o problema possa ser detectado em tempo real.

A segunda funcionalidade, a partir da deteç̧ão de problemas na rede, é averiguar a possibilidade de modificação da rede analisada, propondo uma alteração nos caminhos de comunicação entre os usuários. A modificação proposta para a rede deve buscar anular os efeitos negativos causados pelos problemas existentes em certos pontos da rede ao escolher novas rotas dentro da topologia que apresentem condições melhores de comunicação entre os usuários.

A terceira funcionalidade é a capacidade de atuar diretamente na rede, realizando as alterações previstas pela segunda funcionalidade dentro dos dispositivos de comutação presentes na topologia, instaurando novos fluxos na rede que irão garantir o transporte dos dados através dos novos caminhos definidos pelo mecanismo.

Tendo essas funcionalidades em vista, o principal objetivo do mecanismo é oferecer uma solução para um ambiente de Redes Definidas por Software que seja capaz de amenizar os efeitos ocasionados em aplicações sensíveis a alterações na rede, ou seja, quando sua rota de comunicação é submetida a condições negativas de rede, como por exemplo um aumento súbito de latência. A solução proposta atua em topologias que conectam usuários de aplicação através de diversas rotas, e deve ser capaz de alterar o caminho pelo qual os dados da aplicação são trafegados para uma rota que apresente uma condição melhor de rede, reduzindo os efeitos negativos na execução dessa aplicação.

Como outro objetivo, há a exploração dos pontos positivos das Redes Definidas por Software na forma de programabilidade e dinamicidade. Para tanto, o mecanismo buscar fazer uso da facilidade, proporcionada pelas RDS, de manutenção da rede e de suas regras. Além disso, o mecanismo também busca utilizar da agilidade das RDS, realizando alterações nas regras de fluxo da rede durante sua execução, agindo de uma forma rápida e eficiente, reduzindo ao máximo a degradação 
da experiência dos usuários quando forem impactados pelas condições desfavoráveis da rede.

\subsection{Arquitetura}

O mecanismo proposto nesse projeto tem uma arquitetura concisa, composta por três componentes principais: Um componente responsável por monitorar rotas da rede; um componente responsável por controlar a topologia e decidir quais caminhos serão oferecidos para as aplicações beneficiadas; e um componente responsável por estabelecer a comunicação entre esse mecanismo e o plano de dados.

O primeiro componente, de monitoramento, tem como função o acompanhamento da qualidade das rotas presentes dentro da rede analisada. Esse componente deve ser capaz de extrair informações sobre estado atual da Rede Definida por Software, como por exemplo o valor referente a latência de cada um dos caminhos existentes nessa rede. Esses caminhos são os meios pelos quais os dados produzidos pelas aplicações irão trafegar e, com isso, esse componente poderá encontrará situações em que os caminhos utilizados estejam sofrendo degradações em sua qualidade, apresentando por exemplo altos valores de latência. Essa funcionalidade é importante para poder descobrir, em tempo real, cenários que estejam comprometendo a qualidade na experiência dos usuários dessa rede.

O segundo módulo, de Controle Lógico, é o cérebro do mecanismo. Ele agrupará informações sobre a rede, como por exemplo todas as estruturas que compõem sua topologia, bem como quais são as principais rotas existentes entre cada um dos pontos dessa rede que farão uso das aplicações a serem beneficiadas. Esse módulo irá, também, armazenar os valores produzidos pelo primeiro módulo, de monitoramento, e atualizá-los sempre que novas medições forem realizadas na rede. Esses valores serão utilizados para avaliar a qualidade de cada uma das rotas conhecidas. Além disso, esse módulo conterá informações sobre as exigências de cada uma das aplicações que serão beneficiadas por esse mecanismo. Com todas essas informações, esse módulo terá consciência do estado atual da rede e poderá, a partir desse conhecimento, decidir quais são os melhores caminhos pelos quais os dados devem ser trafegados.

Com esses recursos, o módulo de Controle Lógico deve ser responsável por agregar todas as informações da rede; acompanhar o estado de cada uma das rotas monitoradas da rede e; a partir das informações coletadas, definir por quais rotas as informações das aplicações deverão ser trafegados. O funcionamento do segundo módulo deve ser, além de tudo, reativo. Durante a execução do mecanismo e funcionamento da rede, esse módulo deve ser capaz de descobrir rapidamente situações prejudiciais à qualidade de experiência do usuário. Além disso, deve realizar alterações nos fluxos da rede da forma mais rápida possível, para que possa amenizar ao máximo a degradação na qualidade de experiência dos usuários.

O terceiro módulo, o de Comunicação com o Plano de Dados, é responsável por toda a comunicação a ser realizada entre o mecanismo e o plano de dados. Ele será, portanto, o meio pelo qual o segundo módulo, de Controle Lógico, poderá efetivar as alterações exigidas nas rotas da rede. Uma vez que o segundo módulo decidir quais são os caminhos a serem utilizados e quais as alterações necessárias nos Switches da rede, o terceiro módulo conterá as ferramentas necessárias para modificar o plano de dados e aplicar essas alterações.

O terceiro módulo pode ser usado para outras funções também, como por exemplo para auxiliar o módulo de monitoramento a obter informações do plano de dados, bem como atuar junto do segundo módulo na definição proativa das regras de fluxo da rede, com o intuito de instaurar novos fluxos dentro da rede.

A Figura 4.1 apresenta a arquitetura do mecanismo proposto. Nela, o Módulo de Monitoramento irá consumir dados vindos da rede para avaliar a qualidade de cada uma das rotas presentes na rede, essas informações serão enviadas para o Módulo de Controle Lógico, que consumirá essas informações para decidir a necessidade de alteração nas regras de fluxo da rede. Por fim, o Módulo de Comunicação com Plano de Dados será responsável por efetivar as alterações sugeridas pelo Módulo de Controle Lógico, produzindo comandos a serem enviados para os dispositivos de comutação presentes na rede, alterando seu comportamento. 


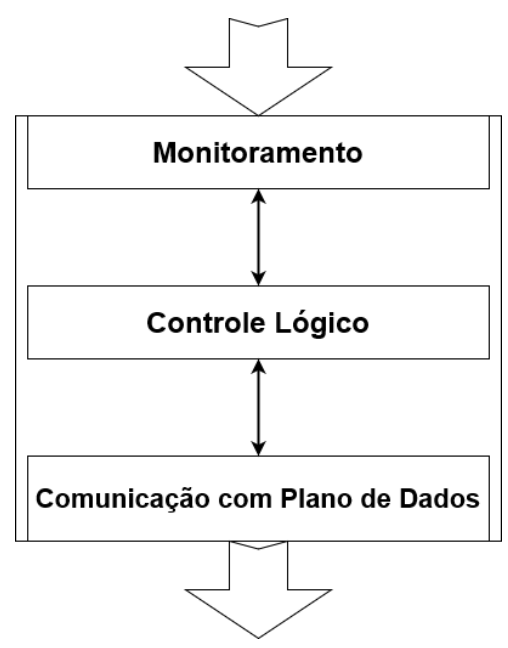

Figura 4.1: Arquitetura proposta do mecanismo

\subsection{Possibilidades de Implementação}

A arquitetura de Redes Definidas por Software apresenta diversas tecnologias diferentes que podem ser utilizadas para a implementação do mecanismo proposto. Cabe ao administrador da rede decidir quais tecnologias atendem as necessidades da rede.

O monitoramento de rede pode ser feito de diversas maneiras. Uma opção seria o mecanismo enviar através da rede diversos pacotes de sondagem. Em seguida, ele recolheria as respostas de cada um desses pacotes de sondagem e obteria informações sobre a qualidade atual da rede. Outra opção seria aproveitar de uma rede onde uma implementação do I.N.T. (In-band Network Telemetry) estivesse pronta e funcional. A partir das métricas coletadas pelos pacotes I.N.T., o mecanismo poderia agir como um I.N.T. Sink, extraindo as informações dos cabeçalhos desses pacotes e, assim, incorporando as informações relevantes para seu funcionamento.

O Módulo de Comunicação com o Plano de Dados, por sua vez, dependerá da infraestrutura em produção no plano de dados. Caso o ambiente possua suporte ao protocolo OpenFlow, esse protocolo poderia ser usado como a principal forma de comunicação entre o mecanismo e os Switches. Assim, o mecanismo teria uma implementação capaz de traduzir as mudanças necessárias na rede em comandos OpenFlow e, assim, disparar essas mensagens na rede, alterando o comportamento desses Switches e atuando como um Controlador. Caso o plano de dados da rede seja todo composto por Switches programados em linguagem P4, o mecanismo poderia utilizar-se da P4Runtime API, oferecendo uma implementação dessa interface de comunicação, permitindo o envio de comandos de alteração de regras de fluxo aos Switches.

O mecanismo poderia ser implementado tanto como parte de um Controlador, quanto como uma aplicação de controle de rede, rodando em paralelo com um Controlador. Nesse segundo caso, o Módulo de Comunicação com o Plano de Dados não agiria diretamente no plano de dados. Ao invés disso, iria comunicar-se com o Controlador responsável pelos Switches da rede, trocando informações e requisitando as mudanças necessárias para realizar a alteração das rotas utilizadas pelos usuários da rede.

O Módulo de Controle Lógico, ao agir juntamente com o Módulo de Monitoramento, pode atualizar constantemente a topologia sendo monitorada e, com isso, encontrar novas rotas em tempo de execução e adaptar a rede para lidar com as possíveis novas rotas disponíveis.

\subsection{Considerações finais}

Este capítulo apresentou as funcionalidades, os objetivos e a arquitetura do mecanismo proposto no projeto. Além disso, foram sugeridas algumas possibilidades de implementação de cada um dos módulos indicados. 
Vale considerar que esse mecanismo é composto de uma arquitetura simples e, por isso, sua definição tem espaço para melhorias. Levando em consideração os diversos exemplos de mecanismos e soluções contidos no Capítulo 3 sobre trabalhos relacionados, seria possível a proposição de um mecanismo que unisse as funcionalidades de todos os mecanismos apresentados. Essa nova proposição, apesar de complexa, poderia resolver diversos problemas dentro de uma só solução, porém ela seria extensa e difícil de ser proposta e implementada. Por conta disso, esse projeto foca em resolver um conjunto menor de casos, de forma simples e direta, funcionando como um complemento das outras soluções.

Uma das suas principais limitações ocorre em cenários onde exista apenas uma rota capaz de conectar dois usuários específicos dentro da rede. Caso essa rota apresente alguma alteração em sua qualidade e tenha seu desempenho comprometido, o mecanismo proposto no projeto não seria capaz de realizar nenhuma ação que pudesse melhorar a experiência do usuário. Isso ocorre por conta da forma como o mecanismo foi planejado em lidar com os problemas na rede, que é através da alteração de rotas, ou seja, ele modifica o caminho pelo qual os pacotes são trafegados na rede. Se não há outra rota pela qual os dados possam ser transmitidos, o mecanismo não realiza nenhuma ação. Assim, ele não consegue atuar de outras formas, como por exemplo alterando os valores de prioridade de tipos diferentes de tráfego de dados dentro da fila de egresso de um Switch, que é um funcionamento apresentado por um dos trabalhos relacionados.

Essa decisão visa manter a simplicidade da proposta, permitindo que sua prototipação seja feita de uma forma mais rápida e, além disso, conferindo a esse mecanismo uma possibilidade de ser facilmente incorporado em outras soluções. 


\section{Capítulo 5}

\section{Experimentos}

Neste capítulo, são apresentados uma implementação de referência do mecanismo proposto no capítulo anterior, assim como os experimentos realizados para comprovar a eficácia do mecanismo. Desta forma, o capítulo inicia com a descrição dessa implementação realizada e em seguida é apresentado com detalhes o ambiente elaborado para realização dos experimentos, que irá fazer uso da implementação de referência do mecanismo proposto. Nessa seção, é também descrito o jogo escolhido para os experimentos, bem como as ferramentas implementadas ou utilizadas, que permitiram a implantação desse ambiente destinado aos experimentos. Em seguida, são descritos os experimentos realizados nesse ambiente durante o projeto e, por fim, são apresentados os resultados obtidos com os experimentos. É importante observar que todos os códigos desenvolvidos estão disponíveis em https://github.com/Tuiuiu/ArquivosMestrado.

\subsection{Implementação de referência}

A implementação de referência do mecanismo proposto, utilizada para a realização dos experimentos, é projetada para um ambiente que faz uso de Switches programados em linguagem P4. Essa característica foi responsável por guiar algumas decisões de implementação realizadas.

Começando pelo Módulo de Comunicação com o Plano de Dados, sua implementação deveria ser capaz de se comunicar com os Switches programados em P4. Para isso, era preciso ser compatível com a P4Runtime API. A decisão tomada foi de utilizar a aplicação "runtime.cli", oferecida pela P4 Language Consortium, que é uma aplicação de linha de comando que faz uso dessa API para popular as tabelas de Switches como os descritos anteriormente. O mecanismo irá utilizar essa aplicação para realizar essas alterações de regras de fluxo.

Já o Módulo de Monitoramento funcionará através do envio e recebimento de pacotes de monitoramento na rede. Para isso, precisaremos que a rede possua alguns elementos capazes de receber e responder esses pacotes dentro da Rede. A esses elementos, daremos o nome de Monitor. Seguindo um exemplo de implementação existente nos tutoriais da linguagem P4, é realizada uma implementação do protocolo de Source Routing e, com isso, os pacotes de monitoramento podem ser enviados através de qualquer rota escolhida, percorrendo o caminho exato de Switches que deve ser monitorado na rede. Esses pacotes de monitoramento são produzidos, enviados, recebidos e respondidos pelo mecanismo utilizando a ferramenta Scapy [Sca19], que é uma ferramenta capaz de enviar, capturar, dissecar e forjar pacotes de rede.

Uma vez enviados os pacotes, o mecanismo guarda o tempo do sistema em que o pacote foi enviado. Ao receber a resposta do pacote de monitoramento, o tempo do sistema é consultado novamente e, subtraindo esses dois valores, é obtido o tempo de espera entre o envio e o recebimento desse pacote de monitoramento através da rota que ele percorre, permitindo assim o cálculo da latência do caminho em questão. Para a implementação de referência, apenas os valores de latência dos caminhos são monitorados.

O Módulo de Controle Lógico, portanto, ao analisar os valores de latência obtidos pelo Módulo de Monitoramento, pode comparar as rotas que conectam os usuários e, a partir dessa análise, 
decidir se alguma alteração deve ou não ser efetuada na rede. Se for necessária a realização de alguma alteração, essa será emitida para a rede pelo Módulo de Comunicação com o Plano de Dados. Os comandos são enviados para os Switches que compõem a rota atual e a rota para qual a mudança será realizada, e os comandos redirecionarão o tráfego nas portas desses Switches.

Outra função deste módulo é a de definição de uma configuração inicial da rede, na qual todos os Hosts possam trocar pacotes e se comunicar. Após a inicialização do mecanismo, essa configuração inicial é emitida, através do Módulo de Comunicação, para a rede. Nela, todos os Switches recebem um conjunto de comandos, indicando para quais portas seu tráfego deve ser encaminhado, criando assim um ambiente inicial funcional da rede.

Para o funcionamento do mecanismo, a versão implementada até o momento da escrita desse trabalho exige que o mecanismo saiba previamente quais são as rotas, dentro da topologia, que deverão ser monitoradas e utilizadas pelas aplicações sensíveis a alterações na rede, bem como quais as alterações necessárias ao Plano de Dados para implantação de cada uma das rotas. Isso ocorre pois não foi implementada uma forma de reconhecer novos caminhos dentro da rede nem a geração dinâmica dos comandos que devem ser enviados para o Plano de Dados.

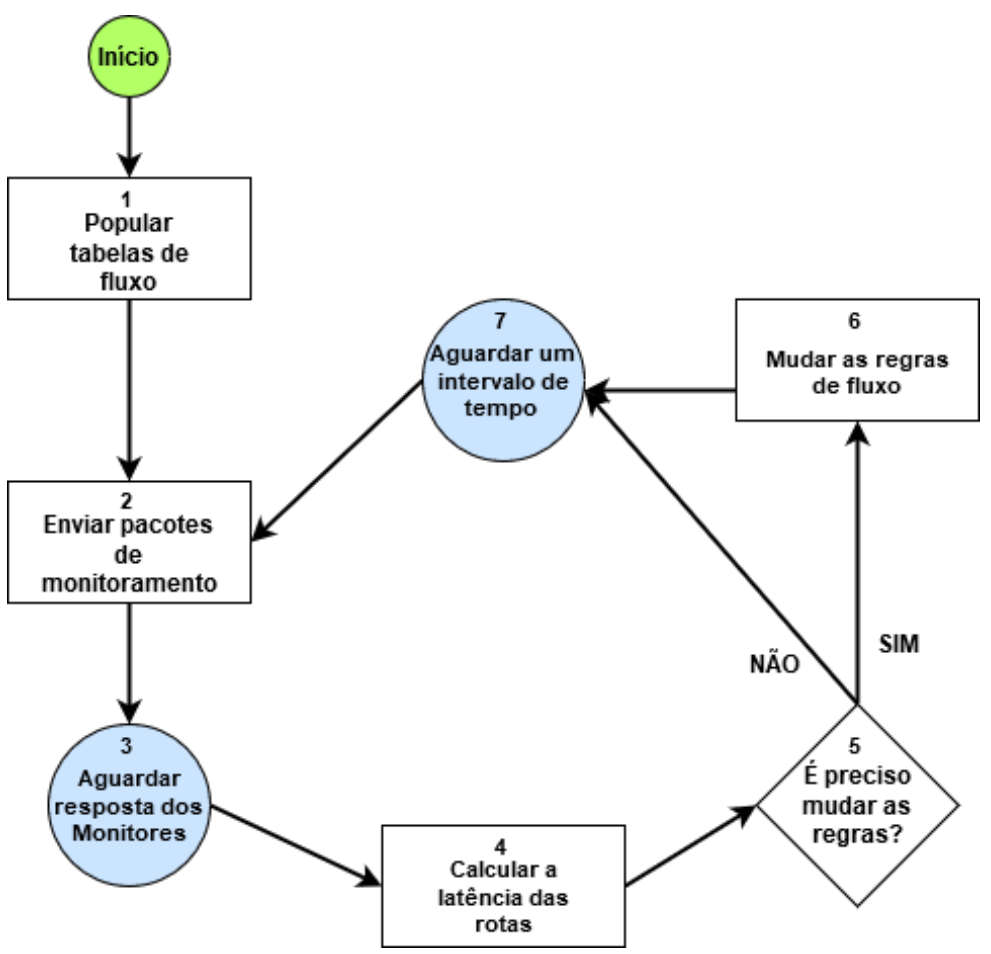

Figura 5.1: Fluxograma do funcionamento do Mecanismo

O fluxograma da Figura 5.1 apresenta a sequência de tarefas executadas pela implementação do mecanismo. O nó "Início"marca o momento onde uma topologia de rede já está criada e, nesse instante, o mecanismo é inicializado. A partir da inicialização do mecanismo, os passos enumerados de 1 a 7 , representados no fluxograma, são executados. Durante o passo 1, o mecanismo irá popular as tabelas de fluxo presentes nos Switches com as configurações iniciais necessárias para que os Hosts presentes nessa rede possam se comunicar. Para as regras que ditarão a comunicação entre os usuários da aplicação, se mais de uma rota é possível, uma delas será escolhida arbitrariamente.

Em seguida, inicia-se o passo 2. Nele, são enviados os pacotes de monitoramento. O Módulo de Monitoramento do mecanismo, então, dispara os pacotes que irão percorrer a rede através das rotas definidas previamente. Esses pacotes são direcionados aos Monitores, que são aplicações conectadas a comutadores onde existam usuários da aplicação a ser beneficiada pelo mecanismo. Os Monitores irão receber esses pacotes e respondê-los, enviando-os de volta ao mecanismo. O mecanismo, portanto, é também considerado um Monitor, e por isso também estará localizado no mesmo dispositivo comutador que um dos Hosts usuários da aplicação. No instante de envio dos pacotes, o 
mecanismo salva o timestamp em que esses pacotes foram enviados, com o intuito de cronometrar o tempo até que eles sejam enviados de volta, provendo, assim, o valor de atraso presente em cada uma das rotas monitoradas. Durante o passo seguinte, 3, o mecanismo aguarda até que alguma resposta do pacote de monitoramento seja recebida.

Ao receber um pacote de resposta sobre o monitoramento, o mecanismo entra no passo 4 . No instante de recebimento desse pacote, o mecanismo salva outro timestamp, que será usado para calcular o valor de latência da rota percorrida por esse pacote. Para isso, subtrai-se o valor do timestamp do momento de recebimento do pacote de resposta, com o valor do timestamp do momento de envio do pacote que originou essa resposta. Com esse valor obtido, uma tabela com os valores de atraso de cada uma das rotas é atualizada, permitindo que o mecanismo mantenha o controle sobre a situação atual de cada uma das rotas de comunicação entre os usuários da aplicação escolhida.

Com o fim do passo 4, o mecanismo entra no passo 5, onde verifica se a rota atual pela qual a comunicação dos Hosts é realizada atende às restrições de usabilidade da aplicação. Caso a rota ainda atenda às necessidades, nenhuma ação é necessária, e o mecanismo segue para o passo 7 . Caso contrário, o mecanismo irá buscar, nas outras rotas possíveis, se alguma delas apresenta uma condição que atenda às exigências da aplicação. Se nenhuma rota possuir tal condição, nenhuma alteração é feita e o mecanismo segue para o passo 7, porém, se alguma rota apresentar uma condição melhor de rede, que passe a atender as necessidades da aplicação, então o mecanismo passa para o passo 6, onde irá alterar as regras de fluxo dos Switches presentes na topologia, de modo que a rota em questão se torne a rota pela qual os dados são transmitidos entre os Hosts dessa aplicação. Ao fim do passo 6, o mecanismo segue para o passo 7 .

Por fim, no passo 7, de acordo com o valor de latência do caminho referente ao pacote de resposta recebido, o mecanismo irá aguardar até o máximo de 0,5 segundos antes de prosseguir ao próximo passo. Se a latência do caminho for menor que 0,5 segundos, ele irá aguardar por (0,5 - atraso) segundos, e se o valor da latência do caminho for maior ou igual a 0,5 segundos, ele irá seguir para o próximo passo. Isso é feito com o intuito de evitar que a rede seja sobrecarregada com pacotes de monitoramento, mas sem que o tempo de espera seja longo demais a ponto de comprometer a experiência do jogador por um tempo muito extenso. Ao término do passo 7, portanto, o mecanismo volta ao passo 2, enviando novamente os próximos pacotes de monitoramento, repetindo o ciclo enquanto a aplicação rodando na rede exigir essas funcionalidades do mecanismo.

\subsection{Ambiente elaborado para os experimentos}

No ambiente projetado para mostrar a eficácia do mecanismo apresentado na seção anterior, temos uma rede baseada na linguagem P4, composta por diversos Switches, e diversos Hosts, capazes de se comunicar dentro dessa rede. A topologia dessa rede apresenta mais de um caminho de comunicação entre alguns desses Hosts.

Dentro dessa rede, por conta das decisões tomadas acerca da implementação de referência, alguns Hosts atuarão como Monitores, monitorando a latência de alguns caminhos presentes nessa rede. Simultaneamente, dois ou mais Hosts executarão, cada um, uma instância do 0 A.D., e todos eles se conectarão em uma mesma sessão dentro dessa rede. A essa sessão, daremos o nome de "partida", e aos Hosts conectados nessa partida, daremos o nome de "Jogadores". Durante a execução dessa partida, enquanto os jogadores estiverem "em jogo", ou seja, com essa partida iniciada, realizaremos alterações nos valores de latência dessas rotas. Quando essas alterações apresentarem aos jogadores uma situação que seja considerada prejudicial à experiência de um jogador dentro de uma partida, essa situação será reconhecida por um elemento dentro dessa rede executando o mecanismo proposto e que irá, então, realizar alterações nas rotas dessa rede com a finalidade de melhorar a qualidade da experiência dos jogadores na partida.

Além de avaliar o mecanismo proposto, o intuito dos experimentos é avaliar o cenário dos Jogos Digitais em Rede como uma possível área de aplicação dos benefícios existentes nas Redes Definidas por Software, ao oferecer maneiras de amenizar um problema recorrente dessa área, que 
ocorre quando os jogadores se comunicam por rotas que apresentam uma latência maior do que um certo nível aceitável, resultando em impactos negativos na experiência desses jogadores.

Todo esse ambiente produzido foi implementado dentro de uma imagem de máquina virtual. A imagem inicial, antes de qualquer alteração ser produzida, é uma imagem concedida pela equipe do P4 durante cursos que são oferecidos no decorrer do ano, em diversas convenções sobre RDS. A versão que foi utilizada foi a oferecida durante o evento "P4 Developer Day", em Junho de 2018 [Con18]. A imagem da máquina virtual foi executada e editada dentro da aplicação de virtualização Oracle VM VirtualBox Versão 5.1.38 [Ora19].

\subsubsection{Jogo escolhido}

Antes da proposição do projeto e da implementação do mecanismo para melhoria da qualidade de experiência, foi realizada a busca por algum jogo que pudesse ser utilizado como estudo de caso. O primeiro pré-requisito era que o jogo fosse gratuito e de código aberto, para permitir possíveis customizações para captura de informações necessárias para avaliar a qualidade de experiência e para eventualmente permitir uma comunicação direta com o controlador da rede, caso isso fosse necessário. O segundo pré-requisito era que o jogo fosse multijogador online, para que a proposta do mecanismo fizesse sentido durante a realização da partida. Um terceiro pré-requisito é que o jogo fosse de um gênero que exigisse do jogador um tempo de reação curto, pois essa propriedade faz com que o jogo seja visivelmente prejudicado por um cenário que apresente condições ruins de latência. Como quarto pré-requisito, o jogo deveria possuir uma comunidade de desenvolvimento ativa e, de preferência, apresentar uma versão recente e atualizada do jogo. Por fim, o jogo deveria ser compilado e instalado sem problemas na plataforma dos ambientes utilizados para a realização dos experimentos. Durante a execução dos experimentos, toda a topologia, incluindo os hosts que executariam o jogo, estavam situados dentro de uma máquina virtual para que fosse possível ter o controle sobre todo o ambiente de rede configurado. Essa máquina virtual fazia uso da distribuição Linux Ubuntu versão 16.04.4 LTS, sendo assim, o jogo deveria ser compatível com o ambiente GNU/Linux, tanto para desenvolvimento quanto para execução.

As buscas pelo jogo foram feitas majoritariamente na lista de jogos de código aberto da Wikipédia [Wik19], além de diversas outras listas menores de jogos [Sla19], e chegou-se a dois possíveis jogos. O Unvanquished [Dev17], um jogo de tiro em primeira pessoa e o 0 A.D.[Gam19], um jogo de estratégia em tempo real. Diversos problemas durante o processo de compilação, instalação e execução do Unvanquished dentro da máquina virtual inviabilizaram sua adoção neste projeto, motivo pelo qual resolveu-se prosseguir a pesquisa com o jogo 0 A.D. Vale ressaltar que outras opções boas de jogos também do gênero de tiro em primeira pessoa foram considerados para utilização nos experimentos, como Red Eclipse[Ecl19] e Xonotic[Xon19], pois esse gênero é um dos melhores exemplos de jogos de ritmo acelerado, porém eles também apresentaram dificuldades no processo de compilação, instalação ou de execução dentro do ambiente utilizado, resultando na desistência em incluir esses jogos nos experimentos.

O 0 A.D. é do gênero conhecido como Estratégia em Tempo Real. Esse estilo de jogo é um subgênero de Estratégia, em que a progressão do jogo não é dada através de turnos. Dessa forma, as decisões e ações tomadas pelos jogadores ocorrem de forma concorrente e simultânea. O objetivo do jogo, para cada jogador, consiste em evoluir sua civilização durante uma partida, desenvolvendo os conhecimentos e a tecnologia de sua civilização com o intuito de produzir construções e unidades mais avançadas, a fim de utilizar sua força bélica para derrotar seus oponentes. Para realizar tudo isso, o jogador deve coletar recursos que estão espalhados pelo mapa, como Pedra, Metal, Madeira e Comida, e utilizar esses recursos para concluir suas produções.

No início de cada partida, o jogador começa com uma estrutura chamada de Civic Center e algumas unidades simples. Essas unidades são capazes de coletar recursos e construir novas edificações. Esses recursos podem então ser utilizados para avançar o nível de tecnologia da sua civilização em seu Civic Center, o que desbloqueia a possibilidade de construir edificações novas, que são capazes de produzir unidades diferentes. Existem três níveis de tecnologia dentro do jogo, que representam a evolução da civilização durante a partida. Em ordem crescente de avanço, eles são chamados de 


\section{Village Phase, Town Phase e City Phase.}

Cada unidade dentro do jogo possui seus próprios atributos, além de vantagens e desvantagens contra outras unidades, tornando o sistema de combate do jogo bastante profundo e estratégico. As partidas se estendem até que reste apenas um time dentro da partida. Para que um jogador seja derrotado, ele deve perder o seu Civic Center e, sendo assim, para que um jogador vença, deve tentar destruir essas edificações dos seus oponentes.

A Figura 5.2 mostra uma captura de tela do 0 A.D. em que o jogador possui uma unidade selecionada próxima ao seu Civic Center, próximo do centro da tela, e está tentando construir uma edificação conhecida como "House", porém não consegue pois já existe uma árvore no local escolhido. Na tela é possível ver, no canto superior esquerdo, um resumo dos recursos coletados pelo jogador, na região superior a versão atual do jogo e, no canto superior direito, o botão para abrir o menu e um conjunto de dados apresentando o número de Frames por Segundo, o horário local da máquina e a duração da partida de acordo com o tempo de simulação do jogo. Na região inferior da tela, é possível ver quatro elementos diferentes de interface. O primeiro é o mapa da partida. O segundo é um menu com ações de batalha que podem ser executadas pelas unidades. Em terceiro há uma imagem e descrição da unidade ou edificação atual selecionada (no caso, um soldado de infantaria, do tipo Swordsman, nomeado de Ezpatari pela facção dentro do jogo conhecida como Iberians). Abaixo, em azul, está o nome do jogador que controla essa unidade, que no caso é Tuiuiu. Por fim, o quarto elemento apresenta as edificações que a unidade selecionada pode construir. Caso uma edificação estivesse selecionada, esse elemento apresentaria quais aprimoramentos podem ser pesquisados e quais unidades podem ser recrutadas nessa edificação. Esses são, em geral, os elementos da interface mais utilizados pelos jogadores durante uma partida.

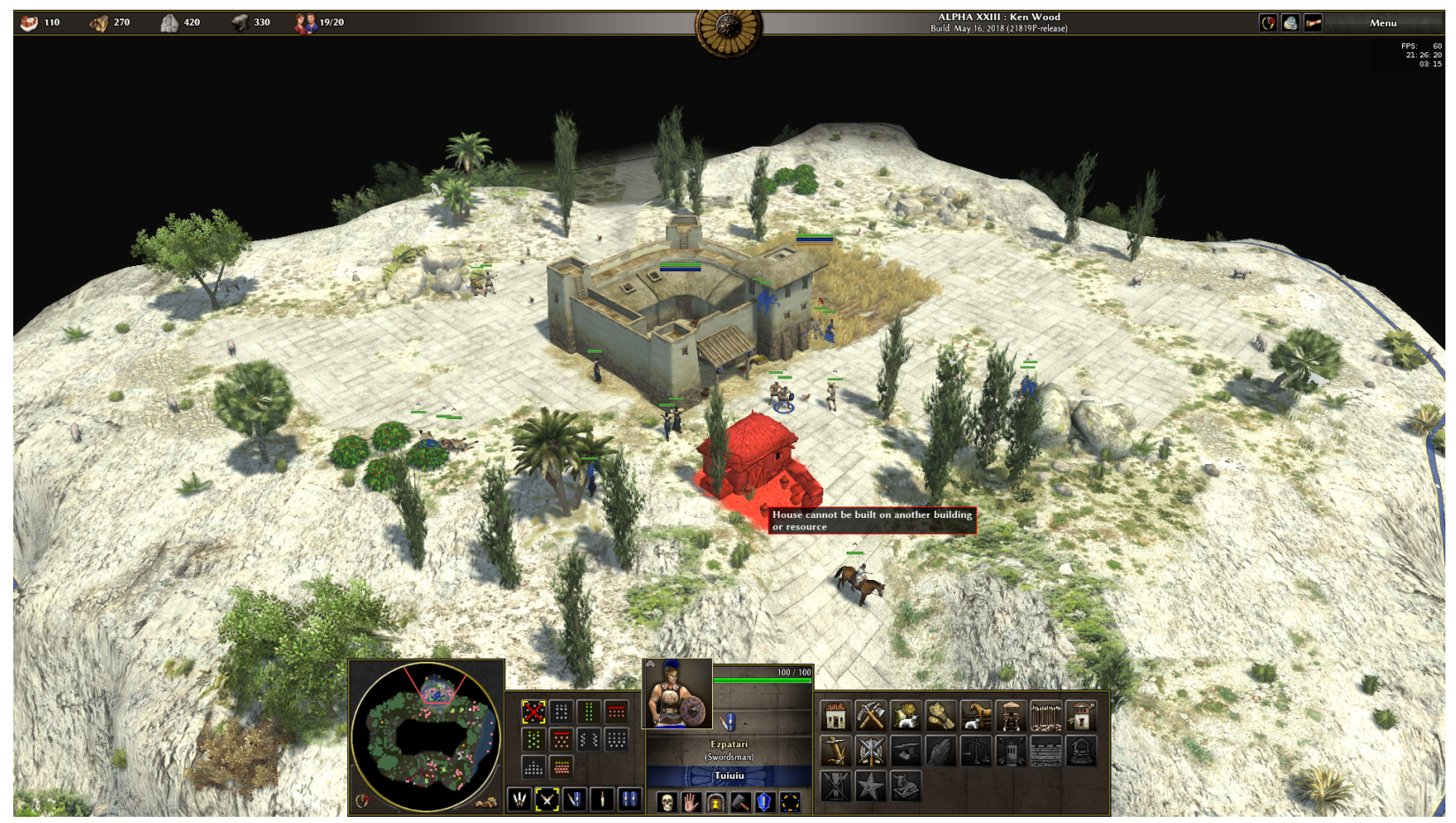

Figura 5.2: Captura de tela do 0 A.D. em uma partida com um único jogador, e um oponente controlado pelo computador

As partidas do 0 A.D. podem ser realizadas em dois modos diferentes: o modo de um jogador, que é executado fora da rede; e o modo multijogador, que será o modo relevante para esse projeto. No modo multijogador, é permitida a conexão entre diversos jogadores na mesma partida. Para isso, um dos jogadores assume um papel chamado de Host, ou seja, ele será o cliente que irá hospedar a partida. A esse Host daremos o nome de servidor da partida, pois durante as partidas, quando ocorre algum problema de conexão, a interface de um cliente se refere a esse hospedeiro como "server", ou seja, servidor. Para a realização de uma partida, todos os jogadores que irão participar dela se 
conectam ao servidor da partida. Esse servidor será responsável por receber os comandos enviados por cada um dos jogadores conectados a ele e, em seguida, redistribuir esses comandos para todos os outros jogadores. Sendo assim, esse servidor será o responsável por atualizar o estado atual da partida para todos os jogadores sempre que novas ações forem tomadas pelos participantes.

Do ponto de vista de implementação, a comunicação entre os jogadores e o servidor da partida é realizada utilizando pacotes UDP, e o envio e recebimento desses pacotes é programado com o auxílio da biblioteca de redes ENet [Sal19], que serve como uma camada utilizada sobre o protocolo UDP com a finalidade de combinar algumas das funcionalidades do protocolo TCP, mas sem perder a eficiência do UDP. Por uma decisão de desenvolvimento, em uma partida multijogador, as informações recebidas pelo servidor da partida são distribuídas para os outros jogadores em intervalos de $500 \mathrm{~ms}$. Dessa forma, a cada $500 \mathrm{~ms}$ o estado da partida é atualizado para todos os jogadores que fazem parte dela. Por conta dessa escolha, o jogo considera qualquer atraso maior que $500 \mathrm{~ms}$ entre a comunicação dos jogadores e do servidor da partida como um cenário apresentando problemas de conexão, e por isso essa informação será utilizada na hora de definir thresholds no mecanismo proposto. Outros jogos provavelmente terão valores diferentes desse, mas o mecanismo foi implementado de modo a permitir mudanças em tais valores.

A Figura 5.3 mostra uma captura de tela do 0 A.D., obtida durante uma partida online, em uma situação onde há a interação de personagens de 2 jogadores diferentes. É possível observar nessa captura de tela, no canto superior direito, o texto "Bad connection to server (561 ms)", que indica que o jogador na máquina em que a captura foi feita está tendo um atraso na comunicação de seus dados com o jogador que está hospedando a partida. No caso, a última comunicação captada entre eles demorou um intervalo de $561 \mathrm{~ms}$ para ser realizada, o que configura um valor de atraso maior do que os $500 \mathrm{~ms}$ de intervalo entre cada uma das atualizações de estado da partida realizadas pelo jogador que tem o papel de servidor da partida, fato que configura uma situação onde a conexão entre os jogadores é ruim.

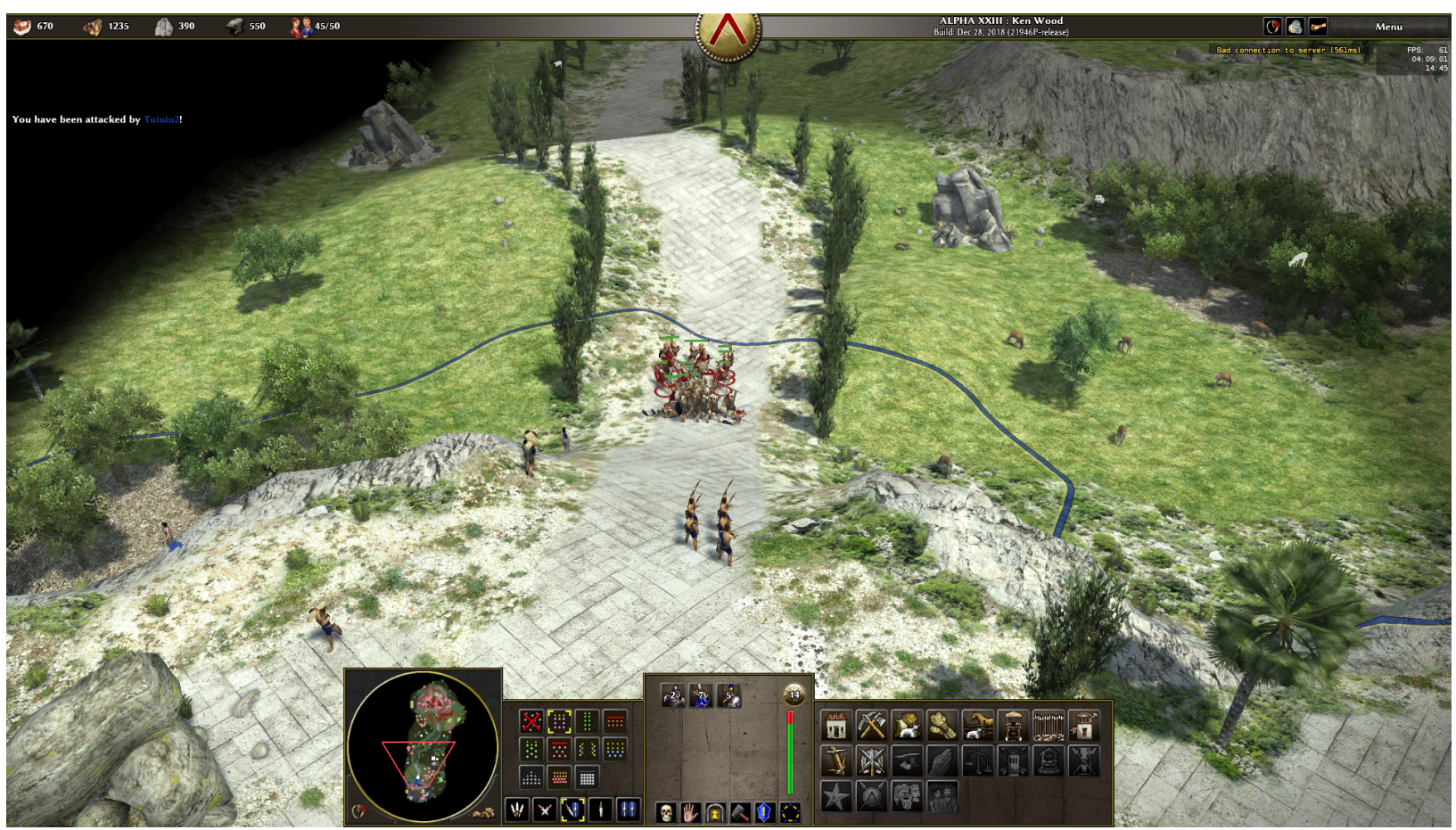

Figura 5.3: Captura de tela do 0 A.D. com dois jogadores

A versão instalada do 0 A.D. dentro do ambiente projetado e que foi usada durante os experimentos é a versão Alpha XX, release 17965 [Gam14]. 


\subsubsection{Topologia}

Para a criação da Topologia dessa rede do experimento, utilizamos a ferramenta Mininet Versão 2.3.0d1 [Min17], que é uma ferramenta extremamente utilizada no meio acadêmico de Redes de Computadores para a realização de experimentos. O Mininet é uma aplicação para emulação de redes, capaz de criar redes virtuais realistas, compostas por Hosts, Switches, Controladores e links. Como o Mininet consegue separar os diferentes Hosts da rede simulada em processos independentes e consegue isolar os componentes de rede de cada um deles através da tecnologia de network namespaces presentes no Kernel do Linux (que é o Kernel executado dentro da imagem da máquina virtual), é possível a realização de experimentos rodando mais de uma instância de um Jogo Digital, sendo uma em cada Host que participará da partida.

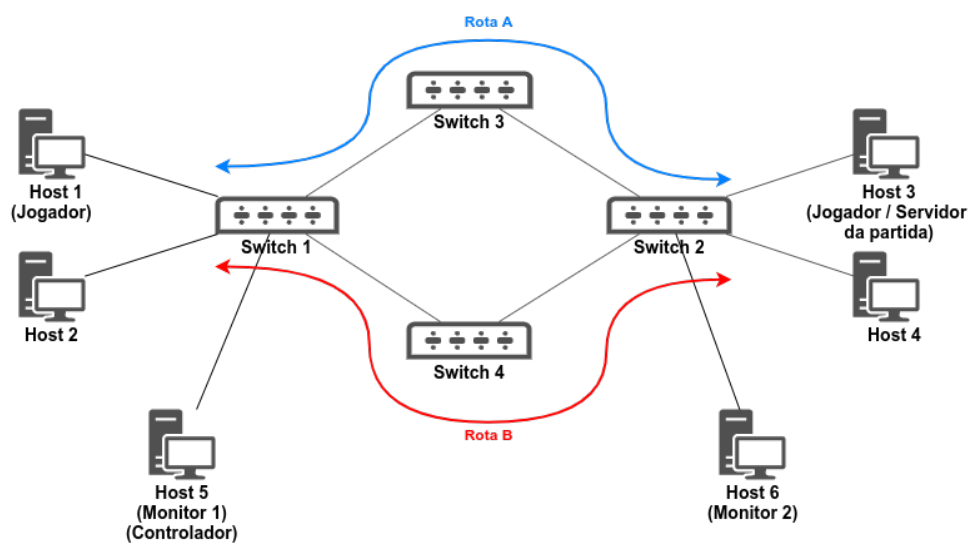

Figura 5.4: Diagrama da topologia da rede utilizada durante os experimentos

A Figura 5.4 mostra a topologia criada para a realização dos experimentos. Essa topologia foi criada através de um programa em Python, e fazendo uso da API oferecida pelo Mininet. Nessa topologia, podemos enviar mensagens entre os Hosts do lado esquerdo (conectados ao Switch 1) e os do lado direito (conectados ao Switch 2) através de dois caminhos diferentes: um passando pelo Switch 3, e um passando pelo Switch 4. Essa possibilidade de escolher entre os 2 caminhos será utilizada durante os experimentos para demonstrarmos a capacidade do controlador em poder alterar os fluxos da rede. Se um pacote, durante seu transporte, passar pelos Switches na ordem 1 $->3->2$, ou na ordem $2->3 \rightarrow$, diremos que ele está percorrendo a Rota A, e se ele passar pelos Switches na ordem $1->4->2$, ou na ordem $2->4->1$, diremos que ele está percorrendo a Rota B. Dessa forma, a Rota A é composta pelos caminhos que passam pelo Switch 3, e a Rota B é composta pelos caminhos que passam pelo Switch 4 .

Dentro dessa topologia, os elementos que funcionarão como Switches, após serem inicializados, executam um target gerado pelo bmv2. O bmv2 (cujo nome completo é Behavioral Model Version 2) é um arcabouço, desenvolvido pela $\mathrm{P} 4$, capaz de gerar o que eles chamam de targets, que funcionam como uma espécie de interpretador, capaz de receber arquivos de .JSON contendo as configurações que descrevem o funcionamento desse Switch. Esse arquivo de configuração é obtido através da compilação de um programa escrito na linguagem P4, utilizando para isso um compilador chamado de p4c, que é disponibilizado nos repositórios do ecossistema do P4. Uma vez que esse arquivo em .JSON é carregado no Switch, este passa a reproduzir o comportamento descrito pelo programa escrito em P4 e que originou essas configurações. O programa em linguagem P4, escrito para definir o comportamento dos Switches durante os experimentos, foi desenvolvido seguindo a especificação P4_16.

O target utilizado durante os experimentos e executado em cada um dos elementos que funcionarão como Switches é o simple_switch [Con20a]. Dentro desse target, como a especificação do P4 utilizada pelo programa escrito é a especificação P4_16, uma arquitetura de Switch deve ser especificada para a implementação do programa. A arquitetura escolhida, que é implementada dentro do target utilizado, é a "v1model" [Con20b]. 
O programa implementado em P4 é capaz de analisar 3 cabeçalhos diferentes: Ethernet, IPV4 e source_routing. Após análise dos pacotes, o programa define como processar esses pacotes e encaminhá-los de acordo com as entradas contidas na sua tabela interna. Internamente, possui uma tabela que relaciona um endereço em IPV4 com um MAC Address e uma porta de saída. Ao receber um pacote, se esse pacote implementa o protocolo IPV4, o Switch então avalia o endereço IPV4 para o qual esse pacote é destinado, consulta sua tabela interna utilizando esse endereço como chave, atualiza os valores internos desse pacote e o encaminha para a porta desse Switch indicada na entrada da tabela a qual o pacote de entrada corresponde. Caso o pacote recebido implemente o protocolo de source_routing utilizado, o Switch extrai a porta para qual o pacote deve ser encaminhado e o envia através dessa porta.

Assim, para que os Switches possam ser utilizados, o processo é o seguinte:

1. Escrever um código em P4 definindo o funcionamento dos Switches do plano de dados;

2. Compilar esse código para um arquivo .JSON usando o compilador p4c-bm;

3. Inicializar os Switches na topologia utilizando um dos targets gerados pelo bmv2 e alimentandoos com os arquivos em .JSON.

Com os Hosts e Switches definidos e inicializados, e os links de comunicação já estabelecidos, o elemento que falta conectar nessa topologia é o Controlador. Para isso, foi realizada a implementação de referência do mecanismo, escrito um programa em Python, executado no Host 5, e que cumprirá um papel semelhante ao exercido pelo Controlador. O mecanismo será o responsável por popular as tabelas de fluxo dos Switches dentro do ambiente dos experimentos e por realizar alterações nessas tabelas quando isso for necessário.

Dessa forma, após a inicialização da topologia, alimentação dos Switches com os arquivos de configuração, e a execução do mecanismo, esse ambiente para os experimentos passa a oferecer recursos suficientes para que todos os Hosts presentes na rede possam se comunicar, uma vez que as tabelas de fluxo apresentarão nesse primeiro instante uma configuração inicial de regras de fluxo, definindo um caminho inicial pelo qual os pacotes que venham a surgir na rede possam trafegar.

Em termos de máquina física, a topologia da Figura 4.3 foi toda construída em um ambiente virtualizado em uma máquina física com processador Intel@ Core $^{\mathrm{TM}}$ i7-7700HQ, com 8 GB de memória RAM e com uma placa gráfica GeForce GTX 1050Ti. Foi criada uma máquina virtual dentro do software virtualizador Oracle VM VirtualBox[Ora19] oferecendo como recurso 4 GB de memória RAM, 2 núcleos com 100\% de sua capacidade, 128 MB de memória de vídeo e disponibilizando aceleração 3D, além de 50 GB de espaço em disco. Cada um dos elementos apresentados como Hosts na figura são implementados nesse ambiente como uma instância de Host do Mininet, assim como cada Switch na representação é implementado como um Switch no Mininet. Todos os elementos da topologia e que fazem parte da rede estão localizados dentro da mesma máquina virtual, na topologia criada pelo Mininet.

\subsubsection{Fluxo de dados}

Instaladas a topologia e as regras iniciais de fluxo, um elemento importante que irá produzir fluxo dentro da rede é o jogo escolhido para a realização dos experimentos. Dada a topologia apresentada na Figura 5.4, o jogo pode ser executado em qualquer um dos Hosts presentes na rede, porém para os experimentos realizados, haverá apenas duas instâncias do jogo em execução, uma no Host 1 e uma no Host 3. Durante a realização dos experimentos, os Hosts 2 e 4 estão presentes na rede, têm capacidade de se comunicar com os outros elementos da topologia, porém não realizam nenhuma ação, então não tem influência no resultado final.

Com a estrutura geral do cenário completa, é preciso uma ferramenta que seja capaz de executar em cima da topologia e que consiga alterar a qualidade dos links da rede, não somente para simular um ambiente inicial "realista", mas também para simular situações em que a rede apresente condições não favoráveis para a realização de uma partida envolvendo vários jogadores do nosso jogo escolhido. 
Para isso, foi utilizada a ferramenta Traffic Control (ou "tc"), que é capaz de controlar o tráfego de dados nas interfaces de rede presentes em um ambiente Linux. O principal recurso que utilizaremos do " $t c$ " durante o projeto é a possibilidade de adicionar valores de latência adicionais nas interfaces que conectam os elementos da nossa topologia, ou seja, nos links. Essa ferramenta é utilizada em 2 momentos específicos durante os experimentos: primeiramente, durante a definição da topologia, em conjunto com o Mininet, para simular um ambiente com valores realistas de latência entre os Hosts e, num segundo momento, no decorrer dos experimentos, aplicando condições negativas na rede, forçando o mecanismo proposto a tomar decisões de alteração dos fluxos para melhorar a qualidade da experiência dos jogadores. Os valores para largura de banda e perda de pacotes não foram definidos durante a criação dos links, então eles seguem os valores padrão, que são $0 \%$ para perda de pacotes, e a largura possui um valor variável, que dependerá do poder computacional do sistema. Como os dados transmitidos entre os jogadores são pequenos e a largura de banda não é uma métrica monitorada pelo sistema, optamos por desconsiderar seu valor durante a criação da topologia, fazendo com que ele seja o mais alto possível, para que esse atributo não seja um problema existente no cenário proposto

Uma vez que a condição da rede estiver alterada através da utilização dos recursos do " $t c$ ", é preciso que o mecanismo seja capaz de acompanhar a qualidade da rede e de alguns caminhos possíveis para os pacotes dentro dessa rede. Para isso, devido às decisões tomadas durante a realização da implementação de referência do mecanismo, para os experimentos foi necessário posicionar dois Hosts nessa rede com a função de atuarem como monitores, sendo um desses monitores o próprio mecanismo. A forma como o monitoramento é realizado foi inspirado em alguns dos exemplos presentes nos tutoriais do repositório da linguagem P4. Para que os pacotes de monitoramento de rede percorram as rotas desejadas, foi implementada uma versão inspirada no código do exercício "Source Routing" [P419a]. A capacidade de processar os pacotes de monitoramento foi inserida no código que define os Switches da rede, e esses pacotes de monitoramento são enviados através dos programas executados nos Monitores.

Para a criação desses pacotes que irão monitorar a rede, além do recebimento e envio deles dentro das aplicações dos Monitores, foi utilizado o Scapy [Sca19], que é uma ferramenta capaz de enviar, capturar, dissecar e forjar pacotes de rede. Utilizando o Scapy, os Monitores são capazes de produzir os pacotes de monitoramento, enviar e receber eles na rede, e através desse processo podem calcular o valor de latência de cada uma das rotas monitoradas. O processo de monitoramento funciona da seguinte maneira: um dos Monitores, implementado dentro do código do mecanismo, dispara um pacote de monitoramento e, ao receber a resposta enviada pelo outro Monitor, calcula o tempo que esse pacote demorou para retornar, obtendo assim a latência desse caminho. Em seguida, aguarda $500 \mathrm{~ms}$ e dispara o próximo pacote, seguindo outra rota. O funcionamento é simples, porém o intuito é não sobrecarregar a rede com pacotes de monitoramento.

\subsection{Cenários dos experimentos}

Fazendo uso do ambiente implementado e descrito na seção anterior, foram realizados e monitorados quatro experimentos. Nessa seção, serão apresentados os quatro experimentos, a motivação por trás de suas execuções e os passos necessários para sua realização.

\subsubsection{Experimento A}

O Experimento A foi o primeiro a ser executado. Sua finalidade foi avaliar se o ambiente implementado era funcional, se era possível perceber os efeitos negativos causados por alterações na qualidade da rede, e se uma execução manual do mecanismo era capaz de solucionar esses efeitos negativos presentes na rede.

Para a realização deste experimento, são posicionados dois jogadores na rede, um no Host 1, e um no Host 3. A implementação de referência do mecanismo como execução manual é executada no Host 5, e um monitor é posicionado no Host 6. As latências nos links e a posição e função dos 
elementos da rede são apresentadas na Figura 5.5. A decisão de quais elementos executariam o jogo foi feita de maneira que os jogadores pudessem se comunicar através de mais de um caminho possível dentro da rede.

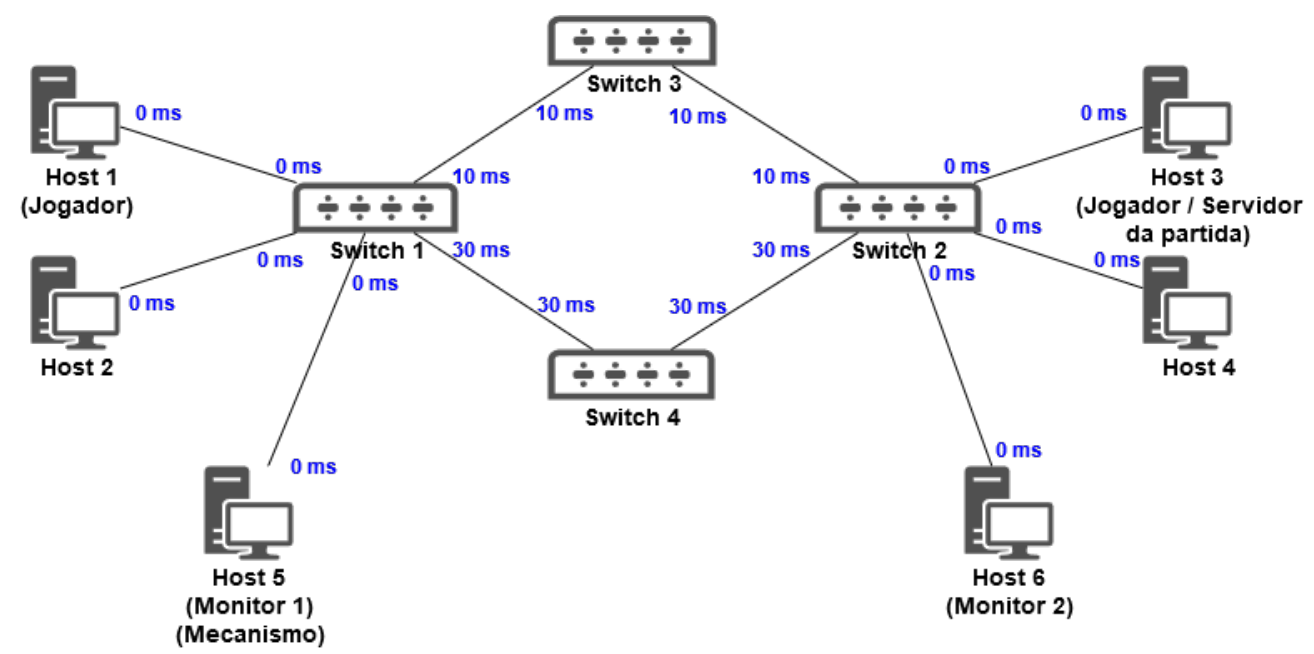

Figura 5.5: Topologia utilizada para a realização do Experimento A, com valores de latência incluídos

Para a execução deste experimento, primeiramente a topologia é inicializada, e em seguida o monitor e o mecanismo são inicializados. Com isso, as tabelas de fluxo dos switches são populadas e as rotas iniciais pelas quais os hosts da rede irão se conectar são criadas. Nesse instante, a rota pela qual os dados entre os jogadores são trafegados é a Rota A, composta pelos Switches 1, 3 e 2. Em seguida, o Host 3 inicializa o jogo e cria uma partida local, fazendo dele o hospedeiro dessa partida. O Host 1, então, inicializa o jogo e se conecta a essa sala utilizando a interface do próprio jogo e o IP do Host 3. Após os 2 jogadores, representados pelo Host 1 e o Host 3, estarem na sala, a partida é iniciada. Durante o período da partida, de aproximadamente 15 minutos, os jogadores jogam normalmente o jogo. Ambos efetuam comandos ao jogo, como movimentar os personagens, construir novas edificações, coletar recursos e produzir unidades. Passados 8 minutos de simulação de jogo, representado pelo valor indicado na interface do jogo, é realizada a degradação na rota pela qual os jogadores estão se comunicando. Isso é feito utilizando a ferramenta "tc", inserindo uma latência de $300 \mathrm{~ms}$ em cada uma das duas interfaces de rede existentes no Switch 3. Os valores atualizados de latência dos links da topologia podem ser observados através da Figura 5.6.

Após aproximadamente 1 minuto, as regras de fluxo são trocadas manualmente, fazendo com que a rota de tráfego de dados entre os Hosts 1 e 3 deixe de ser a Rota A, e passe a ser a Rota B, composta pelos Switches 1, 4 e 2. Para a realização da mudança de rotas, o administrador da rede aplica manualmente as alterações nas regras de fluxo por meio da aplicação "runtime.cli".

Após a troca de rotas, o jogo permanece em execução e os jogadores continuam emitindo comandos ao jogo. Ao fim de 15 minutos de simulação, os Hosts 1 e 3 encerram os jogos em execução, e o experimento é finalizado. Os dados equivalentes à latência de cada uma das rotas são calculados e salvos em um arquivo de texto, em tempo de execução, pelo mecanismo que está em funcionamento no Host 5.

\subsubsection{Experimento B}

O segundo experimento a ser executado foi o Experimento B. O contexto do experimento é muito semelhante ao Experimento A, com a grande diferença no fato de que, neste experimento, o mecanismo é executado automaticamente, sem a intervenção do administrador da rede. A finalidade, portanto, é avaliar o funcionamento do mecanismo, e se sua utilização confere uma melhora na experiência do jogador quando as rotas pelas quais os dados são transmitidos forem prejudicadas. Sobre a topologia deste experimento, temos uma distribuição igual à do experimento anterior, com diferenças apenas nas latências escolhidas. São posicionados dois jogadores na rede, um no Host 1 , 


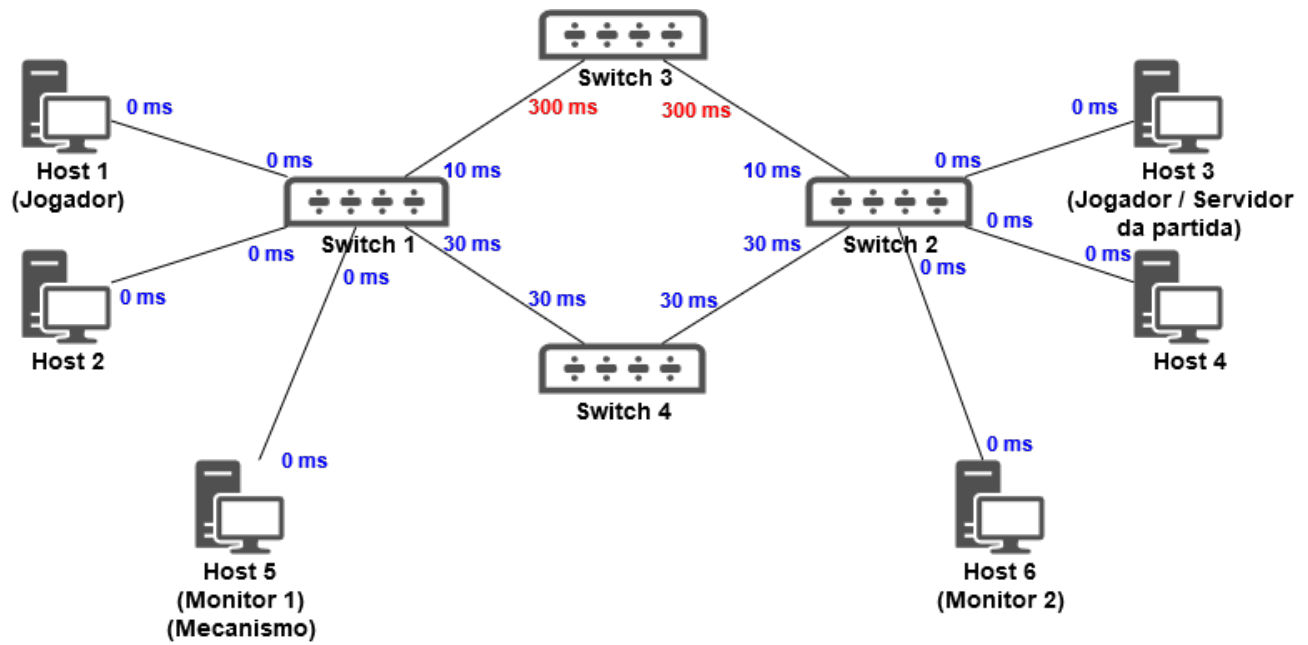

Figura 5.6: Topologia utilizada para a realização do Experimento A, com valores de latência atualizados após influência do "tc"

e um no Host 3. A implementação de referência do mecanismo é executada no Host 5, porém irá atuar de maneira automática, sem a necessidade de interferência do administrador de rede. No Host 6, é posicionado um monitor. As latências nos links e a posição e função dos elementos da rede são apresentadas na Figura 5.7. A decisão de quais elementos executariam o jogo foi feita de maneira que os jogadores pudessem se comunicar através de mais de um caminho possível dentro da rede.

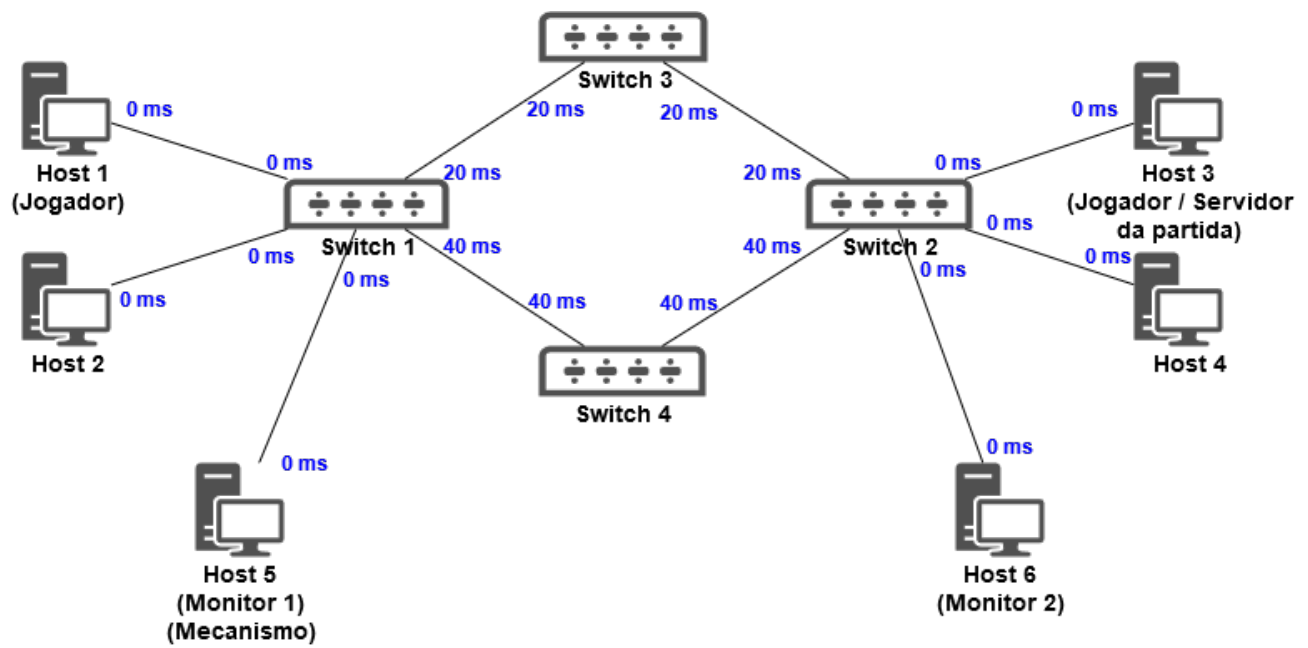

Figura 5.7: Topologia utilizada para a realização do Experimento B, com valores de latência incluídos

Para a execução deste experimento, primeiramente a topologia é inicializada e, em seguida, o monitor e o mecanismo são inicializados. O mecanismo, então, irá popular as tabelas de fluxo e configurar um estado inicial da rede, no qual os dados trafegados pelos Hosts 1 e 3 irão ser transportados através da Rota A, composta pelos Switches 1, 3 e 2. Em seguida, o Host 3 inicializa o jogo e cria uma partida local, se tornando o hospedeiro dessa partida. O Host 1, em seguida, inicializa o jogo e se conecta a essa sala utilizando a interface do jogo e o IP do Host 3. Com os 2 jogadores na sala a partida é iniciada. Assim como no experimento anterior, os jogadores irão jogar normalmente a partida, efetuando comandos no jogo como movimentar os personagens, construir novas edificações, coletar recursos e produzir unidades. Após 8 minutos de simulação de jogo, indicado na interface do jogo, é realizada a degradação na rota pela qual os jogadores estão se comunicando. Para isso, a ferramenta "tc" é utilizada, inserindo uma latência de $300 \mathrm{~ms}$ em cada uma das interfaces de rede existentes no Switch 3. As latências da topologia após as alterações realizadas pela ferramenta "tc" podem ser observadas pela Figura 5.8. Após as alterações, o mecanismo em 
execução no Host 5 deverá, de forma automática, reconhecer a alteração de qualidade na rota atual, avaliar se a outra opção de rota disponível é válida e, caso positivo, realizar a alteração das regras de fluxo dos switches, modificando assim a rota pela qual os dados são trafegados.

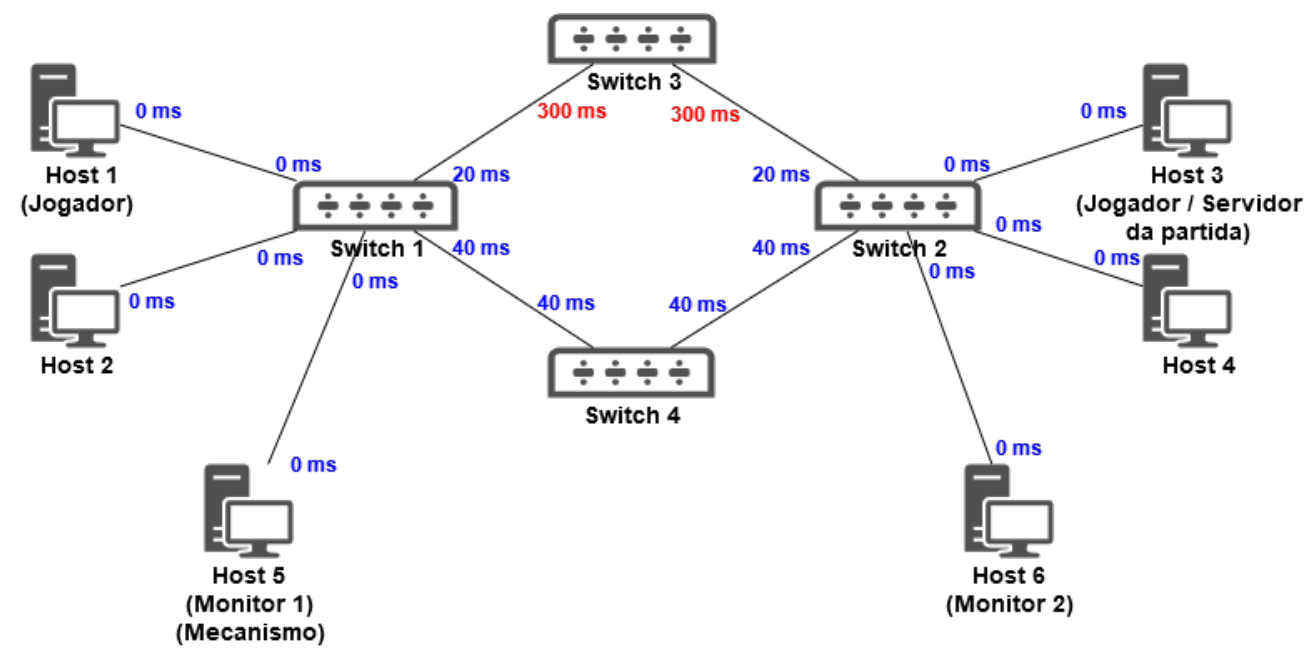

Figura 5.8: Topologia utilizada para a realização do Experimento B, com valores de latência atualizados após influência do "tc"

Após a alteração da qualidade da rota e ações automáticas do mecanismo, o jogo permanece em execução até por volta de 15 minutos de simulação. Durante esse período, os jogadores continuam jogando a partida, emitindo comandos para o jogo. Ao fim dos 15 minutos de simulação, os Hosts 1 e 3 encerram os jogos em execução e o experimento é finalizado. Durante esse período, os dados referentes a latência de cada uma das rotas são calculados e salvos em um arquivo de texto pelo mecanismo em execução no Host 5.

\subsubsection{Experimento $\mathrm{C}$}

O terceiro experimento realizado foi o Experimento C. Neste experimento, seguimos a estrutura e cenários semelhantes aos experimentos A e B, porém a motivação é diferente. Os experimentos A e B buscavam avaliar o funcionamento do mecanismo, ou seja, se sua utilização atendia ao objetivo proposto. $\mathrm{O}$ experimento $\mathrm{C}$, por sua vez, visa avaliar a eficiência do mecanismo. Ao reduzir a duração de cada simulação, é possível aumentar o número de execuções, repetindo o experimento diversas vezes e obtendo os valores referentes ao tempo que o mecanismo leva para agir. Acerca da topologia deste experimento, temos o mesmo ambiente que o utilizado nos experimentos A e B. São posicionados dois jogadores na rede, um no Host 1, e um no Host 3. A implementação de referência do mecanismo é executada no Host 5, agindo no modo automático. No Host 6 , é posicionado um monitor. As latências nos links e a posição e função dos elementos da rede são iguais às utilizadas para o Experimento B. Sendo assim, a Figura 5.7, do experimento anterior, ilustra o cenário inicial deste experimento. A decisão de quais elementos executariam o jogo foi feita de maneira que os jogadores pudessem se comunicar através de mais de um caminho possível dentro da rede.

Cada uma das execuções do experimento segue a seguinte ordem: Primeiro, a topologia é inicializada. Em seguida, os monitores e o mecanismo são inicializados. O mecanismo, por sua vez, irá popular as tabelas de fluxo e configurar um estado inicial da rede, definindo a rota pela qual os Hosts 1 e 3 irão se comunicar inicialmente, que é a Rota A, composta pelos Switches 1, 3 e 2. Em seguida, o Host 3 inicializa o jogo e cria uma partida local, se tornando o hospedeiro dessa partida. O Host 1, então, inicializa o jogo e se conecta a essa sala utilizando a interface do jogo e o IP do Host 3. Com os 2 jogadores na sala, a partida é iniciada. A partir do início da partida, os seguintes passos serão realizados na instância de jogo aberta no Host 1:

- Aos $0 \mathrm{~s}$ de simulação, as unidades de trabalhadoras mulheres são enviadas à coleta de frutas mais próximas ao centro da cidade; os soldados são enviados à coleta de madeira nas árvores 
mais próximas do centro da cidade; a unidade de patrulha recebe ordens para ir até o lado oposto do mapa e voltar ao lugar de origem.

- Aos 30 s de simulação, 4 soldados são produzidos no centro da cidade e enviados para trabalhar coletando pedra, na fonte de recursos mais próxima do centro da cidade.

- Aos 60 s de simulação, um dos soldados coletando madeira é arbitrariamente escolhido para construção de uma edificação "Casa", próxima às árvores sendo coletadas.

Aos 120 s de simulação, a Rota A tem sua qualidade prejudicada através da utilização da ferramenta "tc", inserindo uma latência de $300 \mathrm{~ms}$ em cada uma das interfaces de rede existentes no Switch 3, de forma a apresentar uma configuração de latências igual à representada na Figura 5.8. Automaticamente, o mecanismo deverá reconhecer a degradação na rota e realizar alterações nas tabelas de fluxo para modificar a rota pela qual os Hosts e comunicam e, assim, melhorar a qualidade de experiência dos jogadores. A partida e as instâncias do jogo permanecem em execução até a partida chegar a 2 minutos e 40 segundos de simulação. Nesse momento, a partida é encerrada e as instâncias do jogo são finalizadas. Nesse momento o experimento chega ao fim. Durante todo esse período, a latência da rede é monitorada pelo mecanismo e este indica todos os instantes de tempo em que detecta uma degradação na qualidade de rede e realiza uma alteração nas regras de fluxo.

Todo o processo indicado acima é repetido 10 vezes, seguindo todos os passos na ordem indicada, e os resultados são salvos para análise posterior.

\subsubsection{Experimento D}

O quarto e último experimento realizado foi o Experimento D. Neste experimento, o cenário utilizado é igual ao do Experimento C. Diferentemente do experimento anterior, a motivação deste experimento é avaliar a acurácia das medições de latência do mecanismo, e não sua eficiência. Para isso, são comparados os valores de latência obtidos pelo módulo de monitoramento do mecanismo com valores obtidos através de uma ferramenta amplamente utilizada, que é o utilitário "ping"(Packet Internet Groper), usado no terminal do sistema operacional Linux. Esse comando envia mensagens "echo"do protocolo ICMP (Internet Control Message Protocol) para o endereço escolhido como destino, e aguarda a resposta dessas mensagens, calculando com isso a latência entre o destino e o dispositivo que originou essa mensagem.

Neste experimento, o cenário utilizado é ilustrado também pela Figura 5.7. Nela, há a implementação de referência do mecanismo sendo executada no Host 5 , e um monitor posicionado no Host 6. Os atrasos inseridos nos links são os mesmos do Experimento C. Os jogadores presentes nos Hosts 1 e 3, por sua vez, não serão instâncias do jogo em execução. Neste experimento, o jogador no Host 1 será representado pelo comando "ping", sendo executado com o argumento referente ao endereço de IP do Host 3. Assim, o envio das mensagens ICMP do Host 1 em direção ao Host 3 e as respostas enviadas pelo Host 3 para o Host 1 simulariam a comunicação entre dois jogadores durante uma partida.

A duração completa do experimento é de 300 segundos. O estado inicial da rede define o caminho pelo qual os Hosts 1 e 3 vão se comunicar como sendo a Rota A, passando pelos Switches 1, 3 e 2 . Para esse experimento, a funcionalidade de troca automática de rotas do mecanismo foi desabilitada, e as mudanças de rota realizadas são feitas manualmente. Durante o experimento, quatro instantes de tempo serão relevantes para se considerar. Aos $0 \mathrm{~s}$, o experimento é iniciado, contendo o estado inicial de rede como no experimento C; aos $100 \mathrm{~s}$, a rota A tem sua qualidade prejudicada através da utilização da ferramenta "tc", inserindo uma latência de $300 \mathrm{~ms}$ em cada uma das interfaces de rede existentes no Switch 3, fazendo com que a configuração de latências passe a ser igual à representada na Figura 5.8; aos 200 s, é realizada a alteração manual de rotas, fazendo com que os Hosts 1 e 3 passem a se comunicar através da Rota B, composta pelos Switches 1, 4 e 2. Aos 300 s, por fim, o experimento é finalizado.

Com isso, o experimento cria três intervalos dentro dele. O primeiro, dos $0 \mathrm{~s}$ aos $100 \mathrm{~s}$, contém o momento em que o Host 1 envia o comando "ping" com direção ao Host 3 através da Rota A, em 
um caminho apresentando uma latência positiva para a execução de um jogo. Durante o intervalo de $100 \mathrm{~s}$ aos $200 \mathrm{~s}$, temos o Host 1 enviando esse comando para o Host 3 através da mesma rota, porém com a qualidade dessa roda comprometida. Durante o último intervalo, dos $200 \mathrm{~s}$ até os 300 s, temos a mudança de rotas efetivada e, assim, o Host 1 envia o comando "ping" com direção ao Host 3 através da Rota B. Isso ocorre pois, como um pacote com o protocolo ICMP é encapsulado dentro de um datagrama IPV4, esses pacotes tem sua direção definida de acordo com as tabelas de fluxo presentes nos Switches. Sendo assim, as marcações realizadas pelo utilitário "ping" durante o experimento dizem respeito ao caminho definido e escolhido pelas regras de fluxo para transportar os dados do Host 1 até o Host 3 e vice-versa.

O comando "ping" é executado nesse experimento dentro do Host 1 , no instante 0 s, recebendo apenas o endereço IP do Host 3 como argumento, o que resulta em uma execução do comando que dispara 1 mensagem ICMP por segundo para o endereço requisitado, aguardando a resposta e anotando o tempo até que essa resposta seja recebida. Por não ter sido estipulado um número limite de mensagens a serem enviadas, a execução do comando é interrompida manualmente no experimento ao atingir a marca de $300 \mathrm{~s}$ de duração.

\subsection{Resultados obtidos com os experimentos}

Durante o decorrer do trabalho, a implementação do cenário proposto no Seção 5.2 foi bem sucedida. O ambiente desenvolvido é funcional, e segue uma arquitetura de RDS, utilizando-se do mecanismo proposto para manter a comunicação dos pacotes do jogo dentro dos níveis aceitáveis de atraso, que no caso do 0 A.D. é de no máximo 500 ms. Dentro desse ambiente, é possível executar diversas instâncias do jogo 0 A.D. utilizando os Hosts para isso, e conectá-los através da interface do jogo para realizar partidas multijogador na rede local.

Durante as partidas, o jogo 0 A.D. mantém o cálculo do tempo de atraso entre a troca de informações dos clientes e do servidor escolhido da partida. Por isso, o jogo é capaz de notificar os jogadores presentes dentro de uma partida quando a conexão de algum dos jogadores com o servidor da partida apresenta condições ruins. Aproveitando desse recurso, foi possível perceber notificações sobre latência alta entre o servidor da partida e o cliente com problemas, que foram apresentadas através de um elemento indicado na interface de usuário do jogo. Essa notificação foi apresentada sempre que alterações planejadas foram efetuadas nas condições de rede do ambiente usado nos experimentos.

Além da notificação na interface, quando as alterações na rede prejudicavam a conexão de um dos jogadores, as consequências de jogabilidade causadas pelo lag puderam ser percebidas na execução do jogo, como por exemplo ações a serem efetuadas levarem mais do que um turno de simulação de jogo para serem validadas e realizadas. Uma das situações em que o atraso nas informações prejudicava a experiência do jogador era percebida na movimentação dos personagens, que se tornava muito "travada" quando a latência era alta. Essa característica era agravada ainda mais em batalhas, onde muitos personagens tentavam realizar ações diferentes, incluindo se mover, e o atraso na realização dessas ações, as quais eram designadas pelo jogador, se tornava bastante aparente.

Outro resultado obtido pelos experimentos foi a confirmação do funcionamento das mudanças de rota proporcionadas pelo mecanismo proposto. Quando a mudança era realizada e o fluxo de dados entre o cliente prejudicado e o servidor da partida passava a seguir por uma rota de qualidade superior, as notificações presentes na tela do jogo desapareciam e a experiência visual e de jogabilidade do jogo melhorava drasticamente. Durante os experimentos A e B, que apresentam capturas de tela do jogo como parte dos resultados, podemos ver as notificações apresentadas pelo jogo e utilizá-las como sinal de que o mecanismo funciona, além de comparar os valores de latência presentes na tela com os valores de latência monitorados pelo mecanismo proposto, demonstrando que os valores capturados pelo mecanismo são próximos dos valores apresentados pelo jogo.

O diagrama da Figura 5.9 apresenta um gráfico, mostrando o valor da latência existente na comunicação entre o jogador do Host 1 e o jogador e hospedeiro da partida, do Host 3, em cada uma das duas rotas, no decorrer de uma partida realizada no Experimento A. O diagrama contém 
três imagens. A primeira, aos 16:33:59, captura a partida durante seus primeiros instantes, onde a qualidade da conexão entre os jogadores é boa e nenhum efeito negativo resultante dessa conexão é percebido. Já a segunda imagem, aos 16:34:28, é tirada imediatamente após a condição da rota, através da qual ocorre essa comunicação, ser prejudicada utilizando a aplicação " $t c$ ". As alterações adicionam $300 \mathrm{~ms}$ de latência em cada uma das interfaces de rede do Switch 2 , fazendo com que a latência média da rota $\mathrm{A}$, que era de menos de $100 \mathrm{~ms}$ passe a ser de mais de $500 \mathrm{~ms}$, afetando a experiência do jogador. Essa segunda imagem captura a notificação presente na interface do jogador, indicando que sua conexão com o servidor aparenta estar ruim. Já a terceira captura de tela, aos 16:35:54, foi obtida alguns segundos após as ações do mecanismo tomarem efeito, aos 16:35:48, alterando a rota pela qual os participantes da partida se comunicam. É possível perceber que a notificação na interface desaparece, mostrando que a qualidade da conexão entre o jogador e o servidor da partida foi melhorada.

O Experimento A, portanto, mostra que o mecanismo foi capaz de alterar as regras de fluxos dos Switches da rede, fazendo com que a rota pela qual os jogadores se comunicam fosse modificada. Após essa modificação, a latência da comunicação entre os jogadores foi reduzida, melhorando a qualidade dessa comunicação e, com isso, levando o jogo a detectar uma melhora nessa situação, removendo a notificação da tela.

O diagrama da Figura 5.10, por sua vez, apresenta um gráfico referente ao Experimento B. Nele, são apresentados os valores da latência existente na comunicação entre o jogador localizado no Host 1, e o jogador e hospedeiro da partida, localizado no Host 3, através das duas rotas existentes no experimento, a rota $\mathrm{A}$ e a rota B. O diagrama apresenta três imagens. A primeira, aos 07:53:40, foi obtida instantes antes da rede ter sua qualidade alterada. Nessa imagem, temos o jogo executando normalmente, sem nenhuma notificação sobre a qualidade da comunicação entre os jogadores apresentada na interface. Já a segunda imagem, aos 07:53:50, foi tirada por volta de 1 segundo após a qualidade da rede ser alterada. Nela, é possível ver a notificação na interface, apresentando a mensagem "Bad connection to server (554 ms)", indicando que a comunicação entre os clientes está prejudicada. Por ter sido tirada pouco tempo após a mudança de rota ter sido realizada pelo mecanismo, o valor de latência indicado é de $554 \mathrm{~ms}$, ou seja, menor do que o valor de latência calculado pelo mecanismo para a Rota A. Isso ocorre pois, para o cálculo de latência realizado pelo jogo, ele coleta e faz uma média dos valores dos últimos tempos de latência de pacotes "heartbeat" enviados pelo jogo entre os clientes da partida. Dessa forma, alguns dos pacotes no momento da captura de tela já haviam sido trafegados pela rota com latência menor, resultando na redução do valor médio encontrado pelo jogo. Por fim, a terceira imagem, aos 07:53:58, é tirada poucos segundos após o mecanismo proposto realizar a alteração das rotas. Nela, é possível ver que a notificação sumiu, indicando que a comunicação entre os jogadores voltou a um estado considerado normal, e a qualidade do jogo voltou a ser positiva para os jogadores.

O Experimento B, então, mostrou que o mecanismo, além de ser capaz de alterar as regras de fluxo e melhorar a experiência de jogo para os jogadores como no experimento anterior, foi capaz de realizar essas ações de forma automática. Ou seja, o mecanismo foi capaz de tanto detectar uma situação que apresentava uma condição negativa de rede para os jogadores, quanto de alterar as regras de forma a melhorar a experiência desses jogadores, ao buscar uma rota que apresentasse uma latência menor do que a rota vigente na comunicação dos jogadores. 
Variação da Latência por Tempo

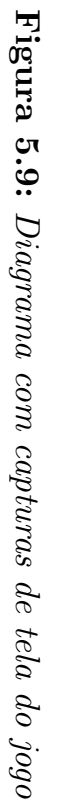

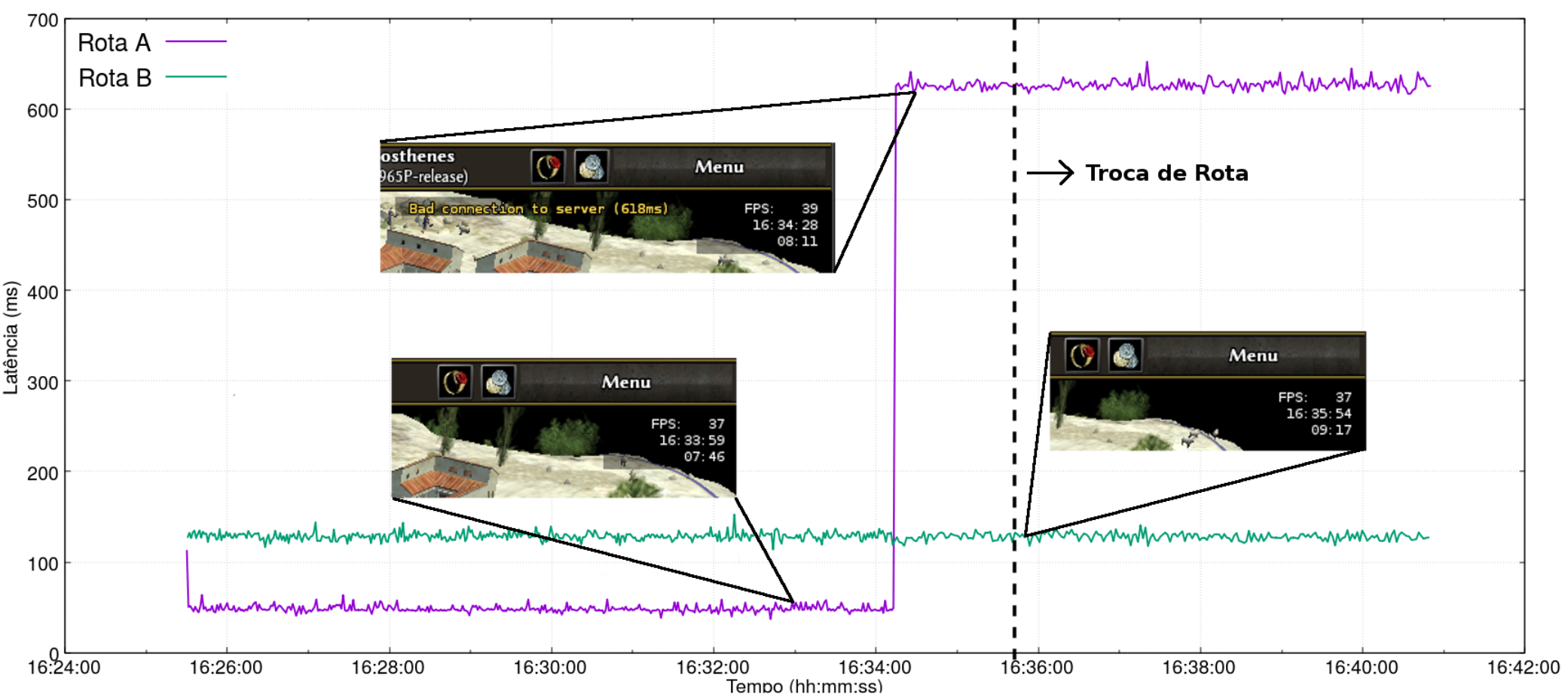




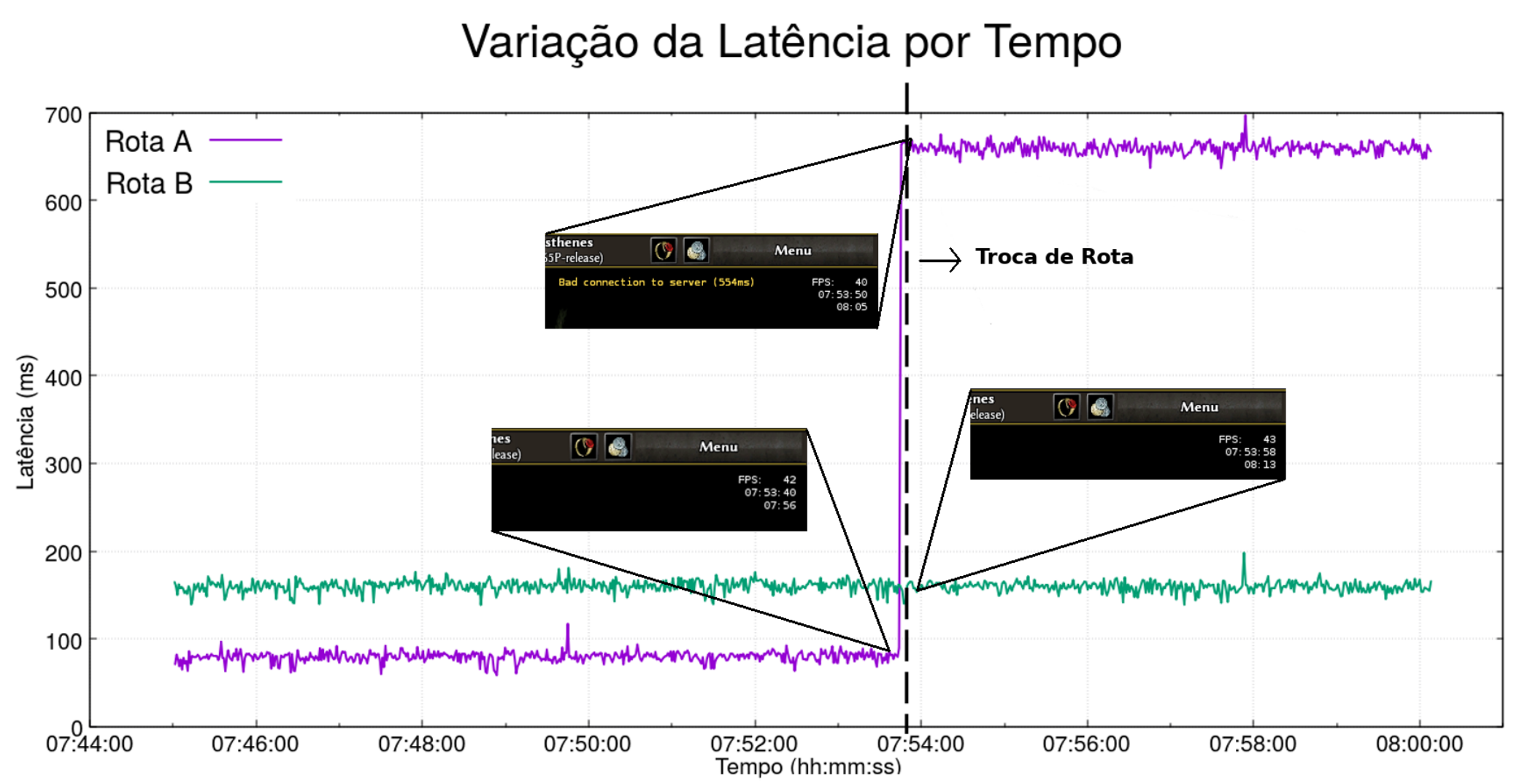


O Experimento C, por sua vez, não possui capturas de tela. O ambiente utilizado pelo experimento é idêntico ao utilizado pelo Experimento B, então pode-se assumir que o resultado do Experimento B vale para o Experimento C. A grande diferença vem do fato que este experimento tem uma duração mais curta, o que permite a repetição. Como seu objetivo é avaliar o tempo de resposta do mecanismo no cenário proposto, esses valores são agrupados e apresentados na Tabela 5.1. Nesta tabela, existem dois valores apresentados: o Tempo de Detecção, que representa o tempo, a partir do momento em que a ferramenta "tc" é utilizada para degradar a qualidade da rede, que o mecanismo proposto leva para detectar esta situação negativa na rede. Já o período de alteração indica, a partir do momento de detecção, quanto tempo o mecanismo leva para alterar as regras de fluxo dos Switches da rede, implantando a modificação das rotas. A soma desses valores indica quanto tempo o mecanismo leva, a partir do surgimento de um problema na rede, para detectá-lo e remediá-lo. Analisando os valores obtidos para média e intervalo de confiança de $95 \%$ desses valores, podemos dizer que o mecanismo leva menos de 2 segundos para detectar e remediar problemas de rede. Esse intervalo de tempo é bastante curto, e indica que o mecanismo pode reduzir drasticamente o efeito negativo que um jogador sofreria em um cenário parecido, uma vez que dois segundos representam um espaço de tempo bem curto perto da duração convencional de uma partida de jogos de estratégia, principalmente o 0 A.D., que podem durar períodos de tempo superiores a 15 minutos.

\begin{tabular}{|c|c|c|}
\hline Execução & Tempo até Detecção & Período de Alteração \\
\hline Experimento 1 & $1,50 \mathrm{~s}$ & $0,39 \mathrm{~s}$ \\
\hline Experimento 2 & $1,09 \mathrm{~s}$ & $0,44 \mathrm{~s}$ \\
\hline Experimento 3 & $0,94 \mathrm{~s}$ & $0,40 \mathrm{~s}$ \\
\hline Experimento 4 & $1,37 \mathrm{~s}$ & $0,30 \mathrm{~s}$ \\
\hline Experimento 5 & $1,14 \mathrm{~s}$ & $0,36 \mathrm{~s}$ \\
\hline Experimento 6 & $0,67 \mathrm{~s}$ & $0,39 \mathrm{~s}$ \\
\hline Experimento 7 & $1,16 \mathrm{~s}$ & $0,43 \mathrm{~s}$ \\
\hline Experimento 8 & $1,61 \mathrm{~s}$ & $0,36 \mathrm{~s}$ \\
\hline Experimento 9 & $1,19 \mathrm{~s}$ & $0,54 \mathrm{~s}$ \\
\hline Experimento 10 & $1,10 \mathrm{~s}$ & $0,32 \mathrm{~s}$ \\
\hline Valores Médios & $\mathbf{1 , 1 8} \mathbf{~ s}$ & $\mathbf{0 , 3 9} \mathbf{~ s}$ \\
\hline Intervalo de Confiança(95\%) & {$[\mathbf{0 , 9 9} \mathbf{~ s , 1 , 3 6 ~ s ]}$} & {$[\mathbf{0 , 3 5} \mathbf{~ s , ~ 0 , 4 4 ~ s ]}$} \\
\hline
\end{tabular}

Tabela 5.1: Tabela contendo medições dos experimentos realizados

O experimento D, por fim, apresenta como resultado uma comparação entre as medições de latência realizadas pela implementação de referência do mecanismo e as medições realizadas por uma outra ferramenta, amplamente utilizada como referência para latência, que é o utilitário "ping". O diagrama apresentado na Figura 5.11 mostra em comparação esses valores. Os valores indicados pelas linhas da Rota A e Rota B refletem os valores medidos pelo mecanismo, enquanto que a curva nominada "Ping"indica o valor de latência sendo coletado pelo comando "ping". Durante o intervalo $0 \mathrm{~s}-200 \mathrm{~s}$, localizado no gráfico do instante 05:07:53 até o instante 05:11:13, este comando está medindo a latência da Rota A, enquanto que nos últimos $100 \mathrm{~s}$, entre os $200 \mathrm{~s}$ e os $300 \mathrm{~s}$ finais, localizados entre o instante 05:11:13 até o instante 05:12:53, a Rota B é que está tendo sua latência calculada.

A Tabela 5.2, por sua vez, indica os valores médios de latência obtidos em cada uma das fases explicitadas no experimento. Além disso, a tabela indica a diferença entre a latência média calculada pelo comando "ping" e o valor calculado pela implementação do mecanismo. Essa diferença utiliza apenas o valor calculado pelo mecanismo que diz respeito à rota pela qual as mensagens do comando "ping" estão sendo trafegadas entre os Hosts 1 e 3, sendo elas a Rota A nas fases 1 e 2, e a Rota B na fase 3.

Pelos valores indicados nessa tabela, é possível verificar uma diferença próxima a $30 \mathrm{~ms}$ entre as marcações obtidas pelo mecanismo e as obtidas pela ferramenta "ping". Apesar de 30 ms parecer uma diferença não tão grande em uma fase como a segunda fase, indicando uma diferença de apenas $4,42 \%$, se for considerada essa diferença em um cenário como a primeira fase, de menor latência, a disparidade passa a ser extremamente impactante, chegando a $63 \%$. 


\section{Variação da Latência por Tempo}

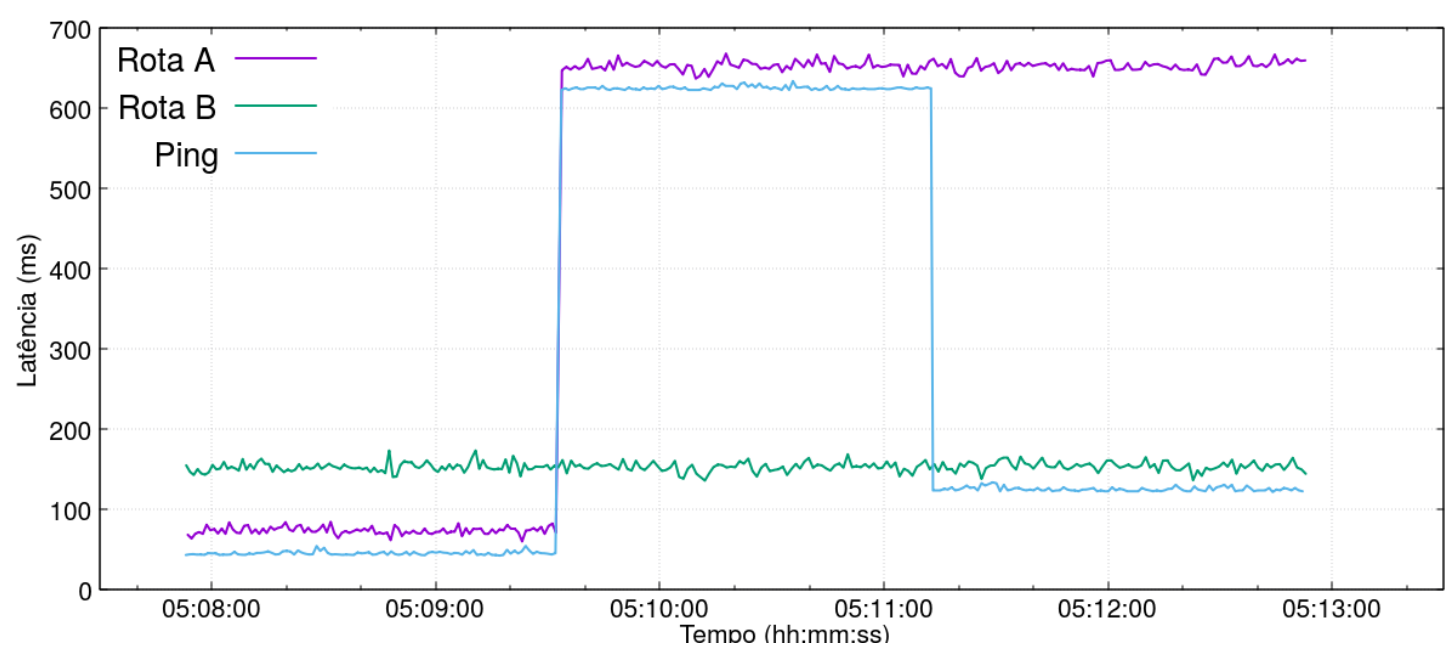

Figura 5.11: Diagrama comparando as medições da Rota A e B feitas pelo mecanismo e as medições feitas pelo "ping"

\begin{tabular}{|c|c|c|c|}
\hline Marcação & $\mathbf{1}^{\mathbf{a}}$ fase (0 s - 100 s) & $\mathbf{2}^{\mathbf{a}}$ fase (100 s - 200 s) & $\mathbf{3}^{\mathbf{a}}$ fase (200 s - 300 s) \\
\hline Rota A (Mecanismo) & $72,95 \mathrm{~ms}$ & $651,96 \mathrm{~ms}$ & $652,19 \mathrm{~ms}$ \\
\hline Rota B (Mecanismo) & $152,06 \mathrm{~ms}$ & $151,96 \mathrm{~ms}$ & $153,40 \mathrm{~ms}$ \\
\hline Comando Ping & $44,75 \mathrm{~ms}$ & $624,36 \mathrm{~ms}$ & $124,67 \mathrm{~ms}$ \\
\hline Diferença Ping e Mecanismo & $28,2 \mathrm{~ms}$ & $27,6 \mathrm{~ms}$ & $28,73 \mathrm{~ms}$ \\
\hline Diferença Ping e Mecanismo(\%) & $63 \%$ & $4,42 \%$ & $23 \%$ \\
\hline
\end{tabular}

Tabela 5.2: Tabela contendo a comparação entre as medições do mecanismo e do comando "ping"

A forma como a medição da latência foi realizada no mecanismo durante essa execução do Experimento D foi a mesma utilizada nos outros Experimentos (A, B e C). Nelas, o mecanismo captura o instante de tempo utilizando o método "now()" do módulo "datetime" do Python. Essa captura é realizada em 2 instantes diferentes: o primeiro, para capturar o instante em que o pacote é enviado, é feito imediatamente antes da chamada do método "sendp()" da biblioteca Scapy, enquanto que o segundo momento, para capturar o instante em que uma resposta é recebida, é feito imediatamente após a função "sniff()" do Scapy indicar o recebimento de uma resposta para o pacote de monitoramento do mecanismo. Essa diferença entre o valor calculado pelo mecanismo e o valor obtido pelo comando "ping" deve-se em grande parte pelo tempo de processamento gasto pela função de envio de pacote do Scapy.

Por conta desses detalhes indicados, a comparação realizada nesta tabela não é tão justa, pois o cálculo da latência realizada pelo mecanismo está considerando um tempo de processamento extra, que o Scapy leva preparando e encaminhando um pacote, que não é considerado da mesma forma pelo comando "ping". Essa forma de monitoramento, porém, foi mantida e apresentada nessa seção por uma questão de consistência com os outros experimentos realizados e apresentados anteriormente.

Porém, para poder ser realizada uma comparação mais justa, durante a realização do Experimento D outro instante de tempo também foi coletado. Esse instante diz respeito ao momento imediatamente após a função "sendp()" do Scapy ter sido executada. Utilizando para o cálculo da latência a diferença de tempo entre esse momento, imediatamente após a função "sendp()" terminar sua execução, e o momento imediatamente após a função "sniff()" receber um pacote de resposta, foi construído um novo gráfico, indicado na Figura 5.12.

Nesse gráfico, essa outra forma de calcular a latência foi utilizada, fazendo com que o tempo calculado não considere a duração do processamento realizado pela função "sendp()" do Scapy. Assim, os valores apresentados no gráfico apresentam uma proximidade muito maior entre os valores 


\section{Variação da Latência por Tempo}

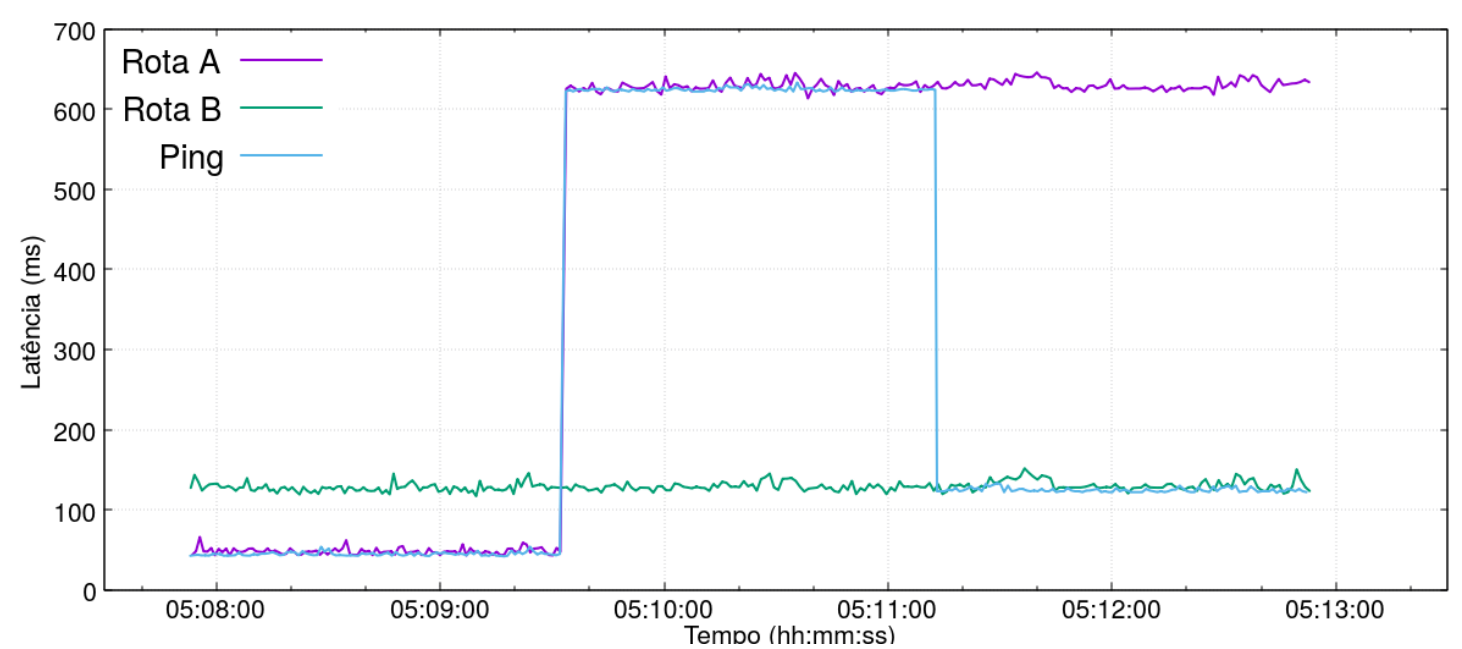

Figura 5.12: Diagrama comparando as medições reformuladas da Rota $A$ e $B$ feitas pelo mecanismo e as medições feitas pelo "ping"

calculados pelo mecanismo e os valores calculados pelo comando "ping". Além disso, a Tabela 5.2 foi refeita, resultando na Tabela 5.3, com os valores de latência atualizados. Nessa nova tabela, é possível perceber que a diferença, antes próxima dos $30 \mathrm{~ms}$, agora foi reduzida para menos de 6,5 ms. Nesse novo cenário, quanto maior é a latência calculada, menos relevante é a diferença obtida pelas medições. Na fase 1, a diferença é a maior entre as 3 fases, chegando a uma diferença de $7,8 \%$, enquanto que na fase 2 , onde as latências calculadas são as maiores, a diferença entre as medições chegou a apenas $0,62 \%$.

\begin{tabular}{|c|c|c|c|}
\hline Marcação & $\mathbf{1}^{\mathbf{a}}$ fase (0 s - 100 s) & $\mathbf{2}^{\mathbf{a}}$ fase (100 s - 200 s) & $\mathbf{3}^{\mathbf{a}}$ fase (200 s - 300 s) \\
\hline Rota A (Mecanismo) & $48,24 \mathrm{~ms}$ & $628,23 \mathrm{~ms}$ & $630,41 \mathrm{~ms}$ \\
\hline Rota B (Mecanismo) & $127,43 \mathrm{~ms}$ & $128,80 \mathrm{~ms}$ & $131,15 \mathrm{~ms}$ \\
\hline Comando Ping & $44,75 \mathrm{~ms}$ & $624,36 \mathrm{~ms}$ & $124,67 \mathrm{~ms}$ \\
\hline Diferença Ping e Mecanismo & $3,49 \mathrm{~ms}$ & $3,87 \mathrm{~ms}$ & $6,48 \mathrm{~ms}$ \\
\hline Diferença Ping e Mecanismo(\%) & $7,8 \%$ & $0,62 \%$ & $5,2 \%$ \\
\hline
\end{tabular}

Tabela 5.3: Tabela contendo a comparação entre as medições reformuladas do mecanismo e do comando "ping"

Com relação aos valores obtidos pelo mecanismo no primeiro método de medição, apesar de apresentarem esse desvio de aproximadamente $30 \mathrm{~ms}$ de um valor confiável de latência, como o desvio é para cima, significa que se uma situação efetivamente negativa ocorresse na rede, o mecanismo ainda seria capaz de detectá-la, uma vez que a latência da rota monitorada ultrapassaria o limite pré-estabelecido de qualidade da rede.

Esse funcionamento só causaria problemas quando o cenário envolvesse aplicações sensíveis a latências relativamente baixas, ou seja, próximas a $30 \mathrm{~ms}$. Nesse caso, como o mecanismo sempre marcaria a latência de uma rota com um valor acima de $30 \mathrm{~ms}$, a rota seria frequentemente acusada como prejudicial ao funcionamento da aplicação, levando o mecanismo a alterar a rota em cenários onde isso não fosse realmente necessário. Como os experimentos realizados anteriormente não apresentavam um cenário com essas características, esse desnível de medição não foi um problema.

Com os resultados da segunda forma de medição apresentados para o Experimento D, é possível ver que os valores de latência monitorados pelo mecanismo apresentam um resultado bem próximo do que o obtido por um utilitário amplamente utilizado por pesquisadores da área. Com uma diferença de medição de latência média inferior a $7 \mathrm{~ms}$, e a discrepância entre as marcações menor do que $8 \%$, chegando a ser de $0,62 \%$ em alguns momentos, o mecanismo se mostra capaz de ser utilizado em diversos cenários diferentes, oferecendo uma qualidade boa de monitoramento de rede, 
permitindo uma detecção eficiente de situações negativas de latência na rede. 


\section{Capítulo 6}

\section{Conclusão}

Neste capítulo são discutidos os resultados obtidos com os experimentos realizados utilizando os cenários apresentados no Capítulo 5. Além disso, são também apresentados alguns obstáculos enfrentados e que influenciaram algumas decisões tomadas durante o desenvolvimento do projeto. Por fim, são indicados assuntos para trabalhos futuros relacionados ao tema abordado por este projeto.

\subsection{Discussão sobre os resultados}

Considerando o objetivo principal dessa pesquisa, que foi apresentado na Subseção 1.2:

"projetar e implementar um mecanismo baseado em RDS para melhorar a experiência de usuários de um jogo eletrônico em rede, quando submetidos a cenários que simulam conexões ruins entre os jogadores."

Conclui-se que o mesmo foi alcançado. A versão implementada do mecanismo foi capaz de detectar, durante os experimentos, as situações em que a conexão entre os jogadores atingia um nível abaixo do considerado ideal para uma experiência positiva de partida. Após a realização dessa deteç̧ão através do módulo de monitoramento, o mecanismo foi capaz de alterar as rotas pela qual esses jogadores se comunicavam através da atuação em conjunto dos módulos de controle lógico e de comunicação com o plano de dados, melhorando, assim, a experiência dos jogadores nessa partida.

Ademais, foi possível observar que a reação do mecanismo foi realizada com um baixo atraso considerando a ordem de grandeza das latências presentes no experimento. A ação do mecanismo durava intervalos menores do que 2 segundos, o que representa um intervalo de tempo bastante curto se comparado à duração de partidas de um jogo como o 0 A.D., que podem levar diversos minutos.

Além disso, os valores de latência monitorados pelo mecanismo apresentaram uma discrepância muito baixa com relação a valores obtidos utilizando um utilitário bastante adotado pela comunidade. Por conta disso, o mecanismo não apresentou problemas em detectar as situações negativas às quais as aplicações utilizadas nos experimentos foram submetidas.

Sendo assim, foi possível explorar as características das Redes Definidas por Software para lidar com um problema comum no contexto de Jogos Digitais, dado um cenário semelhante ao existente nos experimentos realizados.

\subsection{Obstáculos}

Apesar de promissora, essa área de estudo ainda tem um longo caminho pela frente. Vale ressaltar que as Redes Definidas por Software não são uma solução capaz de resolver todos os problemas, mas sim uma abordagem, apresentando novas formas de lidar com redes. Ela é capaz de auxiliar 
a superar diversos obstáculos e desafios, mas ainda não é implementável em todas as estruturas existentes.

Todos os experimentos realizados neste projeto fizeram uso de Switches virtuais, criados dentro do Mininet. Até o momento da escrita desse texto, poucos dispositivos presentes no mercado são compatíveis com as especificações do protocolo OpenFlow, e um número menor ainda de dispositivos é programável utilizando a linguagem $\mathrm{P} 4$. A escassez de dispositivos físicos, principalmente de baixo custo, atua como uma limitação na elaboração de soluções tanto para experimentos quanto para ambientes em produção atualmente. Por isso, todos os experimentos realizados foram feitos dentro de um ambiente virtual.

Outra característica que foi impactante negativamente durante a realização do projeto foi a falta de materiais disponíveis online sobre as ferramentas que foram utilizadas. Pouco material oficial e atualizado sobre o OpenFlow foi encontrado, a maior parte do conteúdo utilizado foi de criação da comunidade. Quanto à linguagem $\mathrm{P} 4$, boa parte dos tutoriais oferecidos pela $\mathrm{P} 4$.org aborda vários aspectos referentes à linguagem em si, mas não sobre todos os passos necessários para se montar um ambiente funcional que faça uso dela. Para isso, foi necessário recorrer a mais tutoriais fornecidos pela comunidade e um bom tempo de experimentação e estudo utilizando o cenário de testes básico fornecido pelos repositórios oficiais.

Durante a realização desta pesquisa, os cenários inicialmente elaborados para realização dos experimentos faziam uso do Protocolo OpenFlow, um Controlador e aplicações escritas utilizando o arcabouço Ryu [Com19], e Switches virtuais do OpenVSwitch [Fou19a]. O problema, porém, foi a falta de uma solução simples e que fosse capaz de monitorar os valores de latência de diferentes rotas dentro da topologia. Uma das soluções que foram propostas foi a utilização de uma ferramenta chamada Granular RTT Monitoring Infrastructure (GRAMI) [AB16], porém houveram problemas durante a inserção da implementação disponível dessa ferramenta [alo17] dentro do nosso ambiente de experimentação. O processo de compilação dessa ferramenta apresentou diversas dificuldades não planejadas e a falta de instruções acerca do funcionamento da ferramenta tornaram sua utilização inviável.

Esses problemas resultaram na decisão por modificar a estrutura do ambiente desenvolvido para os experimentos, migrando os Switches utilizados para a versão oferecida pela $\mathrm{P} 4$, mudando o código do Controlador para uma aplicação capaz de se comunicar com o plano de dados através da especificação do P4Runtime e, por fim, implementando uma solução autoral para o monitoramento das rotas da rede. Essa alteração demandou um certo tempo, o que acabou postergando em alguns meses a conclusão do projeto.

Outro obstáculo importante de ser citado, que diz respeito à escolha do jogo para o experimento, advém do fato dos cenários dos experimentos serem implementados dentro de uma máquina virtual. O processo de virtualização, através da abstração dos recursos de hardware sobre os quais ela é realizada, acaba reduzindo a performance do sistema operacional em execução dentro na máquina virtual. Para diversas aplicações, essa redução de performance é pouco significativa, porém no âmbito de Jogos Digitais essa perda de performance pode ser muito impactante. Além disso, alguns dos passos realizados pelos sistemas de virtualização durante o processo de execução de uma máquina virtual acabam causando consequências negativas para algumas aplicações que fazem uso de capacidades gráficas, como por exemplo o mal funcionamento de algumas bibliotecas gráficas comumente utilizadas no desenvolvimento dos Jogos. Por conta desses problemas, a escolha de qual jogo seria usado nos experimentos foi influenciada também pela capacidade do ambiente virtualizado executar ou não o jogo. Essa é uma das justificativas do porque o jogo escolhido não apresenta um perfil de jogabilidade que seja mais sensível às condições da rede, como seria se fosse um jogo do gênero de Tiro em Primeira Pessoa, por exemplo. Dentre as diversas opções de jogos desse gênero, nenhum dos experimentos foi capaz de ser realizado utilizando um desses jogos. 


\subsection{Trabalhos futuros}

Dentro do ambiente produzido para os experimentos e aproveitando da estrutura já implementada, um primeiro trabalho interessante a se fazer seria expandir a capacidade de monitoramento dos Monitores presentes na rede. Para isso, mais funcionalidades dentro da proposta da especificação do INT poderiam ser implementadas. Para isso, são sugeridas três alterações importantes: a primeira seria a expansão do formato do pacote de monitoramento utilizado, de forma a adicionar os cabeçalhos INT, tornando esse pacote o que podemos chamar de um pacote INT. A segunda alteração seria no código em P4 executado nos Switches, adicionando a capacidade de processar pacotes que possuam cabeçalhos INT, tornando essas interfaces em elementos chamados de INT Transit Hop dentro da especificação do INT. Por fim, seriam necessárias alterações nos códigos dos monitores, a fim de transformá-los em INT Sources e INT Sinks, que seriam elementos da rede capazes de inserir os cabeçalhos INT nos pacotes da rede e extrair esses cabeçalhos INT, respectivamente. Esse último elemento, portanto, ao extrair esses cabeçalhos, poderia agrupar mais informações sobre o estado atual do plano de dados e oferecer essas informações para outros elementos da rede consumirem, como por exemplo o módulo de controle lógico do mecanismo implementado.

Uma segunda proposta seria a de evoluir o código do mecanismo proposto. Sugestões seriam a de permitir que esse mecanismo descubra, de forma autônoma, novas rotas existentes dentro da rede, ampliando assim o seu espaço de decisões a serem tomadas na hora de alterar os fluxos da rede. Outra alteração a ser implementada nesse mecanismo poderia ser a adição de novas estratégias a serem utilizadas durante a tomada de decisão sobre mudanças de rotas, capazes de levar em consideração mais dados sobre a qualidade das rotas do que de apenas o seu valor de latência. Informações interessantes seriam por exemplo a taxa de perda de pacotes, a largura da banda, Jitter, entre outros. Essa alteração expandiria as utilizações desse mecanismo para outras aplicações, que necessitam de outras exigências de qualidade.

Outra sugestão de trabalho futuro consiste no estudo sobre novas abordagens à arquitetura de Redes Definidas por Software, como por exemplo cenários sem a existência do elemento Controlador dentro da topologia, ou soluções que envolvessem um plano de controle distribuído. A partir dessa nova abordagem, perceber as vantagens e desvantagens com relação a forma realizada nesse projeto.

Por fim, fica como sugestão a utilização dos cenários descritos nos experimentos com a execução de outras aplicações, sejam elas outros exemplos de Jogos Digitais, de gêneros diferentes, ou mesmo aplicações com perfis completamente diferentes. 
CONCLUSÃO 


\section{Referências Bibliográficas}

[AAKM18] M. Amine Togou, D. Abdeldjalil Chekired, L. Khoukhi e G. Muntean. A distributed control plane for path computation scalability in software-defined networks. Em 2018 IEEE Global Communications Conference (GLOBECOM), páginas 1-6, Dec 2018. 10

[AAOSA15] Maryam Amiri, Hussein Al Osman, Shervin Shirmohammadi e Maha Abdallah. Sdnbased game-aware network management for cloud gaming. Em Proceedings of the 2015 International Workshop on Network and Systems Support for Games, NetGames '15, páginas 3:1-3:6. IEEE Press, 2015. 19

[AB16] A. Atary e A. Bremler-Barr. Efficient round-trip time monitoring in openflow networks. Em IEEE INFOCOM 2016 - The 35th Annual IEEE International Conference on Computer Communications, páginas 1-9, April 2016. 50

[alo17] alonatari1. Granular RTT measurement infrastructure for OpenFlow networks. https: //github.com/alonatari1/GRAMI, 2017. Último acesso em 14/11/2019. 50

[AML] AMLIGHT. AmLight Website. https://www.amlight.net/. Último acesso em 09/02/2020. 2

[AML19] AMLIGHT. AmLight-INT. https://www.amlight.net/?page_id=3525, 2019. Último acesso em 09/02/2020. 2

[AOS17] M. Amiri, H. A. Osman e S. Shirmohammadi. Sdn-enabled game-aware network management for residential gateways. Em 2017 IEEE International Symposium on Multimedia (ISM), páginas 330-333, Dec 2017. 20

[Bat00] André L Battaiola. Jogos por computador-histórico, relevância tecnológica e mercadológica, tendências e técnicas de implementação. XIX Jornada de Atualização em Informática. Curitiba: SBC, 2:83-122, 2000. 17

[BDG $\left.{ }^{+} 14\right]$ Pat Bosshart, Dan Daly, Glen Gibb, Martin Izzard, Nick McKeown, Jennifer Rexford, Cole Schlesinger, Dan Talayco, Amin Vahdat, George Varghese e David Walker. P4: Programming protocol-independent packet processors. SIGCOMM Comput. Commun. Rev., 44(3):87-95, Julho 2014. 12

[BSN19] Inc. Big Switch Networks. Big Switch Networks | The Cloud-First Networking Company. https://www.bigswitch.com, 2019. Último acesso em 30/08/2019. 2

[BTK $\left.{ }^{+} 15\right]$ Sukanya Bhowmik, Muhammad Adnan Tariq, Boris Koldehofe, André Kutzleb e Kurt Rothermel. Distributed control plane for software-defined networks: A case study using event-based middleware. Em Proceedings of the 9th ACM International Conference on Distributed Event-Based Systems, DEBS '15, página 92-103, New York, NY, USA, 2015. Association for Computing Machinery. 10

[Bun14] Inc Bungie. How much data does destiny require? https://www.bungie.net/en/Help/ Article/12313, 2014. Último acesso em 15/08/2017. 18 
[Cis15] Cisco. Pulsant Delivers Agile and Cost-Effective Hybrid Cloud Services with Cisco ACI. https://www.cisco.com/c/dam/en/us/solutions/ collateral/data-center-virtualization/application-centric-infrastructure/ idc-pulsant-delivers-agile.pdf, 2015. Último acesso em 30/08/2019. 2

[Cis18a] Cisco. Cisco ACI Case Study: Symantec. https://www.cisco.com/c/en/us/ about/case-studies-customer-success-stories/symantec.html, 2018. Último acesso em 30/08/2019. 2

[Cis18b] Cisco. Cisco OpenFlow Agent for Nexus 3000 and 9000 Series Switches. https://www.cisco.com/c/en/us/td/docs/switches/datacenter/nexus/openflow/ b_openflow_agent_nxos_n3kn9k.html, 2018. Último acesso em 18/11/2019. 2

[Com19] Ryu SDN Framework Community. Ryu sdn framework website. https://osrg.github. io/ryu/, 2019. Último acesso em 14/11/2019. 14, 50

[Con15] The P4 Language Consortium. Improving Network Monitoring and Management with Programmable Data Planes. https://p4.org/p4/inband-network-telemetry/, 2015. Último acesso em 30/08/2019. 2, 13

[Con18] The P4 Language Consortium. P4 developer day. https://p4.org/events/ 2018-06-06-p4-developer-day/, 2018. Último acesso em 11/11/2019. 30

[Con19a] P4 Language Consortium. An implementation framework for a P4Runtime server. https://github.com/p4lang/PI, 2019. Último acesso em 18/11/2019. 15

[Con19b] P4 Language Consortium. P4_16 Language Specification. https://p4.org/p4-spec/ docs/P4-16-v1.2.0.pdf, 2019. Último acesso em 18/11/2019. ix, 12, 13

[Con19c] P4 Language Consortium. P4_16 prototype compiler repository. https://github.com/ p4lang/p4c, 2019. Último acesso em 18/11/2019. 14

[Con19d] P4 Language Consortium. runtime_CLI code. https://github.com/p4lang/ behavioral-model/blob/master/tools/runtime_CLI.py, 2019. Último acesso em 18/11/2019. 15

[Con19e] P4 Language Consortium. The reference P4 software switch repository. https://github. com/p4lang/behavioral-model, 2019. Último acesso em 18/11/2019. 14

[Con19f] The P4 Language Consortium. P4 Applications WG repository. https://github.com/ p4lang/p4-applications, 2019. Último acesso em 30/08/2019. 13

[Con19g] The P4 Language Consortium. The P4 Language Consortium contributors. https: //p4.org/contributors/, 2019. Último acesso em 20/11/2019. 14

[Con19h] The P4 Language Consortium. The P4 Language Consortium website. https://p4.org/, 2019. Último acesso em 30/08/2019. 2, 12, 14

[Con20a] The P4 Language Consortium. The BMv2 Simple Switch target documentation. https: //github.com/p4lang/behavioral-model/blob/master/docs/simple_switch.md, 2020. Último acesso em 04/02/2020. 33

[Con20b] The P4 Language Consortium. v1model architecture implementation. https:// github.com/p4lang/p4c/blob/master/p4include/v1model.p4, 2020. Último acesso em 04/02/2020. 33 
[CS19] Inc. Cisco Systems. Cisco Application Centric Infrastructure Solution Overview. https://www.cisco.com/c/en/us/solutions/collateral/data-center-virtualization/ application-centric-infrastructure/solution-overview-c22-741487.html, 2019. Último acesso em 09/02/2020. 2

[Dev17] Unvanquished Development. Unvanquished website. https://www.unvanquished.net/, 2017. Último acesso em 15/08/2017. 30

[Ec119] Red Eclipse. Red eclipse website. https://www.redeclipse.net/, 2019. Último acesso em 25/11/2019. 30

[Flo19] Project Floodlight. Floodlight Controller website. http://www.projectfloodlight.org/ floodlight/, 2019. Último acesso em 18/11/2019. 2, 14

[Fou16] Open Networking Foundation. Special Report: OpenFlow and SDN - State of the Union. https://www.opennetworking.org/images/stories/downloads/sdn-resources/ special-reports/Special-Report-OpenFlow-and-SDN-State-of-the-Union-B.pdf, 2016. Último acesso em 18/11/2019. 2

[Fou17] Open Networking Foundation. Planning a Path For OpenFlow. https://www. opennetworking.org/news-and-events/blog/planning-a-path-for-openflow/, 2017. Último acesso em 13/11/2019. 16

[Fou19a] Linux Foundation. Open vSwitch Website. https://www.openvswitch.org, 2019. Último acesso em 14/11/2019. 10, 14, 50

[Fou19b] Open Networking Foundation. Stratum - Open Networking Foundation. https://www. opennetworking.org/stratum/, 2019. Último acesso em 18/11/2019. 15

[FTKS19] I. Farris, T. Taleb, Y. Khettab e J. Song. A survey on emerging sdn and nfv security mechanisms for iot systems. IEEE Communications Surveys Tutorials, 21(1):812-837, Firstquarter 2019. 16

[Gam14] Wildfire Games. 0 A.D. Alpha Version XX, release 17965. https://trac. wildfiregames.com/browser/ps/trunk/binaries/data?rev=17965, 2014. Último acesso em $29 / 01 / 2020.32$

[Gam19] Wildfire Games. 0 a.d. website. https://play0ad.com/, 2019. Último acesso em 25/11/2019. 30

[Goo19] Google. Google Stadia website. https://stadia.dev/, 2019. Último acesso em 12/11/2019. 18, 19

$\left[\mathrm{HCA}^{+} 19\right]$ A. Hussein, Louma Chadad, Nareg Adalian, Ali Chehab, Imad H. Elhajj e Ayman Kayssi. Software-defined networking (sdn): the security review. Journal of Cyber Security Technology, 0(0):1-66, 2019. 16

$\left[\mathrm{HDG}^{+} 15\right]$ Tim Humernbrum, Stefan Delker, Frank Glinka, Folker Schamel e Sergei Gorlatch. Rtf + shark: Using software-defined networks for multiplayer online games. Em Proceedings of the 2015 International Workshop on Network and Systems Support for Games, NetGames '15, páginas 10:1-10:3. IEEE Press, 2015. 19

[HG13] S. Huang e J. Griffioen. Hypernet games: Leveraging sdn networks to improve multiplayer online games. Em Proceedings of CGAMES'2013 USA, páginas 74-78, July 2013. 20

[JCH84] Rajendra K Jain, Dah-Ming W Chiu e William R Hawe. A quantitative measure of fairness and discrimination. Eastern Research Laboratory, Digital Equipment Corporation, Hudson, MA, 1984. 21 
$\left[\mathrm{JKM}^{+} 13\right]$ Sushant Jain, Alok Kumar, Subhasree Mandal, Joon Ong, Leon Poutievski, Arjun Singh, Subbaiah Venkata, Jim Wanderer, Junlan Zhou, Min Zhu, Jonathan Zolla, Urs Hölzle, Stephen Stuart e Amin Vahdat. B4: Experience with a globally deployed software defined wan. Em Proceedings of the ACM SIGCOMM Conference, Hong Kong, China, 2013. 15

[KR01] J. F. Kurose e K. W. Ross. Computer Networking: A Top-Down Approach. AddisonWesley, $6^{\circ}$ edição, 2001. 5

$\left[\mathrm{KRV}^{+} 15\right]$ D. Kreutz, F. M. V. Ramos, P. E. Veríssimo, C. E. Rothenberg, S. Azodolmolky e S. Uhlig. Software-defined networking: A comprehensive survey. Proceedings of the IEEE, 103(1):14-76, Jan 2015. 8

[ltd19a] Larch Networks ltd. Larch Networks ltd website. http://larch-networks.com/, 2019. Último acesso em 30/08/2019. 2

[Ltd19b] Marvell Technology Group Ltd. Marvell Technology Group Ltd. Website. https:// www.marvell.com/, 2019. Último acesso em 30/08/2019. 2

$\left[\mathrm{MAB}^{+} 08\right]$ Nick McKeown, Tom Anderson, Hari Balakrishnan, Guru Parulkar, Larry Peterson, Jennifer Rexford, Scott Shenker e Jonathan Turner. Openflow: Enabling innovation in campus networks. SIGCOMM Comput. Commun. Rev., 38(2):69-74, Março 2008. 1

[MGS19] Sharat Chandra Madanapalli, Hassan Habibi Gharakheili e Vijay Sivaraman. Assisting delay and bandwidth sensitive applications in a self-driving network. Em Proceedings of the 2019 Workshop on Network Meets AI $\&$ ML, NetAI'19, páginas 64-69, New York, NY, USA, 2019. ACM. 21

[Min17] Mininet. Mininet website. http://mininet.org/, 2017. Último acesso em 15/08/2017. 14,33

[nbn16] The nbn ${ }^{\mathrm{TM}}$. How much data does gaming use? a handful of popular examples. http://www.nbnco.com.au/blog/entertainment/ how-much-data-does-gaming-use-through-popular-examples.html, 2016. Último acesso em 15/08/2017. 18

[Net18] Juniper Networks. OpenFlow Support on Juniper Networks Devices. https://www.juniper.net/documentation/en_US/release-independent/junos/topics/ reference/general/junos-sdn-openflow-supported-platforms.html, 2018. Último acesso em $18 / 11 / 2019.2$

[Net19a] Pluribus Networks. Adaptive Cloud Fabric - Pluribus Networks. https://www. pluribusnetworks.com/products/adaptive-cloud-fabric/, 2019. Último acesso em 30/08/2019. 2

[Net19b] Pluribus Networks. Distributed Cloud - Pluribus Networks. https:// www.pluribusnetworks.com/solutions/distributed-cloud/, 2019. Último acesso em 16/08/2019. 10

[New19] Newzoo. Newzoo Global Games Market Report 2019 | Light Version. https://newzoo. com/insights/trend-reports/newzoo-global-games-market-report-2019-light-version/, 2019. Último acesso em 12/11/2019. 18

[Ora19] Oracle. Oracle VM VirtualBox. https://www.virtualbox.org, 2019. Último acesso em $11 / 11 / 2019.30,34$ 
[P419a] P4. P4 Language Source Routing Tutorial Repository. https://github.com/p4lang/ tutorials/tree/master/exercises/source_routing, 2019. Último acesso em 12/11/2019. 35

[P419b] P4. P4 Language Tutorials Repository. https://github.com/p4lang/tutorials, 2019. Último acesso em 20/11/2019. 14

[Pla18] Enterprise Networking Planet. ONF Announces Stratum Project to Redefine SDN. http://www.enterprisenetworkingplanet.com/netsp/ openflow-is-the-past-as-onf-announcesstratum-project-to-redefine-sdn.html, 2018. Último acesso em 13/11/2019. 16

[PN18] Inc. Pluribus Networks. Pluribus Adaptive Cloud Fabric Product Overview. https: //www.dell.com/learn/us/en/05/product_docs/pluribus-acf.pdf, 2018. Último acesso em 08/02/2020. 2, 10

[Rep19a] NOX Repo. NOX Controller repository. https://github.com/noxrepo/nox, 2019. Último acesso em 18/11/2019. 14

[Rep19b] NOX Repo. POX Controller repository. https://github.com/noxrepo/pox, 2019. Último acesso em 18/11/2019. 14

[Res19] Adroit Market Research. Software Defined Networking Market Size, Solution |SDN Industry Report 2019-2025. https://www.adroitmarketresearch.com/industry-reports/ software-defined-networking-market, 2019. Último acesso em 16/11/2019. 15

[Sal19] Lee Salzman. ENet website. http://enet.bespin.org/, 2019. Último acesso em $14 / 11 / 2019.32$

[Sca19] Scapy. Scapy. https://scapy.net/, 2019. Último acesso em 12/11/2019. 27, 35

[SDx19] SDxCentral. Comcast Deploys Open Source Trellis in 'Multiple Markets'. https://www.sdxcentral.com/articles/news/ comcast-deploys-open-source-trellis-in-multiple-markets/2019/09/, 2019. Último acesso em 16/11/2019. 15

[Sla19] Slant. What are the best open-source games? https://www.slant.co/topics/1933/ best-open-source-games, 2019. Último acesso em 24/11/2019. 30

[Tre19] Trellis. Trellis Documentation website. https://docs.trellisfabric.org, 2019. Último acesso em 16/11/2019. 15

[VMw19] Inc VMware. VMware NSX Data Center Solution Overview. https: //www.vmware.com/content/dam/digitalmarketing/vmware/en/pdf/products/ nsx/vmware-nsx-solution-brief.pdf, 2019. Último acesso em 09/02/2020. 2

[Wik19] Wikipedia. List of open-source video games - wikipedia, the free encyclopedia. https: //en.wikipedia.org/wiki/List_of_open-source_video_games, 2019. Último acesso em 24/11/2019. 30

[Xon19] Xonotic. Xonotic website. https://xonotic.org/, 2019. Último acesso em 25/11/2019. 30 